\title{
INVESTIGATING THE USE OF SUSTAINABILITY AND SUSTAINABLE DEVELOPMENT BY THE CITY OF TORONTO THROUGH A 30-YEAR DOCUMENT ANALYSIS
}

\author{
by
}

\author{
Shenley Audrey Alkins \\ Bachelor of Arts in Environment \& Urban Sustainability \\ Ryerson University, 2016 \\ A thesis \\ presented to Ryerson University \\ in partial fulfillment of the \\ requirements for the degree of \\ Master of Applied Science \\ in the program of \\ Environmental Applied Science and Management
}

Toronto, Ontario, Canada, 2019

(C) Shenley Audrey Alkins, 2019 


\section{Author's Declaration}

I hereby declare that I am the sole author of this thesis. This is a true copy of the thesis, including any required final revisions, as accepted by my examiners.

I authorize Ryerson University to lend this thesis to other institutions or individuals for the purpose of scholarly research.

I further authorize Ryerson University to reproduce this thesis by photocopying or by other means, in total or in part, at the request of other institutions for the purpose of scholarly research.

I understand that my thesis may be made electronically available to the public. 


\title{
INVESTIGATING THE USE OF SUSTAINABILITY AND SUSTAINABLE DEVELOPMENT BY THE CITY OF TORONTO THROUGH A 30-YEAR DOCUMENT ANALYSIS
}

\author{
Shenley Audrey Alkins \\ Master of Applied Science \\ Environmental Applied Science \& Management \\ Ryerson University, 2019
}

\begin{abstract}
The purpose of this research is to map the conceptual and theoretical foundations of sustainability and sustainable development, specifically how these concepts have been defined, conceptualized, and operationalized in the past, in effect to elucidate knowledge gaps and limitations of current research. This research uses an exploratory approach to textual discourse analysis to uncover the ways in which sustainability and sustainable development has been defined, conceptualized, and operationalized by the City of Toronto over the past thirty years. The findings of this research indicate that despite poorly defined conceptions of sustainability and sustainable development, operationalization has continued. However, many challenges to conceptualization and operationalization remain, such as those related to cross-scale coordination, understanding of social, economic, and environmental interdependencies, inadequate understanding of environmental conditions, and issues related to information sharing and reporting across institutions.
\end{abstract}

\section{Keywords}

sustainability; urban sustainability; sustainable development; municipal policy; municipal decisionmaking; textual data analysis; content analysis; discourse analysis 


\section{Acknowledgements}

Foremost, I would like to express my sincere gratitude to my advisor Dr. Lynda McCarthy for allowing me the opportunity to complete this thesis under her supervision, for her continuous support of this MASc study and related research, and her immense patience, guidance, and knowledge. This thesis would not have been possible without Dr. McCarthy's steadfast encouragement, optimism, ingenuity, empathy, and kindness throughout the duration of this research.

Secondly, I would like to extend my gratitude to Dr. Carolyn Johns and Dr. Pamela Robinson for their roles as examiners and advisors on my defense committee, but specifically for their knowledge and expertise on policy and sustainability, the time they dedicated to providing extensive feedback, and the patience they showed me throughout this process. This thesis would not have been possible without their expertise and suggested revisions.

Finally, my deep and sincerest gratitude to my Mom and Dad who selflessly encouraged me to pursue this degree and provided their continuous love and support throughout this journey. I am especially thankful to my siblings, my two brothers and sister who maintained unwavering confidence in me and never hesitated to challenge me on my ideas. I would like to acknowledge Victoria Papp and Angela Kaiser in particular for the countless hours they dedicated to tutoring me and revising my work over the last several years. Finally, I would like to thank Tsvetan whose companionship over the last eight years helped me reach many goals, including this one.

Ultimately, there are no words to describe the invaluable contributions of all those who helped me keep my head above the water throughout my academic career. 


\section{Table of Contents}

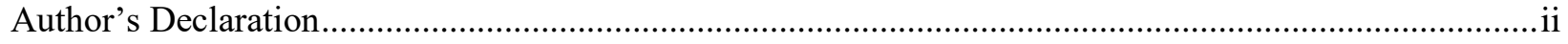

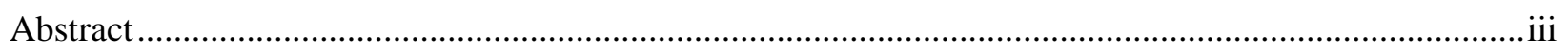

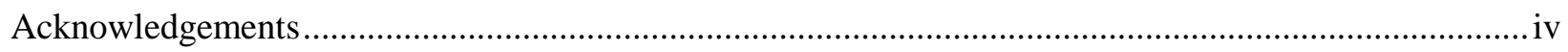

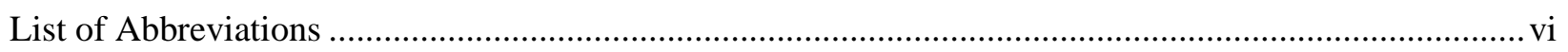

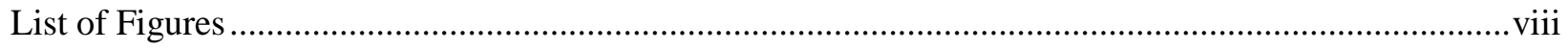

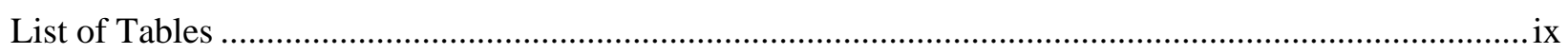

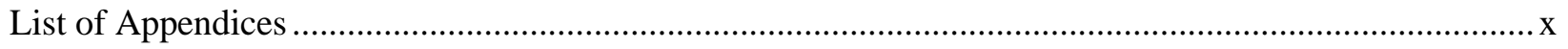

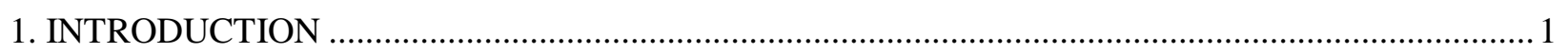

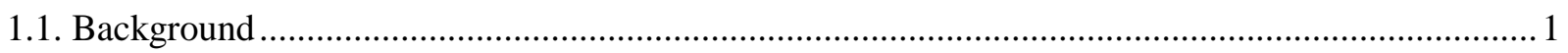

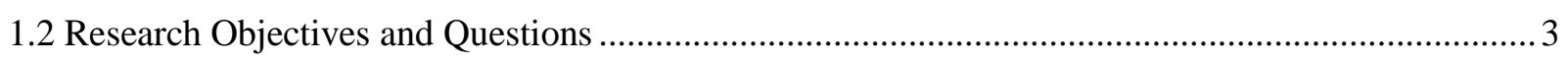

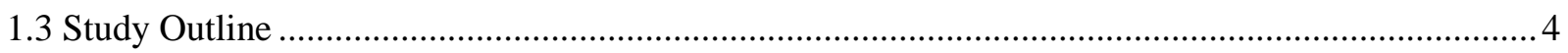

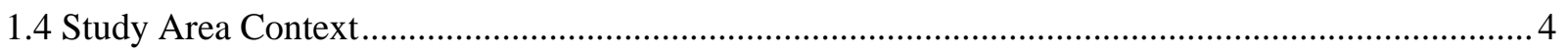

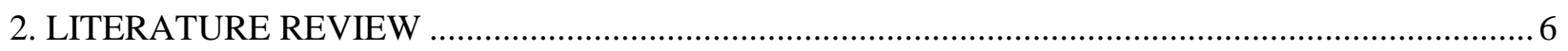

2.1 Theoretical and Conceptual History of Sustainability ............................................................. 7

2.2 Theoretical and Conceptual History of Sustainable Development ............................................... 17

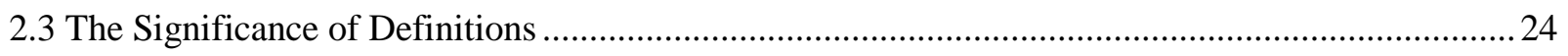

2.4 Scientific Study of Language: The Linguistics of Sustainability .................................................26

2.5 Content \& Discourse Analysis in Sustainability \& Sustainable Development Research ................. 30

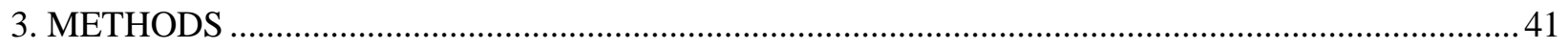

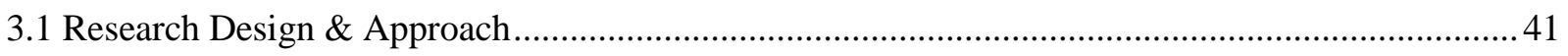

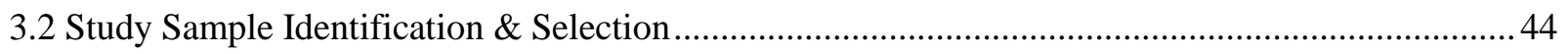

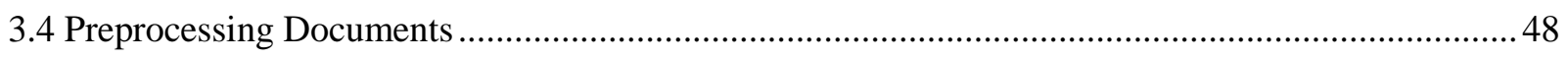

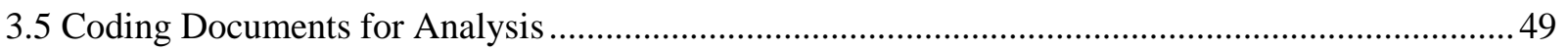

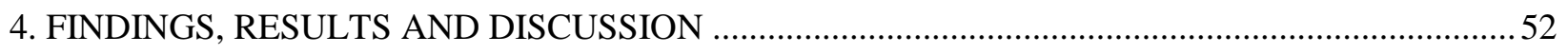

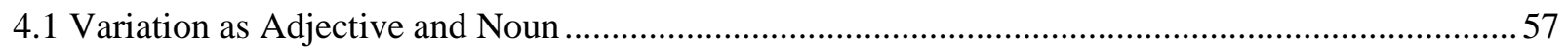

4.2 Interchangeable use of Sustainability and Sustainable Development ...........................................59

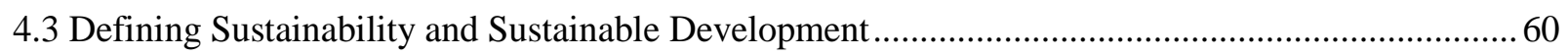

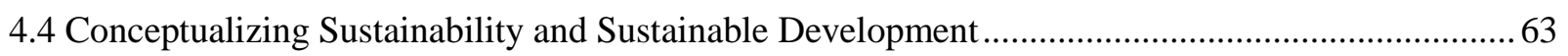

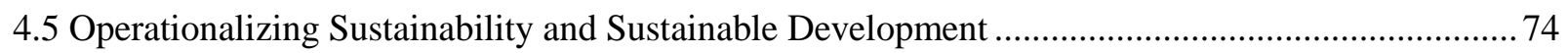

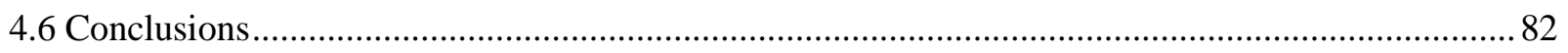

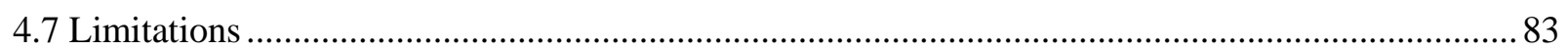

5. CONCLUSIONS \& RECOMMENDATIONS FOR FUTURE RESEARCH ..................................... 85

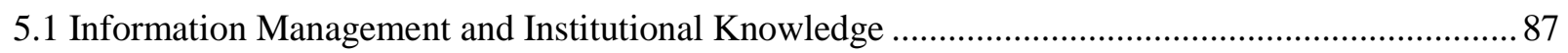

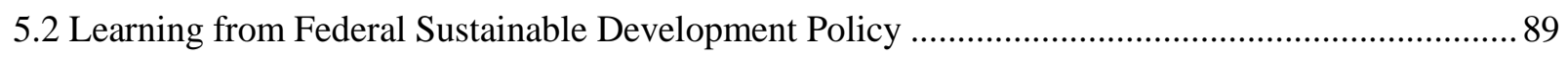

5.3 Recommendations for Sustainable Development in Toronto .......................................................93

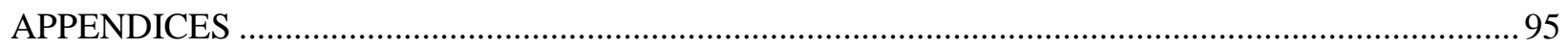

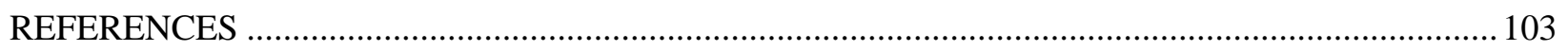




\section{List of Abbreviations}

\begin{tabular}{|c|c|c|c|}
\hline CAC & Computer Assisted Clustering & OED & Oxford English Dictionary \\
\hline CAO & Chief Administrator's Office & PCA & Principle Component Analysis \\
\hline CAQDAS & $\begin{array}{l}\text { Computer Assisted Qualitative } \\
\text { Data Analysis }\end{array}$ & PD & $\begin{array}{l}\text { Planning \& Development } \\
\text { Department }\end{array}$ \\
\hline CDA & Critical Discourse Analysis & PDF & Portable Document Format \\
\hline CFCs & Chlorofluorocarbons & PFR & Parks, Forestry \& Recreation \\
\hline $\mathrm{CH}_{4}$ & Methane & & Division \\
\hline CMO & City Managers Office & PH & Toronto Public Health \\
\hline $\mathrm{CO}_{2}$ & Carbon Dioxide & PNA & Policy Narrative Analysis \\
\hline \multirow[t]{2}{*}{ DPSIR } & Drivers-Forces-Pressure-State- & PSR & Pressure-State-Response \\
\hline & Impact-Response & QNA & Quantitative Narrative Analysis \\
\hline EDC & $\begin{array}{l}\text { Economic Development \& } \\
\text { Culture Division }\end{array}$ & RULA & $\begin{array}{l}\text { Ryerson University Library \& } \\
\text { Archives }\end{array}$ \\
\hline \multirow{7}{*}{$\begin{array}{l}\text { EED } \\
\text { ETF } \\
\text { EU } \\
\text { FMP } \\
\text { GHGs } \\
\text { GSTG }\end{array}$} & Environment \& Energy Division & SCOPE & Scientific Committee on \\
\hline & Environmental Task Force & & Problems of the Environment \\
\hline & European Union & SDFA & Social Development Finance \& \\
\hline & Facilities Master Plan & & Administration Division \\
\hline & Greenhouse Gas Emissions & SDG & Sustainable Development Goals \\
\hline & Toronto Green Streets Technical & SOE & State of Environment \\
\hline & Guidelines & $\mathbf{S O}_{\mathbf{x}}$ & Sulphur Oxides \\
\hline \multirow{4}{*}{$\begin{array}{l}\text { GTA } \\
\text { HFCs } \\
\text { ICSP }\end{array}$} & Greater Toronto Area & SVO & Subject-Verb-Object \\
\hline & Hydrofluorocarbons & SWM & Solid Waste Management \\
\hline & Integrated Community & & Services \\
\hline & Sustainability Plans & TEO & Toronto Environment Office \\
\hline \multirow[t]{2}{*}{ IIASA } & International Institute for & TFPC & Toronto Food Policy Council \\
\hline & Applied Systems Analysis & TGS & Toronto Green Development \\
\hline \multirow[t]{2}{*}{ IPCC } & Intergovernmental Panel on & & Standard \\
\hline & Climate Change & TMMIS & Toronto Meeting Management \\
\hline \multirow[t]{2}{*}{ ICLEI } & International Council for Local & & Information System \\
\hline & Environment Initiatives & TRCA & Toronto and Region \\
\hline \multirow[t]{2}{*}{ ICSU } & International Council for & & Conservation Authority \\
\hline & Science & TSD & Transportation Services \\
\hline \multirow[t]{2}{*}{ IUCN } & International Union for & & Division \\
\hline & $\begin{array}{l}\text { Conservation of Nature and } \\
\text { Natural Resources }\end{array}$ & TSNS & $\begin{array}{l}\text { Toronto Strong Neighbourhoods } \\
\text { Strategy }\end{array}$ \\
\hline \multirow{4}{*}{$\begin{array}{l}\text { LCRC } \\
\text { MDG } \\
\mathrm{NO}_{\mathrm{X}} \\
\text { OECD }\end{array}$} & Living City Report Card & $\mathbf{U N}$ & United Nations \\
\hline & Millennium Development Goals & UNCED & United Nations Conference on \\
\hline & Nitrous Oxides & & Environment and Development \\
\hline & $\begin{array}{l}\text { Organisation for Economic Co- } \\
\text { operation and Development }\end{array}$ & UNCHS & $\begin{array}{l}\text { United Nations Conference on } \\
\text { the Human Environment }\end{array}$ \\
\hline
\end{tabular}


UNCSD United Nations Conference on Sustainable Development

UNDP United Nations Development Programme

UNEP United Nations Environment Programme

UNSD United Nations Statistics

Division
WCCD World Council on City Data

WCED World Commission on the Environment and Development

WCS World Conservation Strategy

WWF World Wildlife Fund 


\section{List of Figures}

Figure 1. Visualization of sustainable development adapted from ICLEI (1996)..................................23

Figure 2. Visualization of sustainable development adapted from Giddings et al. (2002).......................23

Figure 3. Diagram showing the lexical relationships sustain-related words............................................ 30

Figure 4. Work flow diagram for study sample selection.................................................................... 46

Figure 5. Work flow diagram of preprocessing and preparing documents for MAXQDA. ......................49

Figure 6. Work flow diagram of coding process employed using MAXQDA.......................................51

Figure 7. Frequency of sustain* in sample of City of Toronto reports, plans/strategies, and guidelines. ..53

Figure 8. Number of times (counts) environment is explicitly used with sustain*.................................55

Figure 9. Number of times (counts) implicit and explicit environmental terms occur with sustain...........56

Figure 10. Number of times (counts) development is explicitly used with sustain*..............................57

Figure 11. Example of documents operationalizing vision of "Sustainable Toronto 2020"......................80 


\section{List of Tables}

Table 1. Morphological and lexical variations of sustain .................................................................... 40

Table 2. Comparison of similar multi-word expressions coded in study sample. ...................................52

Table 3. Study sample documents ranked based on absolute frequency of sustain* ...............................54

Table 4. Words classified as implicit of the natural environment...........................................................56

Table 5. Multi-word phrases containing nouns most frequently regarded as sustainable study sample.....59 


\section{List of Appendices}

Appendix A: Study Sample Document Variables............................................................................ 95

Appendix B: Document Cross-References \& Reasons for Inclusion .................................................... 96

Appendix C: Study Sample Characteristics - Percentage (\%) of Documents by Primary Author.............. 98

Appendix D: Study Sample Characteristics - Percentage (\%) of Documents by Author Type ................. 99

Appendix E: Study Sample Characteristics - Percentage (\%) of Sample by Document Type ................. 100

Appendix F: Study Sample Characteristics - Percentage (\%) of Sample with Sustain* in Title ............. 101

Appendix G: Study Sample Characteristics - Percentage (\%) of Sample by Mayor ............................... 102 


\section{INTRODUCTION}

\subsection{Background}

Using natural resources, scientific advancements, and technological innovation (Hoornweg et al., 2016), humans have evolved, developed, and thrived for over 10,000 years (Rockström, 2009). During this time, the human population has transitioned to an increasingly urban way of life (Hoornweg et al., 2016). Urban areas, referred to synonymously as cities, are home to over half of the world's population today (Graham et al., 2016). Despite this transition, human civilization remains unequivocally dependant on Earth's natural systems and processes to sustaining its progress (Ehrlich et al., 1973; Lotka, 1925; Soddy, 1933) as it has since inception.

Concerns regarding human sustainability have existed since the beginning of civilization, however the threats society is confronted with have since evolved. Numerous events during the postwar era, for instance, radioactive fallout from nuclear testing, thousands of deaths from the Great Smog of London, the realization that CFCs (Chlorofluorocarbons) created a hole in Earth's ozone layer, and the periodic death of Lake Erie in 1960s (Carson, 1962; Ehrlich et al., 1973; Georgescu-Roegen, 1975) have all evoked uncertainty regarding the sustainability of modern human civilization.

Large-scale societal changes such as globalization, commercialization of agricultural, and increases in material wealth (Graham et al., 2016), particularly those beginning with the Industrial Revolution (Rockström, 2009), have been attributed to the exponential increase of greenhouse gases $\left(\mathrm{CO}_{2}, \mathrm{~N}_{2} \mathrm{O}, \mathrm{CH}_{4}\right.$, $\mathrm{O}_{2}$, CFCs, and HFCs) in the atmosphere (Intergovernmental Panel on Climate Change (IPCC), 2013). More widely known as climate change, these findings led to the most extensive scientific review ever undertaken on record (Robinson, 2006). Scientists from around the world converged to deliver their consensus that human activities, those historically associated with economic growth and the development of the human population, are responsible anthropogenic climate change, and thus are unsustainable. Despite the extent of these impacts and the Earth's capacity to adapt and respond to them being scientifically uncertain, climate change is irrefutable evidence to show that economic growth is and continues to be unsustainable.

Despite these challenges, cities offer some unique opportunities for generating development that is sustainable (Dale, 2012; Sharifi \& Murayama, 2015). With the increasing concentration of knowledge, technology, data analytics, human ingenuity, and financial resources in one area, cities present favourable conditions for implementing sustainable development in practice. Certainly, if society is to change its trajectory to one that is more sustainable, it will need practical methods and tools to measure the dynamic and multifaceted system that is the urban environment (Böhringer \& Jochem, 2007). Considering this, 
how does city navigate where they are going, if they are not sure how far they have come? The most frequently used approach for evaluating or measuring the state, condition, or level of progress regarding sustainable development has been state of the environment (SOE) reporting and more recently through the formulation of indicators. If the saying, 'what gets measured, gets managed' holds any truth, it is suspected to have significant implications for the environment (Heal, 2012; Lipinski et al., 2013), both locally and globally.

For sustainable development to be measured, it must first be defined, conceptualized, and then operationalized. Defining sustainable development means to identify what should be sustained, what should be developed, for whom should it be sustained or development for, and how long (Kates et al., 2005). One of the most prevalent issues in urban sustainability research is the myriad number of studies, especially ones that result in indicators, that only mention the first half of sustainable development as defined in the Brundtland Report, for example Choguill (2008), Li et al. (2009), Huang et al. (2015), Sakieh et al. (2015), Singh et al. (2012), and Turcu (2013). In the process these authors omit the second portion of the definition specifying that sustainable development is comprised of two key components: (1) "ability" refers to the environment's ability, which is limited by the state of technology and social organization; and (2) "needs" refers to the essential needs of the world's poor taking precedence over anything else (WCED, 1987, p. 41). In absence of this information, its' definitional ambiguity led to its pervasive application in just about any context (Dale, 2012; Kates et al., 2005).

Furthermore, the widespread recognition of sustainable development as having first been introduced and defined by the WCED Brundtland Report is a misrepresentation of its conceptual history. The notion of sustainable development was first introduced in 1980 by the International Union for Conservation of Nature and Natural Resources (IUCN) in the World Conservation Strategy (WCS). By 1986, the International Institute for Applied Systems Analysis (IIASA) asserted sustainable development as a management approach for reconciling socio-economic development in their report Sustainable Development of the Biosphere. Finally, the World Commission on Environment and Development (WCED) reinvented sustainable development as a means for addressing economic growth and environmental degradation, which is the popularized from the 1987 Brundtland Report.

Sustainable development and sustainability were increasingly prevalent in public policy shortly after its popularization which saw them turn into "fashionable catchwords of the 1980s" (Peace, 1988, p. 598). Several scholars however, including Lélé (1991), Böhringer and Jochem (2007), Robinson (2004), and White (2013) express concerns regarding the use of sustainability and sustainable development as merely rhetoric. Whether it is the result of ambiguity, misrepresentation, or oversimplification that saw 
sustainability reduced to three interdependent and incommensurable dimensions - social, economic, and environmental - sustainability rhetoric can be found in nearly every enterprise (Connelly, 2007).

Considering this, the way in which sustainability is defined, including the values and principles identified, and who is involved in formulation is of crucial importance because it delineates the foundation from which a conceptual framework and measurement is then built upon (Huang et al., 2015; Kates et al., 2005; Wu \& Wu, 2012). If sustainability or sustainable development is poorly-defined, then the indicators derived from those definitions are at risk of producing erroneous results. With that said, the conceptual framework sets the foundation, structure, and/or position one takes in applying and understanding the phenomena in question. In the conceptual framework, preconceived assumptions and relationships are outlined (Given, 2008), and the scope, context or criteria relating to the phenomena are identified. For instance, 'casual frameworks' are used to identify and model cause-and-effect relationships (Maclaren, 1996, p. 193), which is often used in economic or policy decisions to evaluate the potential environmental impacts. Although casual frameworks can be more analytically-complex, there are some well-known examples such as, the ecological footprint model (Rees \& Wackernagel, 1996), Pressure-State-Response (PSR) framework (Organisation for Economic Co-operation and Development (OECD, 2001), and the later version, the Drivers-Forces-Pressure-State-Impact-Response (DPSIR) framework (Brandon \& Lombardi, 2011). As shown in this example, concepts are formulated as being representative of the phenomena under study, in which they are generally expected to have some definitional and conceptual boundaries.

Concepts start as abstract ideas, perceptions, sometimes even theories (Rallis, 2018). Mueller (2004) defines conceptualization as "the process whereby these concepts [or constructs] are given theoretical meaning" (p. 162). Once the conceptual framework is established, it is then operationalized which can take many forms. In research design, a framework is often operationalized in the form of measurement whereby theoretical concepts are assigned measurable factors or variables that they are characteristics of, and which are then empirically observed or assessed (Mueller, 2004). In a broader sense, operationalization could be simply outlining the boundaries or definition of a concept (i.e. operational definitions) or take the form of a policy whereby concepts are realized in practice or legislation.

\subsection{Research Objectives and Questions}

This research seeks to explore the temporal use of sustainability and sustainable development in key municipal documents (e.g. strategies, reports, plans, and guidelines) published by the City of Toronto over the last 30 years (1988-2018). The purpose of this objective is to (i) investigate how sustainability discourse has evolved over time; (ii) identify thematic patterns associated with the use of these words; and 
(iii) demonstrate the methodological challenges and limitations in various approaches to textual data analysis. Accordingly, this research study seeks to answer the following questions:

(1) How does the City of Toronto define sustainability and/or sustainable development?

(1a) What implications might this have for operationalization and measurement, if any?

(2) How has the use of sustainability and/or sustainable development changed from 1988-2018?

(2a) What thematic patterns are present over time, if any?

(3) What are the implications of how sustainability and sustainable development has been conceptualized and operationalized in relation to public policy in the City of Toronto?

\subsection{Study Outline}

This thesis begins with a literature review to establish the scientific, theoretical, and conceptual foundation that sustainability and sustainable development is derived from and evaluate how it has evolved over time. The literature review will cover the theoretical and conceptual history of sustainability and sustainable development, the role of linguistics in its conceptualization and analysis, the issue of circumventing definitions, and several case studies on content and discourse analysis as they pertain to the analysis of sustainability. The rationale for employing a pragmatic approach in this research will be discussed in Section 3.1. Finally, an overview of the methods which will specifically cover the exploratory search strategy used in sample identification, the criteria for sample selection, and the coding procedure and rationale.

\subsection{Study Area Context}

Canada represents less than 1 per cent of the worlds total population while being home to the third largest supply of freshwater in the world (Statistics Canada, 2016), which by its very nature presents unique circumstances for studying urban sustainability. Since the City of Toronto is the largest urban centre in Canada, in terms of population size and built-up area, (Statistics Canada, 2017), it will be the central focus of this study.

With a population of 2,731,571 (Statistics Canada, 2017), Toronto is considered the fourth largest urban centre in North America (City of Toronto, 2017). Located in southern Ontario, the city is situated along the shoreline of Lake Ontario and covers a land area of 641 square kilometres (Statistics Canada, 2017). In respect to the natural environment, the southern Ontario region has seen drastic changes spanning many decades. The Environmental Commissioner of Ontario calls for attention to southern Ontario, which was once primarily comprised of wetlands, but has since seen a net loss of 70 per cent of its wetland area since European settlement and continues on a downward trend (Saxe, 2017). 
Correspondingly, southern Ontario contains more species at risk than anywhere else in Canada (Saxe, 2017). In a recent report issued by Statistics Canada (2016), it was stated that Toronto had the second largest decrease in natural land cover from 1971 to 2011. Despite the intensification of development in Toronto, it continues to expand outward as well (Statistics Canada, 2016). As the largest metropolitan area in the country and the provincial capital of Ontario, Toronto will play an important role in sustainable development, regionally, provincially, and nationally.

The City of Toronto uses a wide range of international, regional, city, and neighbourhood-scale frameworks for evaluating and benchmarking physical, environmental, social, and economic conditions of the city. Of particular importance when it comes to environmental conditions, sustainability, and sustainable development, is the provincially mandated Toronto and Region Conservation Authority (TRCA) who monitors environmental health and quality in the Greater Toronto Area (GTA) from a watershed purview. TRCA jurisdiction encompasses 3,467 $\mathrm{km}^{2}$ in southern Ontario (Toronto and Region Conservation Authority (TRCA), n.d.), a land area five times larger than the City of Toronto. They are responsible for the management of 9 watersheds, including Toronto Islands and part of Lake Ontario's shoreline, while also coordinating their efforts with of six different municipalities (TRCA, n.d.), one being the City of Toronto. Despite being markedly effective in their efforts, it is reasonable to suggest the TRCA is to some extent limited in human and financial resources and therefore would have to "pick one's battles" when it comes environmental sustainability in the city. With urban sprawl continually encroaching on the more naturalized area surrounding Toronto (i.e. the Greenbelt), it is only logical that the densely populated urbanized area - that is the City of Toronto - may at times be overlooked.

Aside from the TRCAs reporting, the City of Toronto has published several key documents in the past thirty years (1988-2018), such as the Environmental Progress Report, Climate Change Action Plan, Sustainable Energy Strategy, Toronto's Results for World Council on City Data (WCCD) Under ISO 37120: Indicators of City Services Delivery and Quality of Life, and most recently, the Toronto Strong Neighbourhoods Strategy 2020 and TO Prosperity: Toronto Poverty Reduction Strategy. Explicit in their names is that none of these reports specifically or comprehensively address sustainable development and nor are they presumably intended too. Implicit in their language however, is that sustainability is to some extent, on the municipal agenda, but to what extent is unclear. Given these circumstances, a content analysis is needed to ascertain if, how, and to what extent, has sustainability and sustainable development been conceptualized by the City of Toronto. 


\section{LITERATURE REVIEW}

Currently there are numerous conceptual and historical reviews on sustainability and sustainable development, for example, Pezzoli (1997), Mebratu (1998), Lumley and Armstrong (2004), Connelly (2007), Hartmuth et al. (2008), Bolis et al. (2014), and Fu and Zhang (2017), to name a few. Most often, the study objectives, publication title (i.e. Ecological Economics, Sustainable Development, Conservation Biology) and corresponding researchers discipline determines which conceptual, theoretical, and historical components are emphasized. For example, from an economical standpoint there may be more emphasis on ecological economics whereas an ecological standpoint may focus more on ecological dynamics. Few reviews comprehensively capture all the events that have contributed to sustainability and sustainable development as it has been formulated today.

This research study would like to acknowledge the variety of tools available to researchers for improving the comprehensiveness, transparency and reliability of literature reviews. Recently, systematic reviews and a priori protocols are increasingly used to reduce the subjectivity and bias associated with literature reviews. Due to its methodological rigor, systematic reviews were first used in healthcare and biomedical research to summarize evidence-based scientific information from clinical trials and interventions (Frampton et al., 2017; Moher et al., 2015), although these methods have recently been introduced into the fields of policy and environmental management. While techniques like these have proven to be effective for improving the transparency, accountability, and comparability of scholarly work, they depend on the classifying and organizing of scholarly research in some type of logical or relational manner. The organization and cataloguing of such research has historically been discipline-specific or according to subject matter. Considering the inter- and multi-disciplinary nature of sustainability and sustainable development, the typology required by a systematic review may pose some challenges for investigating these concepts. Despite this, systematic reviews are increasingly prevalent technique for bridging the disciplinary gap in sustainability and sustainable development research (Amui et al., 2016; Cohen, 2017; Cucurachi \& Sangwon, 2017; Gan et al., 2017; Howes et al., 2017; Luederitz et al., 2013; Mahon et al., 2017; Salas-Zapata et al., 2017). While this is beyond the scope of this study, it is recognized that this is one of the few ways to expound problems relating to exhaustiveness, comprehensiveness, transparency and reliability in inter- and multi-disciplinary research investigations such as these. Systematic reviews necessitate broad collaboration and consultation among members of academia, and in some cases, even non-academic members, and for this reason, they would be presumably be accommodating of the inter- and multi-disciplinary nature that is sustainability and sustainable development. To that end, this research highly recommends exploring the use of systematic 
reviews in investigating concepts alike or within the concept of sustainability. It is with significant regret that such an investigation could not be conducted in a timely manner for inclusion in this research.

With that said, the literature review to follow will neither be comprehensive nor exhaustive. Instead, the following review of the theoretical and conceptual history of sustainability and sustainable development seeks to accomplish the following: (i) trace the historical use of the terms sustainability and sustainable development; (ii) identify some of their dominant conceptualizations; (iii) reveal the thematic similarities and differences found in these conceptualizations; and (iv) discuss the importance of language in communicating sustainability and sustainable development.

\subsection{Theoretical and Conceptual History of Sustainability}

In the most general sense, sustainability is about maintaining something (i.e. an activity, event) at a certain rate over a given period of time. Nonetheless, the first reported use of the concept was in 18th century (1701-1800) Germany where it was applied in the field of forestry. 'Nachhaltigkeit' which is 'sustainability' in German was used by Hans Carl von Carlowitz (1645-1714) in his book Sylvicultura oeconomica nearly 300 years ago. The book title can be loosely translated in English as 'forestry economics'. Hans Carl von Carlowitz, an accountant and mining administrator, is also said to have coined the term 'sustainable yield' in response to his growing concern that the rate of local timber harvest would be unsustainable in the long-term (Biely et al., 2018; Duerr et al., 1979; Wiersum, 1995). Despite being concerned with managing timber in a way that was not a detriment production (i.e. reducing the likelihood of a timber shortage), he also emphasized that logging the area too quickly would be a detriment to the locally-dependant population (Duerr et al., 1979; Wiersum, 1995). Despite the more general and technical uses of sustainability frequently found in scholarly research, public policy, and corporate management, it is evident that the notion of being sustainable emanates from early conceptions of human dependence on the natural environment.

Humans have known that nature provides them sustenance since the beginning of civilization. Evidence such as archaeological records and written history indicates that humans were cognizant of nature, its processes (especially hydrological processes) and their importance in sustaining human life and other life forms (i.e. plants, animals, etc.). General awareness of Earth's biophysical system was apparent in Egyptian, Mesopotamian, Minoan, and Greek civilizations, among other civilizations, existing more than 5,000 years ago. These civilizations took advantage of natural topography and utilized piping to create water systems that brought water into city-states while also draining out wastewater. As these ancient civilizations urbanized, their water systems became increasingly more integrated. Water was piped and tunneled (i.e. aqueducts, qanats, etc.) from aquifers where they were intricately connected to cisterns and 
reservoirs which stored rainwater and allowed for water conservation, and even included diversion dams for floodwater control (Ortloff, 2005).

Evidently, humans have used tools and technologies to adapt to the constraints of their local biophysical environment for thousands of years. As urban populations grew, the need for water increased simultaneously, necessitating innovative solutions (Ortloff, 2005) to improve water utilization and conservation. These societies were conscious of the material goods and processes (i.e. water, sugar, etc.) provided by nature and at the same time were perhaps equally aware of the consequences of manipulating the biophysical environment, which often became apparent through trial and error. Butzer (2012) and Diamond (1994) provide a glimpse into several civilizations that collapsed because of extensive anthropogenic change and environmental degradation, which in turn, led to a collapse of the local ecosystem. Despite this awareness of human-ecological relationships, written articulation of sustainment had not been explicitly found during this era, although there are likely many parallels that equate to the concept of sustainability.

\subsubsection{The Paradox of Human Sustainability}

As indicated by the first recorded use of sustainability, concerns regarding human development, resource use and distribution, and biophysical limits have existed for centuries. While economic growth and development will not be the primary focus on this research, it is important to acknowledge its role in the long and complex history of unsustainable human development. The works of Adam Smith (1723-1790) play an important role in discussions on classical economics; but despite this importance, the evolution of economic systems is beyond the scope of this research and the global economic challenges to sustainability are far too complex to adequately address in this thesis. Nonetheless, if one wishes to pursue a more comprehensive understanding of how the economic system came to be what it is today, they directed to the works of Adam Smith, especially his book An Inquiry into the Nature and Causes of the Wealth of Nations (1776), among many others, including David Ricardo's Principles of Political Economy and Taxation (1817) that was influenced by Smith's work, and John Stewart Mill's Principles of Political Economy (1848) thereafter.

Adam Smith's work had influenced Thomas Robert Malthus, a scholar in the field of political economy and demography, who published a seminal book An Essay on the Principle of Population (1798). His theory echoed similar sentiments expressed in the earlier work of Hans Carl von Carlowitz, although Malthus (1798) was more concerned with Earth's ability to provide subsistence for an exponentially growing population rather than forestry. His main premise asserted that the human population would increase at an exponential rate, while Earth only provides subsistence in a linear function. At the time, world population was just reaching one billion and concerns surrounding overpopulation were prominent 
in public discourse. From this theory, Malthus (1798) predicted that widespread starvation would ultimately lead to the demise of the human population. At the time, Malthus (1798) did not consider technological innovation which led to significant advances in agricultural production. Accordingly, the timeline of Malthus's theory has since passed, and his argument is technically disproven. Despite this, his underlying concerns about the Earth's ability to provide substance for the current and future human populations remains to be a contentious area of discussion two centuries later.

Conceptualizing the natural environment as a resource to be utilized by human society has exacerbated environmental problems for centuries, brought rise to the question of long-term sustainability, and introduced concerns regarding intergenerational equity. In the early 1900s, the limits of perceiving Earth's materials as 'natural resources' was conveyed by several renowned scholars, including, biophysicist Alfred Lotka (1925), radiochemist Frederick Soddy (1933), and mathematician Harold Hotelling (1931). Essentially, the limitations of resource economics were conveyed by introducing biophysical economics in its place. This allowed for the incorporation of thermodynamic laws into economics and the characterization of ecological processes and materials as 'natural capital' instead.

Lotka's (1925) Elements of Physical Biology predominantly focuses on biophysical capital as he explains how the hydrological cycle, and phosphorus, nitrogen, and carbon cycles, are all interdependently connected to and within the food chain network. He discusses how the human population is living on a finite stock of this capital, emphasizing that living on biophysical capital economically while changing it biologically at the same time. The biological change Lotka (1925) is referring to relates to the using and displacing of capital. For example, carbon dioxide is taken from the lithosphere/geosphere and displaced into the atmosphere at an unprecedented rate. Lotka (1925) was among few early scholars that acknowledged how the economic system is embedded within Earth's natural system and processes. Lotka's research essentially grounded both abiotic (non-living) and biotic (living) processes in the movement of energy "to provide a common perspective on processes in nature and society" (Røpke, 2004, p. 297). He emphasized that the human population could not afford to simply pay attention to immediate supplies of food (i.e. annual crop yields). As it was becoming increasingly apparent that organic material (i.e. organic matter such as dead plants and organisms, minerals, living organisms, liquid, and gases) could not be drawn continuously and indefinitely from soil, especially in agricultural situations at the time, without giving the soil adequate time to replenish (Lotka, 1925). Lotka (1925) maintains that because the system is in a state of constant progressive change from its interacting components - simple statistical averages are insufficient - and thus, improving knowledge of the system is imperative. This is especially because there are biophysical re-adaptions that have time-lags associated within them; and depending how large the change and associated re-adaption is, the change may be 
irreversible. Hotelling (1930) and Soddy (1933) on the other hand, contrasted physical capital with wealth and capital return.

Economic theorist and statistician Harold Hotelling (1931) for instance, published The Economics of Exhaustible Resources in 1931, between the works of Lotka (1925) and Soddy (1933). Hotelling is known for having developed one of the most widely used methods of analysis employed in the field of statistics and computer science, principle component analysis also known as PCA. Hotelling (1931) contends that the worlds contemplation over the depletion of "exhaustible assets", such as minerals and forests, has led to calls for regulating their exploitation. At the time there were rising concerns regarding the pricing of exhaustible assets, specifically that prices were far too cheap given their potential exhaustion and valuation like such is what permits selfish exploitation and wasteful consumption. Under these circumstances there will be significant impact to the good of future generations, which is the precise point, he says, that led to the conservation movement. Hotelling (1931) contrasts the two diverging perspectives on the issue. While one believes the supply should not be reserved for distant generations, the other believes in absolute prohibitions, perhaps for posterity or for maintaining high prices because they too have invested interests. He calls these "public questions", appearing implicit in that such contentions should be up for public discussion, then again, perhaps these were apart of the public discourse at the time of his publication.

Hotelling (1931) stresses that the economics of "exhaustible assets" also referred to synonymously as non-renewable resources (e.g. fossil fuels such as oil, coal, and natural gas; and minerals such as phosphorus and nitrogen), present "a whole forest of intriguing problems" (p. 138). The economic theory behind the well-developed economic system, he describes, "is plainly inadequate for an industry where indefinite maintenance [of steady rate of production] is a physical impossibility, and which is therefore bound to decline" (p. 139). Hotelling (1931) argues that discounting future generations may be done on a few grounds, but each is problematic in one way or another. Natural resources are given social value based on their "total production of goods" rather than their full utility or happiness attributed to the use of such goods, directly and indirectly, that is. This is because the latter refers to the distribution of wealth access to the financial means to obtain such goods - which Hotelling (1931) decides he is not going to get into.

Two years after Hotelling (1931), English radiochemist Frederick Soddy published Wealth, Virtual Wealth, and Debt: The Solution of the Economic Paradox in 1933. Soddy immersed himself with similar ideas as Lotka (1925) and Hotelling (1931), but addressed economics more directly, emphasizing the paradox of economics could not be solved by mechanical science, biological science, or the humanities alone. Soddy (1933) does not hesitate to clearly assert the laws of thermodynamics are in fact, universal 
physical laws, based on empirical energy observations over the past 100 or so years, and are laws that govern the use of energy by all life on Earth; a fact emphasized by Lotka (1925) and many others before. To put this in perspective, the average citizen would (hopefully) not question the laws of gravity despite being unable to feel or see them. Although anyone may test the laws of gravity and find that they cannot be broken (for instance, if you drop a watermelon from the second story of a building this should become apparent). The laws of thermodynamics however are much more difficult to test out. These laws are generally not felt or seen by the average citizen, nonetheless these biophysical laws cannot be broken (Boulding, 1966; Lotka, 1925; Soddy, 1933)

Soddy (1933) spends most of his time analyzing capital wealth, and especially in terms of its interrelationship with production, consumption, and increase in human efficiency, which in turn, creates more production and consumption, inadvertently depleting the stock of capital. He attributes the most profound change in history to when "men began to tap a large capital store[s] of energy and ceased to be entirely dependent on the revenue of sunshine", which is what they were dependant on historically. The burning of coal is then equivalent to the "burning of sunshine" (or solar energy) which had reached the Earth millions of years earlier (Soddy, 1933, p. 47). Once coal, among other fossil fuels, are burned they are no longer tangible capital stores which humanity can have, nor is there any way (thermodynamically) to extract any "perennial interest from [them]" (p. 47). Soddy (1933) argues that this is not a problem of physics but a "mystery" he calls it, pertaining to the "inexorable laws of economics" (p. 47).

Kenneth E. Boulding published the Economics of the Coming Spaceship Earth in 1966, echoing similar sentiments to those conveyed 30 years earlier by Lotka (1925) and Soddy (1935) and used them to reformulate the paradoxical relationship between biophysical laws of Earth and the functions of the economic system. Boulding (1966) uses an analogy in which he describes Earth as a spaceship, limited in material supplies (i.e. for food, hygiene, and other activities) being provided by a single source of energy (i.e. solar energy), and limited by its assimilation capacity (i.e. for disposal of human waste). In spaceship Earth, humans would have to adapt to this cyclical nature if they are to survive. Consequently, consideration must be given to the non-human passengers aboard spaceship Earth (e.g. plants, animals, etc.) who also require the single source of shared energy and which are equally necessary for human survival. The paradox being that the current economic system wholly disregards the biophysical limits of the spaceman economy, with that said, Boulding (1966) describes the economic system as a "cowboy economy" characterized by illimitable plains and reckless behaviour and exploitation.

Building on Thomas Malthus (1798), Garrett Harden (1968) theorized around ideas of exponential population growth, Earth's finite resources, and the limitations of technology in his work on The Tragedy of the Commons. Harden (1968) illustrates this theory by describing a pasture know as the 'commons', a 
place for all people and where each herdsman can raise their cattle (e.g. equal and open access for all). As rational human-beings, each seeks to maximize his benefit by adding another cattle to their herd, which later results in adding another; and another. The function of adding one more cattle has both a positive (e.g. herdsman receives proceeds from selling another animal) and negative component (e.g. more overgrazing from each additional animal) but when every herdsman makes this rational decision, this is what results in the tragedy of the commons (Harden, 1968). Harden (1968) does not limit his argument to the grazing of cattle, instead he describes pollution or the incremental addition of something - chemicals, sewage, fumes, heat - into the commons (e.g. Ocean, Lake, air) as being equally as dangerous as the removal of something from the commons. He contends that for each rational, independent, and free-living individual, the cost of dumping into the commons will always appear less at one given time than it is for one to pay for cleaning of the waste before discharge.

Consequently, many authors discredited Harden (1968) and his interpretation of "the commons", ultimately leading Hardin to clarify in his publication Extensions of "The Tragedy of the Commons" in 1998. Building on Forster Lloyd's work on "the commons" in 1933, Hardin (1998) clarified that when "resources were available to all [unmanaged commons], the greediest herdsmen would gain - for a while as mutual ruin was inevitable for all". (Hardin, 1998, p. 682). In the same year of The Tragedy of the Commons, Stanford University Professor Paul Ehrlich (1968) published his rather controversial book The Population Bomb where he continued the Malthusian theory of overpopulation, and perhaps considered it more than Hardin (1968) did. Malthus (1798), Hardin (1968), and Ehrlich (1968) all proposed rather controversial and perhaps unethical methods of population control, which undoubtably overshadowed some of their work. Additionally, their works were heavily criticized for having incorrectly estimated the time in which the human population collapse would happen. While Rogers et al. (2008) quips that the human population is still here, feeding 6.5 billion people and counting, the reality is that Earth's life supporting system were critically compromised to achieve such an objective.

Conceptions of sustainable yield, natural capital, "the commons", finite resources, and the operational challenges that accompany them have already materialized, although most prominently at the local level (i.e. community, city). Achieving a sustainable yield of renewable resources for example, has endured both triumph and failure. While sustainable yield has had some success in forestry, its application in fisheries management has been far more complex. Estimating current fish stocks to determine what level of harvest is sustainable has proven difficult, that is, in addition to the process of governing fishing vessels in open bodies of water. Such estimations have failed before (Stavins, 2011), for example, the Northern Cod fishery off the coast of Newfoundland in Canada. Despite efforts of local fisherman, fishery scientists, Canada's Department of Fisheries and Oceans and the numerous moratoriums placed on cod 
fishing in the mid-1970s, the cod fishery experienced near-collapse many times over. Consequently, this had considerably negative impact on the local community who heavily relied on the cod industry for its livelihood. What has since been learned from this experience is that the information needed for sustainable environmental decision-making must be available for more than one level, for instance, at the individual level and not just the aggregate level (i.e. population and community level) (Dietz et al., 2003). Concerns surrounding environmental degradation, exploitation of non-renewable resources, and everincreasing population and economic growth, gained significant public attention at the international level when The Club of Rome issued their first report in 1972 entitled the Limits to Growth, the same year the United Nations Conference on the Human Environment was held in Stockholm, Sweden. The Club of Rome, a non-profit, non-government organization made up academics, the Organisation for Economic Co-operation and Development (OECD), UN bureaucrats, and high-ranking politicians and economists (i.e. David Rockefeller) arose in 1968 (Schmelzer, 2017) in attempt to foster better understanding of the global system and the economic, political, natural, and social interdependencies that it is made up of. The Limits to Growth (1972) was authored by several academics from the Massachusetts Institute of Technology (MIT), such as Donella and Dennis Meadows, Jørgen Randers, and William Behrens III, to name a few. The Limits to Growth (1972) was concerned with the naturally-imposed limits to population and economic growth. Moreover, the report mentions the works of Malthus (1798) and Boulding (1966), among many others that having expressed similar concerns.

Meadows et al. (1972) conceptualizes the Earth as a closed system, corresponding with earlier descriptions provided by Carson (1962), Boulding (1966) and Hardin (1970). Meadows et al. (1972) suggests the lack of acknowledgement in practical politics regarding the closed system and finite planet has consequences that are beyond far-reaching. The report continually maintains that scientific understanding of the earths ability to absorb pollution is very poor due to a lack of complete measurements, which is characteristic of society lacking concern for the impact of its activities. From a global perspective, the difficulties in understanding and controlling future ecological systems comes down to four major points: (i) the pollution that is measurable (i.e. carbon dioxide, thermal energy, radioactive waste) has continually increased in the environment exponentially; (ii) there is little, if any knowledge of how much pollution Earth can actually absorb; (iii) the fact that there is natural delays in ecological processes suggests that we will inevitably underestimate what pollution controls are needed and inadvertently reach the upper limit of the systems absorption capacity; and (iv) the global distribution of many pollutants (i.e. DDT, PCBs, radioactive waste) means that their negative effects are transboundary (Meadows et al., 1972). The main premise of the report is that the ecological footprint of the human population is already unsustainable. Many local environments have already passed their upper 
limits which is why the such limits are known of. It was in The Limits to Growth (1972) that current rates of economic and population growth were said to be unsupportable beyond 2100 despite any advances in technology.

The Limits to Growth (1972) was a direct attempt to discuss the problem of population and economic growth in the context of non-renewable resource depletion. The report has been credited for conveying the notion of limits to the growth, specifically pertaining to the human population. Meadows et al. (1972) made the complex dynamic interrelationships of human-ecological systems reach the international stage by arguing that these systems are comprised of circular, interlocking, and time-delayed relationships among its constituents (p. 31) and thus necessitate further understanding and consideration. It was recommended that these 'System Dynamics' be modelled in effort to better understand the feedback mechanisms involved within these systems. Meadows et al. (1972) credits the success of the human population thus far to great technological achievements; but also cautions that this success combined with a faith in technology to solve all our problems, would ultimately obscure and distract attention from the fundamental issue of Earth being a finite system, in turn adverting us from solving the real problem.

Despite the Limits to Growth being praised by many, it was also met with much criticism. Solow (1972) is well-known critic of what he refers to as "Doomsday Models" and calls the work of Meadows et al. (1972) nothing more than an assumption. At the same time, Solow (1972) suggests that his claim is neither factual nor based on deduction, rather it is simply a claim that Meadows et al. (1972) is making assumptions in the absence of a "price system". Solow (1972) proposes the idea that natural resources are substitutable with other forms of more efficient and cheaper capital, but he fails to provide any scientific foundation for such a claim. Another concern surrounding The Club of Rome's inclusion of several rich elitist, was its relationship with the OECD which did not go unnoticed. The complex relationship between the OECD, The Club of Rome, and global development is important but much to expansive to be acknowledged here. In any case, Schmelzer (2017) provides a comprehensive historical review and analysis of what he describes as the "OECD-Club of Rome nexus" which is helpful for further contextual understanding.

In the same year The Club of Rome published the Limits to Growth, the United Nations Conference on the Human Environment was held in Stockholm, Sweden from June $5^{\text {th }}$ to $16^{\text {th }}$. This conference marked the first international gathering of its kind on the environment. The conference sought a common outlook and principles for the world's population to "preserve and enhance the human environment" (p. 3). Despite the conference using human environment, they proclaim that the human environment gives "[man] physical sustenance and affords him the opportunity for intellectual, moral, social, and spiritual growth" (p. 3). They refer to man's environment as encompassing both the natural and man-made 
environment, emphasizing that both are essential to human well-being and to life itself. The conference acknowledges that humans have heedlessly used their capabilities to transform their surroundings in a way that has caused incalculable harm to human beings and the environment. Some of these include precarious levels of pollution in the air, water, land, and organisms; "major and undesirable disturbances to the ecological balance of the biosphere; [and the] destruction and depletion of irreplaceable resources" (p. 3). The conference mentions that if man transforms his environment wisely, "all peoples [could be brought] the benefits of development and the opportunity to enhance quality of life" (p. 3). The conference suggests that humans can have freedom from a world of nature, if they use their knowledge in collaboration with nature rather then in control. Such a characterization evades the question that if nature provides humans sustenance, how would humans ever be free from nature itself? Humans depends on nature for all that they are, including life itself.

The conference describes the overall imperative of mankind as "defend[ing] and improv[ing] the human environment for present and future generations" (p. 3). This requires conserving and protecting earths natural resources which are described as the air, water, land, flora and fauna. It emphasizes the importance of nature and wildlife conservation in any further economic development and planning. They also condemned the widespread use of nuclear testing and called on all nations to abandon such testing. The conference describes environmental problems in industrialized countries (i.e. Canada, United States) as being "generally related to [their process of] industrialization and technological development" and a product of the gap between industrialized and non-industrialized nations. Overall, the conference shed light on the need to reduce the impairment to biophysical systems which the human population depend on for their sustainment.

While some might regard their reference to the human environment as being underpinned by both ethical and philosophical assumptions that are anthropocentric in nature. Specifically, the use of human environment may suggest the environment in which we live is ours for the taking, and in a sense, it disregards all other organisms that use and live off the natural environment. The fact that biodiversity was not included may as well reflect their anthropocentric position. Nonetheless, this was the first international environmental conference of its kind that sought to encourage nations around the world to consider the environment; accordingly, the United Nations needed to place the problems in a context that was relatable at that time, which may explain the human part of environment.

Nonetheless, some major accomplishments are said to have resulted from the United Nations Conference on the Human Environment. The notion that humans can affect the climate was acknowledged for what might have been the first time. Attitudes towards the "Third World" or less-development countries began to shift (Bassow, 1979) and vice versa. The United Nations Environment Programme was established and 
appointed as the "environmental conscience" of the United Nations (Biswas \& Biswas, 1985). It has been said before that the United Nations Conference on the Human Environment woke up many nations, for instance Canada's participation during the two years leading up to the conference under then President Pierre Trudeau, is said to have influenced national policies such as the Arctic Waters Pollution Prevention Act (AWPPA) established in 1970 (Manulak, 2015).

Many approaches have been proposed to account for biophysical externalities in society's economic systems. For instance, ecological economics was formulated to address problems that natural resource economics failed to account for. Ecological economics reiterated that humans must not forget that they cannot extract (i.e. water, plants, fossils for fossil fuels, nutrients, air, etc.) and send outputs (i.e. human waste, thermal and biological pollution, etc.) indefinitely because it would accumulate in Earth's system based on the physical laws of such system (Boulding, 1966; Costanza, 1980; Georgescu-Roegen, 1975). Hence, ecological economics is concerned with the establishment of an economic system that behaves in a steady-state (of inputs and outputs) over time. This is one of the many places that economists and ecologists start to diverge. A steady-state should not be equated with a stationary state; while the former may still be in a state of growth, the latter is a state of non-growth (Daly, 2009; Georgescu-Roegen, 1975) which the economist might consider as stagnation (Daly, 2009). A steady-state that focuses equilibrium would likely provide little understanding regarding the transient behaviour of disturbed and undisturbed ecological systems (Holling, 1973). Considering historical trends, increases in resource use, human population or economic growth would presumably push Earth's biophysical system further away from equilibrium (Holling, 1973). Thus, improving our knowledge of the way in which ecological systems behave in these circumstances is imperative to understanding their resilience and anticipating changes, if even possible.

While initial ideas were to account for the biophysical components of the economic system (i.e. flow of energy in the production and consumption of resources), it quickly became apparent that energy calculations for such inputs and outputs simply do not exist (Costanza, 1980). In absence of this information, estimations were frequently made using financial data (Costanza, 1980) instead of geophysical or ecological data, despite knowing that financial data inadequately captures the biophysical and ecological costs of production and consumption. Accounting for energy inputs and outputs still exist, some examples include urban metabolism, life-cycle assessment and circular economic. Furthermore, ecological economics also uses ecosystem goods and services valuation. The challenges and limitations associated with the valuation of ecological or ecosystem goods and services remain contentious due to questions surrounding trade-offs, social costs, and the disparity between actual value and perceived value (Daily, 1997). However, Constanza et al. (1997) points out that these decisions are made regarding public 
expenditures everyday and which often involve some trade-offs, valuations, and/or have some social or environmental costs.

If anything, this theoretical and conceptual history of sustainability here stresses that human sustainability and ecological sustainability must remain central in public dialogue and public policy and should be used to inform decision-making.

\subsection{Theoretical and Conceptual History of Sustainable Development}

In contrast to sustainability having existed for nearly three hundred years and perhaps even longer, the concept of sustainable development rose to prominence primarily in the last for decades, although scholars having contended with the long-term sustainability of human development many years earlier. Sustainable development was formally introduced in 1980 by International Union for Conservation of Nature and Natural Resources (IUCN) in the World Conservation Strategy: Living Resource Conservation for Sustainable Development. The report was commissioned by the United Nations Environment Programme (UNEP) and financially supported by the World Wildlife Fund (WWF). It was issued to reflect a policy consensus, or a comprise rather, between conservationists and practitioners of development. In this report, sustainable development objectives and requirements are established, and key terminology is defined. More notably, conservation is positioned as the fundamental component needed to sustain development for human survival.

The three main objectives of the World Conservation Strategy are: (i) to maintain ecological processes and life-supporting systems (e.g. soil and water regeneration, nutrient recycling, etc.); (ii) to preserve genetic diversity (e.g. genetic material found in organisms); and (iii) to ensure the sustainable utilization of species and ecosystems (e.g. fish, wildlife, forests, "grazing lands"). The IUCN emphasizes that both human survival and development depend on the existence of these three objectives and especially for the protection of plant cultivation, scientific and medical advancement, technological innovation, and the security of industry.

At this time, the IUCN listed several major obstacles to successful conservation as being: (i) the narrow view of conservation as a silo, isolating it from other sectors; (ii) subsequent failure to consolidate conservation with development; and (ii) the notion that the development is uncompromising and excessively destructive, which is a result of inadequate environmental planning, irrational resource use, and the prioritization of narrow short-term interests. The report concludes with an outline suggested for achieving sustainable development, and specific requirements for national and international actions. The broader sustainable development requirements range from preserving and managing quality cropland, protecting watersheds and specifically catchment areas (e.g. rivers bays, and other outlets), controlling 
pollution, preventing soil degradation and species extinctions, to securing a "comprehensive network of protected areas" (p. 63). The priority requirements for national actions place significant emphasis on anticipatory and cross-sectoral policy; non-monetary indicators; evaluation of ecosystems; environmental assessments for all major activities; establishing, expanding, and ensuring the financial sufficiency of conservation authorities; improving research, training, and environmental education; and increased public participation (IUCN, 1980). In all of these requirements for sustainable development, whether general, national, or international, there is an emphasis placed on creating the regulatory and legislative mechanisms needed to achieve these requirements.

The IUCN (1980) specifically defined development as "the modification of the biosphere and the application of human, financial, living and non-living resources to satisfy human needs and improve the quality of life" (p. 1). Emphasis is placed on accounting for social, ecological, and more moderately economic factors, including long-term and short-term actions and their advantages and disadvantages. Rather than defining sustainable or sustainability, the IUCN (1980) defined conservation as being the primary concern of sustainability. Accordingly, conservation was defined as "the management of human use of the biosphere [to yield] the greatest sustainable benefit to present generations while maintaining its potential to meet the needs and aspirations of future generations" (IUCN, 1980, p. 1). Despite it being defined in terms of "conservation" and "development", it is presumed that conservation in this respect, takes the role of sustainable in the term sustainable development.

In the years leading up to the IUCN (1980) publication, the International Council for Science (ICSU) had established the Scientific Committee on Problems of the Environment (SCOPE) in 1969, and also cofounded the peer-review journal Environmental Development. As the concept of systems thinking evolved and the need for interdisciplinary scientific research became increasingly pertinent, non-governmental, multi-national organizations such as the International Institute for Applied Systems Analysis (IIASA) emerged to address common problems concerning global biosphere change such as, global increases in $\mathrm{CO}_{2}$ emissions and chlorofluorocarbons ( $\mathrm{CFCs}$ ). One year before the Brundtland Report, the IIASA published Sustainable Development of the Biosphere in 1986, in attempt to detail interactions between human development and the environment and provide the foundation for investigating sustainable development of the biosphere.

The IIASA (1986) recognizes the 1972 Stockholm Conference as being one of the earlier intellectual foundations of sustainable development, acknowledges the work of Malthus (1798) and the contributions made by SCOPE, among others. Furthermore, recognition was given to highly anthropocentric nature of controlling and management the environment, this entails an approach that is primarily focused on the environment as a utility to humans, although they also acknowledge that sustainable development is a 
response to anthropocentric environmental problems. IIASA (1986) suggests that perhaps sustainable development should be sustainable redevelopment as most systems will need to be redevelopment if they are going to be sustainable. They also emphasize that sustainable redevelopment the concept of ecological rehabilitation is of crucial importance. For sustainable development to be implemented at the institutional level, IIASA (1986) suggests that institutional resilience be encouraged, that is, an institutional structure that has a network of high-level technical expertise available from a wide range of scientific disciplines. It also requires institutional flexibility transparency is promoted and especially in the exchanging of ideas and information.

IIASA suggests the key to understanding ecosystem relationships begins with global biogeophysical events and the way societal perception and management responds to them (IIASA, 1986). What remains imperative is how local ecosystems are perceived to interact between the various biosphere systems atmosphere, water, and land - and the management approaches that are used to deal with those systems. Sustainable Development of the Biosphere (1986) did not seek to predict future environmental impacts citing reasons such as technical infeasibility and practical irreverence. They also noted that such predictions are ignorant to the complexity of environmental problems as they are a product of the synergistic interactions of development, that which are almost entirely dependant on implausible predictions of prospective patterns of social choice and evolution. At the same time, the state of science is insufficient for such predictive assessments. Instead, IIASA emphasizes the importance of institutions in managing the larger scale problems associated with the biosphere. Environmental problems such as soil erosion and hazardous waste disposal invoke questions regarding intergenerational trade-offs. In these circumstances the strengths, weaknesses, and functional gaps.

The IIASA (1986) also stresses that in the long-run, knowledge should increase regarding the way economic activities are interacting with the environment, they contend that this may be our most powerful means for managing sustainable development of the biosphere. Based on past experiences, they trust that the research agenda will take care of itself, but the most useful research will come from studies that investigate the relationship between chemical, physical, geological, and biological components of the Earth's system. The IIASA's recommendations for operationalizing sustainable development certainly recognize the challenges related to biophysical complexity and limitations of knowledge, both factors which continue to make conceptualization and operationalization of sustainable development rather difficult but arguably, not impossible.

Accordingly, seven years after IUCN (1980) and one year after IIASA (1986), the World Commission on Environment and Development (WCED) convened the Brundtland Commission and issued the Brundtland Report entitled Our Common Future. It appears the WCED conception of sustainable 
development is, in part, built upon the earlier formulation of sustainable development by the IUCN. While many of the IUCN principles were still intact in the definition, the notion of conservation and its role in sustainable development became much more obscure as the word itself was entirely absent in the Brundtland definition of sustainable development.

The WCED (1987) defined sustainable development as "development that meets the needs of the present without compromising the ability of future generations to meet their own needs" (p. 41). This exact statement is the most widely cited definition by governments, institutions, and in academic literature today (Brandon \& Lombardi, 2011; Franks, 1996; Kates et al., 2005; Shaker, 2015). Explicitly absent is the rarely cited portion of the definition clarifying that: (i) "ability" refers to the environments ability which is limited by the state of technology and social organization; and (ii) "needs" refers to the essential needs of the world's poor taking precedence over anything else (WCED, 1987, p. 41). In absence of this information, its definitional ambiguity led to its pervasive application in just about any context (Dale, 2012; Kates et al., 2005), which will be discussed in further depth throughout this thesis. Despite attempts to be concise, the two fundamental components that made up the Brundtland definition were almost, if not entirely abandoned upon its popularization.

Nonetheless, both definitions of sustainable development formulated by the IUCN and WCED contained the notion that development must meet current needs and the needs of future generations to come. The IUCN (1980) further described it as being the ethical imperative in which they expressed that "we have not inherited the earth from our parents, we have borrowed it from our children" (p. 1). While the statement in the Brundtland report about current and future needs was nearly identical to the one used by the IUCN seven years earlier, Our Common Future did not mention the IUCN report in-text. Perhaps this is because the United Nations was a significant, if not primary actor in the production of both reports, they may not have seen the need to. This decision contributed to the common misconception that sustainable development was first used in 1987 when in fact, it was used seven years earlier and conceived in the context of conservation. The disconnect between these two reports could be a contributing factor to the misuse of sustainable development in the years that followed. Arguably, the largest and most fundamental difference between the definitions was that the IUCN was explicit in the role of conservation by including it outright in the definition. On the other hand, the WCED was simply implicit in their language, with the term conservation only being acknowledged 12 paragraphs after. Campagna et al. (2017) points to a proposition in the Brundtland Report (1987) that readily acknowledges that species problems lack the political clout to present or perceive them as economic or resource concerns. This admission, Campagna et al. (2017) contends, is the Brundtland Commission suggesting it 
cautiously selected its language for the sake of political clout, and as a result, articulated sustainable development in favour of a human-centered instrumentalist agenda.

Accordingly, the IUCN, IIASA, and WCED conceptions of sustainable development are anthropocentric in their language and nature. Some were considerable direct in acknowledging the anthropocentrism of sustainable development, for instance, the IUCN (1980) asserts that "conservation, like development, is for people" (p. 1). Although one should be reminded that development in this case specifically refers to the satisfaction of human needs and improving the quality of human life. Devall and Sessions (1985) argue that both the IUCN and WCED approaches to sustainable development are justified in anthropocentric terms not biocentric ones, meaning their reason for protecting the biosphere are based on the utility it provides to humans. Devall and Sessions (1985) suggest that if there were an interim management plan that could capture the biocentric goals we need for the long-term future, it would be the IUCN's World Conservation Strategy. Although whether Devall and Sessions (1985) considered the IIASA's (1986) formulation of sustainable development for this recommendation is uncertain.

Five years after the Brundtland Report, the WCED had the largest gathering of world leaders it had ever seen (Rogers et al., 2008) at the UN Conference on Environment and Development (also known as the Earth Summit). At this conference, Agenda 21, an action plan and non-binding international agreement for implementing sustainable development was ratified by 178 governments from around the world (Rogers et al., 2008). Despite the absence of the Brundtland definition of sustainable development in Agenda 21, the report did reiterate that sustainable development encompasses social, economic, and environmental dimensions.

What was particularly different about Agenda 21 was that it provided greater detail and guidance on implementation (Rogers et al., 2008) by specifically stating improved data systems and analytical methods were needed to support integrated decision-making at every stage of planning and management. In fact, the contents of Agenda 21 are largely characterized by its repeated requests for improved data and information systems at all levels of civil society, explicitly noting that sustainable development necessitates the systematic and simultaneous use of social, economic, developmental, ecological, and environmental data; and in a way, that allows for evaluating interactions and synergisms amongst them (United Nations Conference on Environment and Development (UNCED), 1992).

Given that climate change is a global problem, participation at the local level is difficult to conceptualize; however, Agenda 21 provided an important assertion to local authorities (Cartwright, 2000). Specifically, Chapter 28: Local Authorities' Initiatives in Support of Agenda 21 emphasized that the determining factor in achieving a "Local Agenda 21" will depend on the actions and leadership of local governments whom play a vital role as their position of governance is closest to the people. As pointed out by the 
UNCED, the problems and solutions that are addressed by Agenda 21 are rooted in local activities, coinciding with the understanding that all environmental problems manifest themselves first in the degradation of local environments.

Chapter 40: Information for Decision Making, is the last chapter of Agenda 21 and provides the means for implementation by outlining two programme areas that will ensure decision-making becomes increasingly more robust over time: (a) bridging the data gap; (b) improving information availability (UNCED, 1992, 40.1). The data gap referred to here is largely focused on the capacity of developing countries to collect sufficient data, but at the same time, developed countries require improved coordination of data and information activities. Moreover, to make decision-making on the environment and development more reliable, the UNCED asserts that indicator development is needed at all levels to provide a sound basis for decision-making, additionally noting that parameters must be sufficiently developed and applied (UNCED, 1992).

The notion of "think global, act local" was born from the realization that local decision-making has global consequences (Perey, 2014) (i.e. climate change), which is precisely what Local Agenda 21 (Brugmann, 1996), World Conservation Strategy and the Brundtland Report attempt to convey. Efforts operationalize sustainable development as a conceptual framework and mechanism for reconciling human-ecological relations continued over many decades primarily through international summits, such as the 1972 United Nations Conference on the Human Environment (UNCHS) in Sweden, the 1992 United Nations Conference on Environment and Development (UNCED) in Brazil, the 2002 World Summit on Sustainable Development (WSSD) in South Africa, and the 2012 United Nations Conference on Sustainable Development (UNCSD) (also known as Rio+20) in Brazil (United Nations, n.d.).

Notably however, the United Nations updated their Millennium Development Goals (MDGs) and replaced them with Sustainable Development Goals (SDGs) as their successor (Hák et al., 2016). SDGs are a framework meant to guide the United Nations Development Programme (UNDP) which operates across 170 countries and territories. SDGs are comprised of 17 goals, 169 targets and 303 indicators. The SDGs came into effect in January 2016 and targets are expected to be reached by 2030 (United Nations, 2019). Some SDG build on previous MDGs, in particular goals 1-6, while goals 7-17 are new (United Nations Statistics Division (UNSD), 2014). Considering the unprecedented rate of urban growth around the world with "54 per cent of the world's population" living in cities (United Nations, 2017, p. 40), SDGs place greater emphasis on sustainable cities than its predecessor, which is evident from the addition of SDG 11: Make cities and human settlements inclusive, safe, resilient and sustainable. While it is premature to evaluate whether this change will impact the adoption of sustainable development in cities, it certainly helps to keep sustainable development in the public dialogue. Despite there being considerable 
emphasis on locality, conceptualizations of sustainable development are dominant at the international level, as shown from the definitions and conceptual frameworks established by the IUCN, IIASA, and United Nations, among others. Nonetheless, since sustainable development was formally defined at the international level, it is important to recognize the potential challenges that international conceptualizations of sustainable development might have on local operationalization, such as issues relating to local environmental, social, economic, and cultural context. In any case, the international conferences and their commitments to sustainable development have had a profound impact on global awareness of the environment, leading sustainability into mainstream. As a result, the three dimensions - social, economic, and environment - infiltrated the thinking processes of many

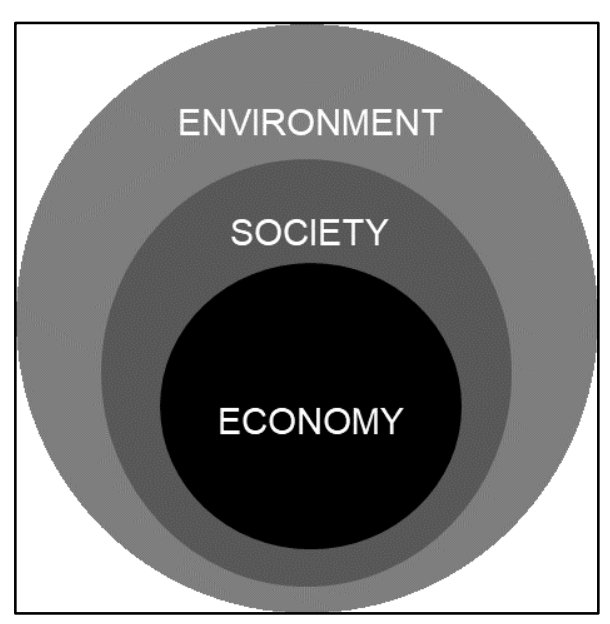

Figure 1. Visualization of sustainable development adapted from ICLEI (1996). governments, scholars, institutions, companies, laypeople, and others alike around the world.

This research recognizes there are many diagrams for visualizing sustainable development; and although the efforts continue, two conceptualizations continue to remain the most dominant. First, shown in Figure 1, is sustainability in the form of interlocking circles, also known as a venn diagram. At first glance, it appears that sustainability can only be achieved with a synergism of all three; however, the image also implies that both society and economy can continue - to some extent - independently of the

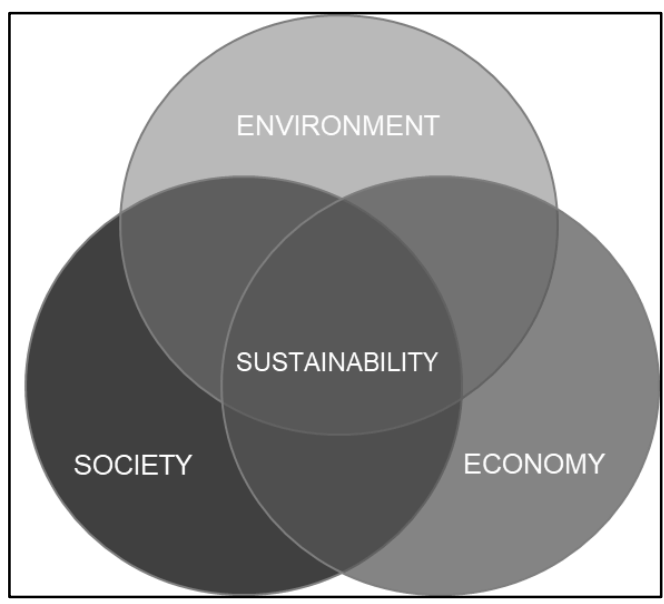

Figure 2. Visualization of sustainable development adapted from Giddings et al. (2002). environment. Not only is this shown in a compartmentalized way of thinking, but it also assumes that each are in some way autonomous of one another (Giddings $e t$ al., 2002). Following several criticisms, a concentric or nested version of sustainability emerged as shown in Figure 2. What is most significant is this illustration reflects the fact that society and economy are a function of the environment and would not exist autonomously from it. Economy, society, and environment are not independent of one another; rather, they are mutually reinforcing. It should be noted that although the visualization above is a significant improvement from its earlier works, it is not meant to be a definitive representation of sustainability. Rather its intention is to accentuate an ongoing need for discernment in this field of research for there are many more depictions of sustainability that illustrate 
these three dimensions among others (i.e. cultural, institutional, biophysical); each of which have an opportunity to get us to the same end goal.

\subsection{The Significance of Definitions}

Evidently, when sustainable development or sustainability is inadequately defined, many conceptual formulations arise. As mentioned earlier, there are both quantitative and qualitative aspects to sustainability and sustainable development. Many would argue that without qualitative understanding of the multiple meanings and consensus on the qualitative foundations, quantification will be challenging. In any case, neither quantitative and qualitative understandings are expected to be static. As knowledge, awareness, and comprehension of sustainability and sustainable development evolve, the conceptualization and operationalization of quantitative and qualitative aspects should change accordingly. With this in mind, establishing the qualitative and quantitative foundations of sustainability and sustainable development requires processes that are deliberative, adaptive, and well-defined.

To genuinely understand sustainability or sustainable development, quantification in some form must occur. For instance, if sustainable development is to be a goal, there must be parameters to quantify where we are in terms of where we want to be; in other words, we require a means for which progress, performance, and change can be monitored. To achieve this, one must first define, conceptualize, and operationalize these concepts before they can be measured. Defining sustainable development means to identify what should be sustained, what should be development, for whom should it be sustained or development for, and how long (Kates et al., 2005). As previously mentioned, many studies can be found inadequately defining sustainable development, such as those only referencing the first half of sustainable development as defined in the Brundtland Report (see Choguill, 2008; Li et al., 2009; Sakieh et al., 2015; Singh et al., 2012; and Turcu, 2013). One cannot stress enough that the way in which sustainability is defined, including the values and principles identified, is of crucial importance because it delineates the foundation for a conceptual framework and measurement to be built upon (Huang et al., 2015; Kates et al., 2005; $\mathrm{Wu} \& \mathrm{Wu}, 2012$ ). If sustainability or sustainable development is poorly-defined, then the indicators derived from it are at risk of producing erroneous results.

Biely et al. (2018) points out at least two consequences of circumventing definitions of sustainability; both of which are likely applicable to sustainable development, as well as any terminology that may have more than one meaning. On the one hand, sustainability may always be regarded as ambiguous because it has several meanings; however, this is not unique to sustainability or sustainable development and in fact, likely applies to a majority of words found in the English dictionary. Nonetheless, when the meaning is not made explicit and the word contains generality, it may be used in any context, In the case of sustainability, there have been creations of nearly anything sustainable, even conceptions of "sustainable 
growth" (Biely et al., 2018) which seem even more contradictory than the notion of sustainable development.

In explaining the difference between "sustainable development" and "sustainable growth", Daly (1990) provides the dictionary distinction between "to grow" and "to develop". However, Daly (1990) does not acknowledge that both words "grow" and "develop" have at least three different meanings attributed to them in the Oxford English Dictionary. Not only does Daly (1990) not differentiate which word sense he refers to, but he doesn't indicate what dictionary he used either, making his delineation redundant if the meanings are ones that he devised himself. Even if this were the case, it could at least be placed in context of the meanings that already exist.

There are a profound number of definitions for both sustainability and sustainable development (Pearce, 1988) that continue to be a challenge for scientific community and for putting sustainability into operation (Biely et al., 2018). Considering this, it is important that policy-makers, scientists, and researchers alike, make explicit the contextual meaning behind sustainability as it is used. Another issue is the instance of "cherry picking" certain components of a definition, as issue that remains prevalent in sustainable development research and perhaps policy as well. In absence of the components the WCED (1987) specified as having made up the definition of sustainable development, the definitional ambiguity that followed led to its pervasive application in just about any context (Dale, 2012; Kates et al., 2005). In the case of sustainability, Goodland and Daly (1996) and Neumayer (2010) are among a group of scholars that suggest there are two opposing conceptions to the definition, known as strong and weak sustainability. Weak sustainability is built on notions derived from neoclassical economics that view natural capital as abundant (Neumayer, 2010), and substitutable with any form of human or man-made capital (Goodland \& Daly, 1996; Neumayer, 2010). Furthermore, weak sustainability asserts that any constraints imposed by natural capital can be overcome by advances in technology. Neumayer (2010) emphasizes that strong sustainability is much harder to define but its foundational principle is that "critical" natural capital can not be substituted with other forms of capital, such as human or man-made (p. 24). He also asserts that strong sustainability requires preservation of natural capital in terms of physical stocks, not value terms. Nonetheless, Neumayer (2010) cautions that strong sustainability could be interpreted incorrectly and emphasizes that it is not implicit in nature being kept "as it is" (p. 24), a view that Goodland \& Daly (1996) refer to as “absurdly strong sustainability”. Lastly, Neumayer (2010) stresses that flows from natural capital must not exceed natural regenerative capacities, if its functions are to maintain intact.

Many have acknowledged there being some fundamental issue in the conceptualization of sustainability as strong and weak (Biely et al., 2018; Ekins et al., 2003; Moore, 2011). This is primarily due to the 
perception that weak sustainability is inevitably unsustainable in the long-term (Moore, 2011). Biely et al. (2018) refers to weak sustainability as completely invalid. Similarly, Ekins et al. (2003) asserts strong sustainability as the only legitimate conception of sustainability.

Numerous scholars have spent considerable time and effort in search of precise definitions or descriptions of sustainable development and sustainability (Biely et al., 2018; Clarke, 2002; Costanza \& Patten, 1995; Giddings et al., 2002; Goodland \& Daly, 1996; Klauer, 1999; Maclaren, 1996; Neumayer, 2010; Parris \& Kates, 2003; Peace, 1988). Depending on whether these definitions are produced from the perspective of social sciences (i.e. political scientists, economists, etc.) or the natural sciences (i.e. biologists, geologists, physicists, etc.), the meaning may vary considerably. Moreover, it appears that few, if any of these scholars refer to the dictionary definitions of these terms, prioritizing definitions as they are discussed in the scholarly literature instead. In any case, the way in which sustainability or sustainable development is defined, including the value and principles identified, is of crucial importance for it delineates the foundation from which measurement (Huang et al., 2015; Wu \& Wu, 2012) and operationalization is built upon. If sustainability or sustainable development is poorly defined, then the indicators derived from it are at risk of producing erroneous results.

\subsection{Scientific Study of Language: The Linguistics of Sustainability}

Language being the complex system that is human communication, is the primary means allowing humans to mutually understand, and collectively produce and disseminate information about the world around us (Hagoort et al., 2004). Throughout human history, language has continued to evolve to and from a multitude of different languages and dialects (Fritze, 1989). Language eventually required scientific study of its own, formally known as linguistics. The primary objective of linguistics is to empirically research the structure and function of language, which may include language form, meaning, and context. Any research that investigates communicated information, whether it be spoken, written, or signed, inevitably engages in some form of language analysis, either explicitly or implicitly. One of the first and primary components of this research study involves investigating and mapping the discourse surrounding the lexeme sustainability and sustainable development. In preparation for this, the following section briefly discusses some key terminology used in the scientific study of language as it relates to this research and the multiple and fluid definitions of sustainability and sustainable development.

Linguistic analysis may cover any component of language structure, such as syntax (sentence structure), morphology (word structure), and lexicon (vocabulary). Each of these branches maintain some general principles and rules that when considered collectively logically produce formal language. One of the fundamental components of language structure is the vocabulary that which it is comprised of. Vocabulary (a body of words) or lexicon, whether it is that of a person, language, or body of knowledge, 
is most well known in the form of a dictionary ("Dictionary", 2010). Typically, a dictionary entry will have information on the origin of the word, how it was formed, how its meaning changed over time, and the meanings that are in current use. The study of words and their meanings throughout history is referred to as etymology.

Two circumstances make words and their meanings throughout history considerably ambiguous. The first relates to the origins of language having predated historical records (Fritze, 1989). Certainly, early efforts to compile words into one book were more a product of "guesswork" (Liberman, 1994) than logical deduction. Shortly thereafter, it became commonplace to summarize the "guesswork" of one's predecessors as if there was some equivalence among the guesses (Liberman, 1994). As a result, dictionaries and especially the earlier ones, contain many conjectures. While Liberman's (1994) statements are highly plausible given the challenges of literary research at the time, he makes no remark on the alternative means for which scholars could have acquired this information. However, Liberman (1994) appears to be a proponent of etymology reform.

The second circumstance that contributes to word meaning ambiguity relates to the development of language over time, particularly English language. English evolved from and is rooted in several other languages, for instance, Germanic, Latin, and Ancient Greek. Dictionaries in Greek and Latin came long before scholars began composing an English dictionary nearing the end of the 16th century (Fritze, 1989). As discussed earlier, sustainability and sustainable development have some of their origins in German and have development and evolved significantly in English. However, there are potentially uses in other languages but that which have not yet been identified.

In any case one should not overlook controversy surrounding language as mere rhetoric or semantics (Campagna et al., 2017). Indifference and disregard of language comes with consequence. For example, inattention to language use during the early years of the conservation movement contributed to the distorted values placed on species conservation. In the political realm, the rhetoric surrounding the "conservation", "stewardship", and "wise use" of natural resources has exemplified how language without concrete meaning can manifest into perhaps "...the development of resources as quickly as is technically possible..." (Devall \& Sessions, 1985, p. 56). Accordingly, interpretation will always contain some underlying ethical assumptions and consequences. There have been cases in the past where abstract language such as "wise use", in combination with other factors such as, policies, laws, and social behaviour, have had significant consequences for certain species such as the Passenger Pigeon (Ectopistes migratorius) and American Bison (Bison bison) (Campagna et al., 2017). Correspondingly, Campagna et al. (2017) stresses that "language influences and consolidates ethical positions, inspires interventions, and 
offers hindsight" (p. 58), which is especially the case in the politics of environmental management, sustainability and sustainable development.

\subsubsection{Lexical Semantics of Sustainability and Sustainable Development}

This section will discuss the words derived from and pertaining to the word 'sustain', including their various word senses, also known as word meanings. The branch of linguistics concerned with the meaning of words is also known as lexical semantics (Martin \& Ringham 2006). It should be noted that some of the words derived from sustain, especially sustainability, sustainable and more specifically sustainable development, often carry a variety of technical definitions and meanings, which are in part, rather exclusive to the scholarly literature on the subject and/or industry specialists who engage in sustainability discourse. While the technical discourse surrounding sustainability and its derivatives will be covered, it is important that an overview of the dictionary definitions be provided first. Arguably, dictionary definitions are the meanings that are most likely accepted or understood by the broader general public.

Sustain is a verb used to describe an action, state, or occurrence. The Oxford English Dictionary (2010) indicates that its first appearance was in Middle English, having originated from Old French soustenir and Latin sustinēre, meaning sub- 'from below' + tenere 'hold'. The Oxford English Dictionary (2010) defines sustain as (1) strengthen or support physically or mentally (e.g. it could barely sustain the weight; or the thought had sustained him throughout the years); (2) undergo or suffer (e.g. he sustained a severe injury); (3) cause or continue for an extended period or without interruption (e.g. the food supply will not sustain this population; or he cannot sustain a normal conversation); or (4) uphold, affirm, or confirm the justice or validity of (e.g. the allegations of discrimination were sustained). Considering these, sustain can have four different meanings when used. It may also be used as an adjective, a descriptive word that modifies (or qualifies) a noun (person, place, or thing) (e.g. water is a life sustaining resource; or a sustaining breakfast of bacon and eggs). In summary, sustain is a present tense verb that may also be used in the past tense (sustained) or as an adjective (sustaining), and in any circumstance, could have at least four different meanings. Sustained although listed as the past tense of sustain, only refers to sustain sense (3), specifically sense (3) cause or continue for an extended period or without interruption (e.g. several years of sustained economic growth). Furthermore, Oxford English Dictionary (2010) also lists sustainer (noun) and sustainment (noun) as derivatives, meaning the base of the word is directly formed or derived from the word sustain.

The etymology of sustainability is not provided in the The Concise Oxford Dictionary of Etymology (1996), rather the etymology of sustain given instead, suggesting sustainability is a derivative of the truncate sustain. On the contrary, the Oxford English Dictionary (2010) does not list any etymological 
origin for sustainability. While, on the other hand, WordNet ${ }^{\circledR}$, a lexical database by Princeton University, has sustainability listed as a derivative of the adjective sustainable, perhaps because they share a common sense (word meaning). This etymological origins and lexical relationships of sustainability and sustainable appear more ambiguous than the word sustain.

Sustainability is a noun used to identify a class of people, places or things; more specifically, it is denoted as a mass noun. The Oxford English Dictionary (2010) defines sustainability as (1) the ability to be maintained at a certain rate or level (e.g. the sustainability of economic growth). Sustainable which is an adjective (describing word) is similarly listed as (1) able to be maintained at a certain rate or level (e.g. sustainable economic growth); but may also mean (2) able to be upheld or defended (e.g. sustainable definitions of good educational practice). The first sense that both sustainability and sustainable also share a second meaning (1a) avoidance of the depletion of natural resources in order to maintain an ecological balance (e.g. the ecological sustainability of the planet; or our fundamental commitment to sustainable development).

Sustainably, is an adverb that modifies or qualifies an adjective, verb, or other adverb, expressing a relation of place, time, circumstance, among others. Again, the etymology is not provided in the Oxford English Dictionary (2010) and the term is not listed in The Concise Oxford Dictionary of Etymology (1996) or WordNet®. Nonetheless, the definition provided in the Oxford English Dictionary (2010) is nearly indistinguishable from sustainable as sustainably is listed as (1) in a way that can be maintained at a certain rate or level (e.g. ability to grow sustainably; or sustainably low prices). It also includes the same, more specific definition, that is shared with sustainability and sustainable, that being (1a) in a way that avoids the depletion of natural resources in order to maintain an ecological balance (e.g. sustainably managed forests). Notably, sustainable development is mentioned in the example provided for sense (1a) of sustainable. Perhaps a more recent addition to the dictionary is the term sustainable development, which the OED (2010) defines as (1) economic development that is conducted without depletion of natural resources (e.g. international policies should support sustainable development). The OED does not list any information regarding the etymology of sustainable development. Lastly, the word self-sustaining was included here because it appeared in the qualitative data of this study and although it is a compound word with sustaining in it, self-sustaining maintains its own word sense that is unique from all the other iterations. Self-sustaining is an adjective defined by the Oxford English Dictionary (2010) as (1) able to continue in a healthy state without outside assistance (e.g. studies have thrown doubt on whether these businesses are really self-sustaining). Furthermore, the OED lists self-sustained as its derivative. For comprehension, the different variants of sustain, sustainable, self-sustaining, and sustainable 
development, and the corresponding word sense relationships discussed in this section are illustrated in Figure 3.

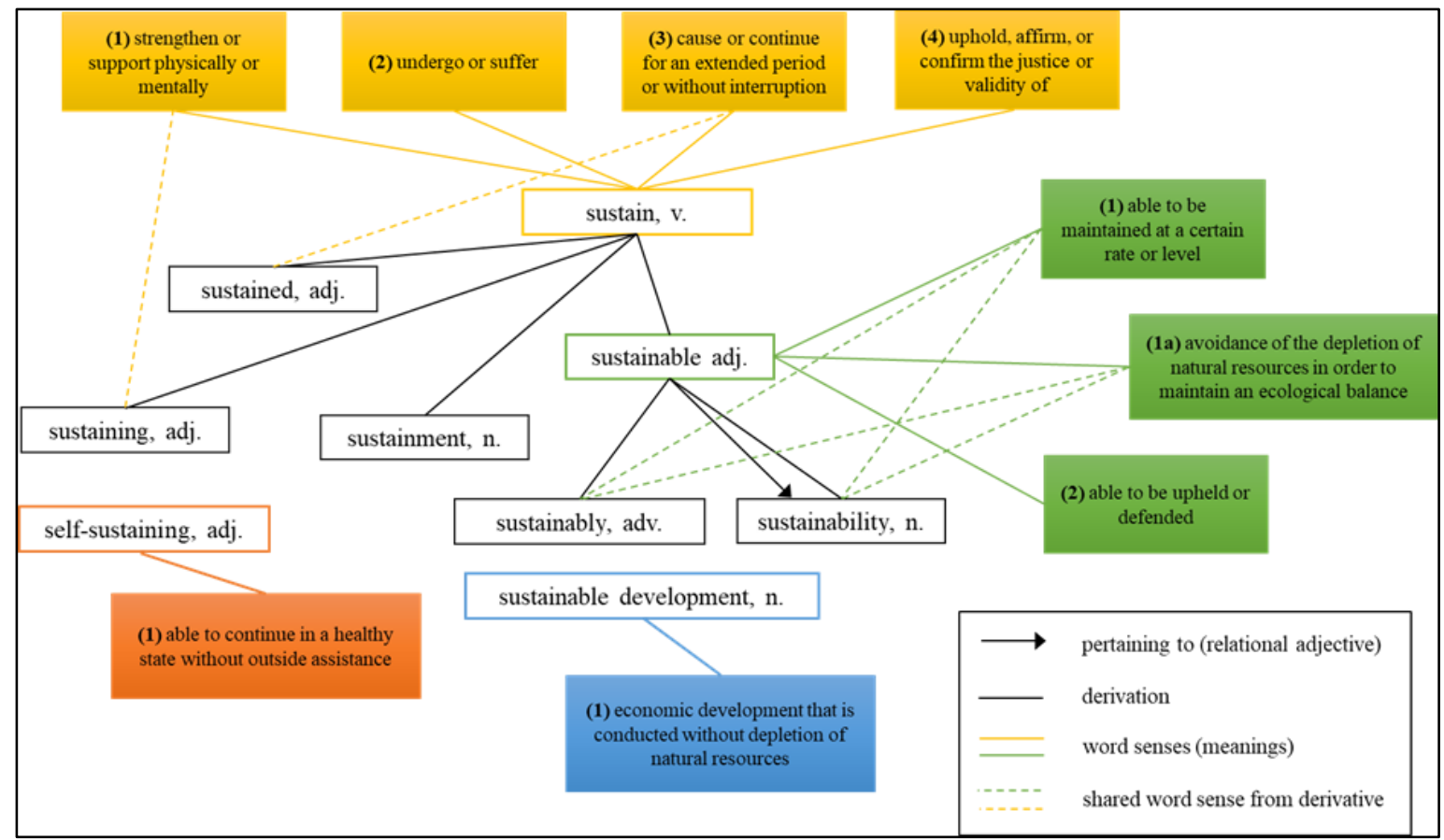

Figure 3. Diagram showing the lexical relationships sustain-related words

There are numerous meanings ascribed to sustainability and sustainable development, by organizations and institutions (i.e. United Nations, local governments), in the Oxford English Dictionary and scholarly journals, and many if not all, are still contested in some respect. In consideration of these circumstances, it is necessary that this research focuses on language, discourse, content and narratives in policy analysis.

\subsection{Content \& Discourse Analysis in Sustainability \& Sustainable Development Research}

Content analysis in the broadest sense, is an empirical research method used to investigate and analyze qualitative symbolic and textual material (Krippendorff, 2004; Neuendorf, 2002) in what some contend as a relatively systematic and objective manner (Elo \& Kyngäs, 2008). It is an approach that allows researchers to elucidate themes, patterns, or textual phenomenon through categorical or conceptual description and analysis (Elo \& Kyngäs, 2008) of textual data. Textual data can take the form of interview transcripts, narratives, questionnaire responses, speeches, news articles, scholarly journal publications, laws and policies (Given, 2008).

There are two overarching approaches, that may also be combined together. Qualitative content analysis, also referred to as latent content analysis, which is primarily descriptive and often explores questions as to "why" certain phenomena are present in text. This approach investigates latent attributes of the text, in other words, the underlying meaning behind the text (Carney, 1972; Given, 2008; Lasswell et al., 1965). 
Often these meanings are not directly observed in the text (Gray \& Densten, 1998). It is seldom that the author of the textual data under analysis is consulted on "why" certain patterns or themes were produced. Therefore, researchers are left to their own interpretations of what the text means (Carney, 1972). There can be more systematic ways of conducting qualitative content analysis, but it often requires considerable transparency regarding how one came about their interpretations. In any case, these are inferences made by the researcher, and thus subjectivity is inevitably involved. One of the most contentious issues with latent content analysis is replication. If another researcher was to replicate the same approach, using the same data, would the inferences made be the same or variable?

In contrast, quantitative content analysis typically explores the question of "what" textual phenomena are present (Given, 2008). Arguably, the most objective way of doing this is by identifying explicit textual patterns, for instance, ones that are directly observable and have been recorded in verbatim. This is often referred to as the thematic or structural analysis of textual data (Greckhamer \& Cilesiz, 2014). For example, the number of times environment and development occur in the same sentence is an explicit textual pattern. Considering this, phrases and word counts are directly observable in textual data, and associations among them may be analyzed, however formal linguistic structure in which logical rules apply should be kept in mind. It should be noted that once a researcher attributes meaning behind the words or phrases being used, especially in cases where there is more than word sense and contextual circumstances within the surrounding text must be considered, objectivity becomes much more difficult to achieve. Despite textual data being difficult to analyze, historical texts have been analyzed and interpreted since the beginning of written communication, however often using more qualitative means such as narrative and discourse analysis.

In the broadest sense, discourse is the processes of communicating written, verbal, or sign language; although written communication will be the only type of discourse discussed here. Much like many of the concepts in this study, discourse can be difficult to define in contrast to the other types of linguistic analysis (i.e. semantic, morphological, etc.) identified earlier. Perhaps one of the fundamental contentions between the two schools, linguistic and discourse analysis, will help to delineate the difference between two. This contention is situated between the often-absent discussion on reference and sense. In other words, one may refer to a particular word or phrase based on specific intentions or context, whether this corresponds with the semantic sense provided in the dictionary is arguably based on the readers interpretation (Bruner, 1984).

Discourse analysis puts the linguistic functions and structure into practice to formulate another level of meaning that extends beyond the explicit language; known as the discursive level of meaning. At this level of meaning, the unit of analysis is larger than a sentence (Martin \& Ringham, 2006) and often 
extends to paragraphs, chapters or entire written works. Accordingly, discourse analysis differs because it doesn't concern itself with the explicit meaning of the words employed or statements made. It is concerned with the more abstract level of discourse where the underlying or implicit meaning is derived; and therefore, deals primarily with latent content.

Both content and discourse analysis techniques are wide-ranging in application; for instance, content analysis techniques may be used corporate environmental reporting (see Beck, 2010; Fallan, 2016), public health, policy, and economics, among others. Despite the frequent use of these analyses, the analytical approaches used often differ from study-to-study; few studies can be found using the same identical approach. Understandably, any choice of analysis is dependant on what questions are being asked of the text. The variability in the application of these techniques will be exemplified through several case studies using content analysis and discourse analysis to 'map' or assess sustainable development in public policy Broadly speaking, there are two ways text can be analyzed depending on what the researcher wants to understand the text instrumentally or representationally. In the former, the text is interpreted according to the researcher's theory, while in the latter, the researcher attempts to establish the intended meaning of the sources' text (Roberts, 2000). Several examples of content and discourse analysis relating to sustainable development is provided below.

Berke and Manta (1999) present six principles that reflect the concept of sustainable development to analyze thirty plans and policies. They identify these principles to be: (1) work in harmony with nature; (2) liveable built environments; (3) place-based economy; (4) equity; (5) polluters pay; (6) responsible regionalism. They also contend that the first four principles are characteristic of long-term system "reproduction", while the last two link global and local concerns. Berke and Manta (1999) then conduct their analysis based on whether the principle was suggested in the plan versus required by the plan. This was determined by allocating terminology that reflects their intention, for instance suggestive words (i.e. encourage, consider, intend, should) and mandatory or required words (i.e. shall, will, require, must). Berke and Manta (1999) also separated their sample in terms of whether the integration of sustainable development was explicit or implicit.

Engström et al. (2008) investigated which environmental problems receive the most policy attention in Sweden. In determining which topics were "environmental hotspots" being focused on. The authors used several avenues which included assessing Swedish ecotaxes to determine what impacts Swedish society places the most value on, receiving feedback from a survey of panel experts, and a life cycle impact assessment software for sustainable product development (EPS 2000 Design Systems). The environmental topics identified were resources, climate, eutrophication, toxicity, biodiversity, air quality, and acidification. The analysis focused on whether the environmental topic was acknowledged, the level 
of policy attention it received (emerging, low, medium, high), the level of knowledge on the topic (insufficient, fair, average, good, excellent), and the measures being used to reduce environmental impact (reduce pesticide use, renewable energy). Although this study largely focused on the energy and agricultural sectors within Swedish public policy, Engström et al. (2008) addresses several interesting characteristics (i.e. level of knowledge) of environmental issues with the public policy and sector context. Furthermore, Engström et al. (2008) identifies the categories of environmental issues through a rather objective approach, or at least objective in the sense that the authors did not arbitrarily select the categories themselves.

Dade and Hassenzahl (2013) is another example of content analysis in a sustainability context. Researchers conducted an evaluation of higher education institutions and their communication of sustainability via online websites. The websites were manually coded in a manner that addressed several of their research questions, for instance, how sustainability was being defined, whether it was being listed as a "priority", whether sustainability was being integrated into objectives, responsibilities, or mission statements, and the references or sources of their information (Dade \& Hassenzahl, 2013).

Dade and Hassenzahl (2013) and Engström et al. (2008) are primarily examples of manifest content analysis because they are explicitly concerned with visible features (i.e. presence or absence of terms) within the text. Although implicit, each study does seem to incorporate some form of latent content analysis. Engström et al. (2008) for instance, includes a 'level of knowledge' variable that is arguably determined by inference, and seems to be included in attempt to provide some insight into why certain environmental issues are more present than others. Similarly, Dade and Hassenzahl (2013) identified whether sustainability was listed as a priority, implicitly or explicitly; in either case, it would affect whether sustainability is incorporated into the objectives and responsibilities as well.

Fleig and Tosun (2017) used a content analysis to assess how frequently the concept of sustainability was used by political parties in several European Union (EU) countries over time. Their research examined the explicit use of sustainability, sustainable, sustainably, sustaining, sustained, while also cross-referencing the frequency of their use with several major sustainability events. Namely, the publication of the World Conservation Strategy (1980), the Brundtland Report (1987), the Rio Earth Summit (1992), the Kyoto Protocol (1997) and the release of the Stern Review (2006) (Fleig \& Tosun, 2017). Since the focus was largely on political parties, their analysis was conducted using WORDFISH, a world scaling software that analyzes word frequencies to estimate political party positions using an expectation-maximum algorithm. Fleig and Tosun (2017) appears to have used "latent traits" as a weighting mechanism but because it is apart of the WORDFISH software, it is unclear how this weighting scheme is employed. 
In Canada and Ontario, there are at least two studies that have analyzed the use of sustainability in municipal policy in Ontario, although neither were concerning the City of Toronto. Stuart et al. (2016) analyzed the incorporation of sustainability principles in four mid-sized municipalities in Ontario, including Kingston, Markham, London, and Burlington. Markham borders the City of Toronto, while the others are within a couple of hours of the city, with Burlington being the next closest municipality. Stuart et al. (2016) selected a sample of documents by focusing on "high-level municipal plans", such as Official Plans, Strategic Plans, Infrastructure Master Plan, and Integrated Community Sustainability Plans (ICSPs). The highest-level plan in Ontario municipal policy planning is the Official Plan as it is required under the Ontario Planning Act. Under the Act, municipalities are required to establish an Official Plan that includes goals, objectives, and policies relating to the management of physical changes within their municipality, and the implications for social, economic, built, and natural environments within the municipality boundaries. It also requires that such policies ensure adequate affordable housing and outline the procedures and processes that will be used to obtain public views regarding such polices. Strategic Plans are like corporate management plans, they summarize and outline the vision and the actions to be implemented within a specified time (Stuart et al., 2016). Coding and analysis were in part, borrowed from the principles of sustainability identified by Gibson (2006).

Gibson (2006) identified several core criteria for sustainability assessments which included socioecological system integrity, livelihood sufficiency and opportunity, inter- and intra-generational equity, resource maintenance and efficiency, socio-ecological civility and democratic governance, and precaution and adaption. It should be noted that these were explicitly devised for sustainability-based environmental assessments. He also sets several sustainability assessment trade-off rules, which include concepts such as avoidance of significant adverse effects, protection of the future, maximum net gains, etc. Nonetheless at least half of the criteria Gibson (2006) identified (i.e. inter- and intra-generational equity, resource maintenance and efficiency, socio-ecological system integrity, livelihood sufficiency and opportunity) are in part, dependent on what components of the biosphere are being accounted for, to what extent are they being accounted for, and how long their accounting has been conducted for.

Stuart et al. (2016) development a hierarchal codebook to analyze the text based on the criteria provided by Gibson (2006). The title of each criteria was designated as the 'nodes', and the concepts within the criteria were assigned as "parent codes", and "child codes". The reason for this is to aggregate the data afterward to analyze how many criteria had been addressed. Although some meaning can be lost using this approach, there are few, if any, means for aggregating textual data without simplifying meaning. The approach used by Stuart et al. (2016) would be referred to as instrumental analysis, meaning the framework was set and the words were coded according to the researchers' theoretical framework. 
Obviously interpreting text comes with its challenges, some of which have been addressed here. This paper argues nonetheless, that discourse and semantics, to some extent, cannot be separated.

Tozer (2018) analyzed sustainability and climate change discourses in 15 sustainability plans from 15 different municipalities in Canada. Their sample of sustainability plans was identified using University of Alberta's Sustainability Plan Inventory where municipalities voluntarily upload their plan to the inventory. The selection of plans was narrowed down by selecting only ones that contained 'sustainable' or 'sustainable development' in the plan title or sub-title. Documents were then coded using several categories: social, environment, economy, culture, and cross-cutting. Tozer (2018) used both an inductive and deductive approach to identify categories as the first three categories (social, economic, and environment) were determined from the literature on sustainability and sustainable development, but the last two (culture and cross-cutting) were derived from data collected. Authors conducted their analysis according to a previous study conducted by McGuirk et al. (2015) who used a "governmentality approach" for analyzing different programs of carbon governance. They specifically focused on subjects, objects, and mechanisms in the practicing of each of the categories as they relate to sustainability.

The case studies provided are intended to demonstrate the analytical variability observed in the scholarly research conducting textual content analysis relating to sustainability and sustainable development. This variability ranges in the definitions employed, theoretical and conceptual frameworks used, principals and themes identified, and the subsequent measurements that may be derived. The diversity in methodological and analytical options can be cumbersome for any researcher who is trying to determine the most suitable and reliable method to adopt for researching sustainability. This variability certainty has advantageous and disadvantages, particularly in the validity and reliability of sustainability and sustainable development research, which remains to be a highly contested area of discussion and difficult in application. Sustainability science is often characterized by its unconventional approach to science, in which explanations and predictions are not easily testable through the means of the scientific method. Recently however, several studies uncovered reproducibility issues in an assortment of scientific studies, including those in preclinical research (Begley, 2013; Freedman et al., 2015; Open Science Collaboration, 2015), an area of study considered to be more rigorous than most. Given these circumstances, studies on measuring sustainable development should at least contain enough detail that one can evaluate why and how the research was produced and developed in the way the researcher has chosen. Some have proposed that validity may have to come from the way in which sustainable development research is produced or developed (Bell \& Morse, 2001), rather than its testing through the scientific method.

This research study first sought to clarify the historical origins of sustainability and sustainable development, present the dichotomy between conceptual and theoretical perspectives, and establish the 
relationship between defining, conceptualizing, operationalizing, and measuring sustainability and sustainable development. The literature review herein delineated the importance of language use in existing scholarship and knowledge on sustainability and sustainable development research. This research study contributes to existing scholarship and knowledge by investigating the various qualitative and mixed method approaches available for analyzing sustainability-related content and discussing the challenges in their application. Experimenting with search techniques similar to those used in systematic reviews, and applying them in a policy context, will hopefully elucidate some of the barriers to the implementation of systematic approaches in sustainability policy analysis and research.

\subsubsection{Coding Textual Data}

As mentioned earlier, there are several types of analysis that can be used with textual material, some of which may include, thematic analysis, linguistic analysis (e.g. sentiment analysis; semantic analysis), narrative analysis, discourse analysis and critical discourse analysis (CDA), and others. These analyses are not mutually exclusive of one another, rather they can be used on their own or in combination. Each form of analyses involves type of categorization or coding of the textual data. While this can be done descriptively which is more common in narrative and discourse analysis, it may also be achieved numerically by assigning codes to the non-numeric textual data (Geisler, 2018; Hopkins \& King, 2010). Coding is essentially the process of defining your data (Gibbs, 2007), typically through the process of categorical classification (Grimmer \& Stewart, 2013).

Coding is dependant on several study characteristics, such as: (i) the research question and type (e.g. exploratory or explanatory); (ii) type of analyses (e.g. thematic analysis, semantic analysis, etc.); (iii) format of textual data (e.g. blog posts, news articles, reports, etc.), including pronoun(s) of narration (e.g. first, second, and third person); (iii) unit of segmentation (e.g. sentence, paragraph, page, etc.); (iv) selection of manual or automated coding; or both; (v) the functionality of Computer Assisted Qualitative Data Analysis (CAQDAS) tools if used; (vi) the type of codebook (dictionary, sequential sentence structure, thematic, etc.), among other characteristics that may have been overlooked here. Given that there can be considerable variation in coding techniques and subsequent categorization, many scholars have expressed the need for greater systematicity (Geisler, 2018).

Before coding, researchers must designate the textual data into segments or units. One example would be to segment the text according to linguistic or discourse units. For example, a linguistic unit may be words, sentences, clauses, etc., while a discourse unit may be determined by topical segmentation, paragraphs, chapters, or some other contextual unit (Geisler, 2018). 
In any case, the choice of segmentation has implications for both meaning and context when it comes to analysis regardless of the units one chooses. For example, coding sentence-by-sentence can lead to misinterpretation several different ways. At the same time, coding sentences appears to be the most straightforward due to there being a distinct beginning and end to the statement being made. Nonetheless, a proposition or statement can be pertaining to the sentence prior or after the one being analyzed. Without reference to the statement earlier, the proposition could be interpreted incorrectly or lack contextual meaning. For example, consider the following statement: "The GTA's urban forest is generally made of three types of trees (maple, cedar, ash)" (TRCA, 2016, p. 44). This sentence is essentially descriptive. The property or subject it pertains to is the GTA's urban forest and it includes several descriptive attributes, those being, maple, cedar, and ash. It does not ascribe positive or negative value, but it does make a universal claim indicated by the term "generally". In contrast, an absolute claim, for instance, would be the GTA's urban forest is made up of maple, cedar, and ash. Coding becomes complex and multidimensional when trying to account for not only what is being said, but how it is being said. In general, coding may be conducted deductively or inductively. In the case of deductive coding, researchers formulate a categorization matrix that is theoretically informed or based on some standard or norm (Carney, 1972). Textual data is then exclusively categorized based on the pre-defined theory or model (Graneheim et al., 2017). Alternatively, researchers may explore the data first, developing theory or thematic categories in the process. In this bottom-up approach, researchers often progress the data from specific to more abstract or generalized categories or themes (Graneheim et al., 2017). One of the objections to deductive, top-down, or theoretically-based approaches, is that defining or narrowing the researcher's attention is also restricting it (Carney, 1972). However, an inductive, bottom-up, or interpretive approach is often much more susceptible to researcher bias. Carney (1972) suggests that restricting attention in content analysis is inevitable, regardless of the approach used. Rather, the decision rests with the researcher as to whether they want to restrict their attention consciously or unconsciously. In any case, the researcher is still required to interpret the text accordingly, even when applying it to a theoretical model or framework, and thus human interpretation continues to be a threat to the reliability of any study (Bolognesi et al., 2017; Gibbs, 2007; Norton, 2008). One of the most common ways to reduce interpretation, expand the focus of attention, and assess the content as a whole, rather than its parts, is to use Computer Assisted Clustering (CAC) (Grimmer \& Stewart, 2013) which will be discussed in the section to follow.

Despite the importance of coding in the reliability, validity, and objectivity of any quantitative research study, there are very few studies that guide researchers on the selection of coding tools, including their methodological commitments and corresponding workflow process and procedure (Geisler, 2018). 
Exploring coding tools, their suitability in the context of the study sample, and the inherent methodological pluralism they contain can be cumbersome and timely for any researcher (Geisler, 2018). Considering this, coding of textual data continues to be an underdeveloped area in qualitative and mixed method research.

Coding necessitates a commitment to understanding the extent of language complexity for the reason that language is multidimensional, rhetorical, and requires interpretation that is often context-dependant (Geisler, 2018). One of the greatest challenges in this research relates to the multidimensionality of language. There will always be more than one way for a sentiment to be coded or categorized. For example, consider the following statement: "The GTA's urban forest is generally made of three types of trees (maple, cedar, ash)" (TRCA, 2016, p. 44). This statement has many possibilities when coding thematically. It could be coded according to its geographical context, whether it is the scale (city, regional, country) being referred to or the population type (urban versus rural). It may also be coded in regard to the object(s) or subject(s) it mentions, for instance "trees", or more specifically "type of trees", or even more explicitly "cedar", "maple", and "ash". In addition, it may also be coded based on the overall theme of the statement, for instance "forest composition". Depending on how abstract the themes are, meaning can easily be obscured or lost in the process of aggregating textual data into thematic categories. As the example above shows, coding schemes are fundamental in that how these categories are defined and differentiated will determine whether the method can be replicated by another researcher and how well.

Another issue that relates to multidimensionality and language complexity is mutual exclusivity. Generally speaking, mutual exclusivity requires researchers to allocate each piece of data to only one category. In essence, each piece of data cannot fit simultaneously into two different categories and still maintain logical truth for both. In quantitative research, mutual exclusivity is essential for testing results statistically. Qualitative analysis, such as narrative or discourse analysis, does not value mutual exclusivity in the same way that quantitative approaches do, often viewing it as rigid and overly systematic (Geisler, 2018).

As mentioned earlier, one approach to quantitative analysis of qualitative data is to assign numerical codes to the non-numeric data. Hopkins and King (2010) refer to this as taking unstructured text and representing it in numerical variables. Both, Hopkins and King (2010) and Wang et al. (2016) both refer to their textual data as unstructured. Research by Hopkins and King (2010) focuses on speeches, blogs, newspapers, and government records, while Wang et al. (2016) is concerned with consumer surveys and product reviews. Nonetheless, the notion of unstructured text requires clarification since any 
understanding of textual data as structured versus unstructured would likely have consequences in the analysis and results of any study.

The text is referred to as unstructured in the sense that when complied together, the complied information lacks a structure for which it can be processed and analyzed. It is unlikely that several separate pieces of text or documents follow identical formats (e.g. paragraphs, bullet points, headings and sub-headings). In standard statistical analysis this typically takes the form of dependant and independent variables, after which some form of exploratory, confirmatory, or other type of statistical analysis may be conducted. While each document may have some been formulated in some organized and logical manner, when dealing with several documents that are formatted differently, and which are then complied together, it can be very difficult to extract information for statistical purposes in a systematic manner. Identifying independent and dependant variables in the statistical analysis of unstructured textual data is a study area that still requires further research (Wang et al., 2016).

While there are certainly many unresolved challenges with textual data lacking a specific structure for statistical purposes, referring to the text itself as unstructured is problematic from a linguistic standpoint. Arguably, written communication is organized in some predefined manner, specifically one that is linguistic. Textual data is comprised of words, clauses, and sentences that adhere to rules which collectively form the structure of formal language.

For instance, Franzosi et al. (2013) differentiates quantitative narrative analysis (QNA) from content analysis by suggesting the coding categories are "based on invariant, structural properties of [the] narrative" (p. 3220), in other words, the coding scheme follows the sequential organization of sentence structure. S-V-O (subject, verb, object). The approach to quantitative narrative analysis (QNA) Franzosi et al. (2013) references is more generally known as a linguistic typology. Using this approach, sentences are coded based on the subject, verb, and object they refer to. In contrast to thematic coding, S-V-O allows for researchers to code according to linguistic typology (Roberts \& Popping, 1993). Also known as semantic text analysis, this technique has also been expanded to include other syntactic components as well (e.g. agent, position, action, etc.) (Popping \& Roberts, 2015). While this analysis technique the most suitable for reducing researcher bias and subjectivity, and increasing systematicity, it presents some challenges when applying to the textual data under consideration in this study.

\subsubsection{Coding Textual Data for Sustainability: Morphological Challenges}

One of the largest challenges in coding for sustainability relates to its morphological derivation and the implications it has on semantic function and meaning. A morpheme, is the smallest unit of grammatical analysis and meaning, often referred to as suffixes (e.g. -ly, -able, -ity) and prefixes (e.g. re, un, pre) (Ford 
et al., 2010). Furthermore, morphology is routinely divided into three categories: (i) inflectional (e.g. sustain+ed, sustain+ing, sustain+s); (ii) derivational (e.g. sustain+able, sustain+ably, sustain+ability, sustain-ment); and (iii) compounding (e.g. self+sustaining) (Ford et al., 2010). The morphological changes related to sustain are summarized in Table 1. Given that sustain is a verb, inflection and derivation will be discussed only in the context of verbs.

Inflection typically indicates a change in tense

Table 1. Morphological and lexical variations of sustain when added to verbs (Ford et al., 2010). For example, the addition of -ed changes sustain from present tense to past tense. Whereas, -ing at the end changes it from present tense to a progressive or continuous tense. Since inflection only changes the tense of the root word, the

\begin{tabular}{llccc}
\hline Infinitive & Suffix & Lexical Category & Morphology & Meaning \\
\hline 1 sustain - able & verb $\rightarrow$ adjective & derivational & may change \\
2 sustain - ably & verb $\rightarrow$ adverb & derivational & may change \\
3 & sustain - ability & verb $\rightarrow$ noun & derivational & may change \\
4 & sustain - ment & verb $\rightarrow$ noun & derivational & may change \\
5 sustain - ing & verb $\leftrightarrow$ verb & inflectional & unchanged \\
6 & sustain - ed & verb $\rightarrow$ adjective & inflectional & unchanged \\
\hline
\end{tabular}
semantic meaning remains the same. Considering this, coding for the words "sustain", "sustains", "sustained", and "sustaining" can be achieved in a rather systematic and consistent manner. All four variations of sustain have the same word senses attributed to them, however the semantic function of "sustained" changes from a verb to an adjective.

On the other hand, derivational morphology is considerably less systematic in terms of syntax form and semantic meaning because the adding of a derivational affix can change both (Ford et al., 2010). Derivational morphology is the process of forming a new word using an existing word. It should be known that the function of derivational affixes is still debated by some linguists in the literature. Whether derivational affixes are roots, headwords, or both, is still under debate (Creemers et al., 2018). The reason for pointing this out is to simply convey the challenges associated with lexical word processing.

While the quantitative narrative analysis (QNA) or S-V-O (subject, verb, object) linguistic typology was considered for this research, there were several barriers to its application that could not be overlooked. The first being that S-V-O typology is predominantly used for capturing an entire narrative. Although this might present some interesting findings in the context of this research, this study is specifically concerned with the use of sustainability and its other variants (i.e. sustainable, sustainable development, etc.). An investigation using both S-V-O typology and one that investigates sustainability-related words semantically would be advantageous, however the sample size included in this study makes such an undertaking significant in terms of the time cost. Secondly, derivatives of sustain may contain similar senses but they are used for different semantic functions, such as an adjective (sustainable, sustained), adverb (sustainably), noun (sustainability, sustainment), or verb (sustain, sustaining). Accounting for the different variations of sustain and their semantic functions while applying the S-V-O typology is unclear. 
Despite efforts to locate research studies pertaining to single words or word-phrases and which account for semantic variation, one could not be found.

Recall this research study being situated around the use of "sustain*", but more specifically "sustainability" and "sustainable development". While mapping the discourse of sustainability and sustainable development over time would be preferred, the process of coding sustain-based words which not only have multiple word senses, but also include changes in syntax and thus semantic function, remains challenging. That is, in addition to the challenge of capturing what is being said and how it is being said, without simply providing an exhaustive description of the text. Considering these circumstances, three different textual data analyses were explored in this document analysis, in particular linguistic analysis, thematic analysis, and policy narrative analysis, each of which are described in the section to follow.

\section{METHODS}

\subsection{Research Design \& Approach}

The transdisciplinary nature of sustainable development research necessitates widespread information and knowledge synthesis across conventional disciplinary boundaries. Much like governments, universities are also often divided into departments that are field or discipline specific. Similarly, research funding and academic journals are frequently positioned towards specific sectors or topics of study. As this is a rather large barrier when it comes to knowledge mobilization for urban sustainability, there has been a recent shift to establish a more multi- or trans-disciplinary approach to research. Despite the contrary, remnants of the historically compartmentalized approach to research and management (Boschken, 2017; Giddings et al., 2002) can still be found throughout scholarly research, public policy, and overall society. The process of creating and containing information in silos has surely created barriers to knowledge mobilization and most likely impacted the viewpoints contained within the sustainability knowledge generated thus far.

To resolve this potential gap, Cohen (2017) suggests using a mixed-method design to achieve the integrative approach often proposed by scholars (Giddings et al., 2002; Roseland, 2000; Singh et al., 2012; Sharifi \& Murayama, 2013) conducting urban sustainability research. Mixed-methods design is a considerably newer approach, relative to its counterparts at least as qualitative and quantitative research designs are often used independently and shape much of the research landscape that exists today. Some have articulated mixed-methods as the third major research paradigm (Johnson et al., 2007) that seeks to merge the first two. Despite there being several definitions that exist, Greene et al. (1989) provides one of the earlier definitions as a research design "...that include[s] at least one quantitative method (designed to 
collect numbers) and one qualitative method (designed to collect words), where neither type of method is inherently linked to any particular inquiry paradigm" (p. 256). The definition has since evolved largely focusing on its methodological domains.

More recently, Creswell and Clark (2011) used the core characteristics of mixed-methods research as a means of defining it. In doing so, they contend that a researcher would engage in the following: 1) persuasive and rigorous collection and analysis of both qualitative and quantitative data guided by research questions; 2) connection of both qualitative and quantitative data concurrently by having them build on one another, or integrating one within the other; 3) prioritization of one or both types of data depending on the research questions; 4) conduct the aforementioned procedures in several phases of a study or as a single study on its own; 5) situate the procedures within some philosophical or theoretical perspective; 6) incorporate the procedures into explicit research designs to instruct how the research will be conducted (Creswell \& Clark, 2011). To ensure this study follows the nature of mixed-method research, it will engage in the procedures identified above.

Given that mixed-method research is still in its premature stages there is still much dispute regarding what it entails and how it should be conducted, and with that comes many unanswered questions and controversies. Addressing all the issues pertaining to mixed-method research would be a research study on its own and is therefore beyond the scope of this research. To reduce any uncertainty pertaining to the philosophical assumptions and research methodology, transparency will be maintained in all aspects, including but not limited too, the research design, process, conduct, analysis, and interpretation. In other words, justification will be explicitly provided for any position or steps taken in this research study. The most dominant philosophical approach used in mixed-method research is pragmatism (Johnson et al., 2007), although mixed-method research can be conducted from a variety of ontological and epistemological perspectives (e.g. positivist, constructivist). Its ontology involves both singular and multiple realities; while its epistemology is that of practicality (e.g. "what works" for addressing the research question(s) being investigated) (Creswell \& Clark, 2011). The pluralistic and flexible nature of pragmatism is often most suitable for mixed-method research (Creswell \& Clark, 2011). Sustainable development research requires flexibility and its indicators are often encouraged to be policy-relevant (Böhringer \& Jochem, 2007; Huang et al., 2015). Consequently, pragmatism has been the recommended as the approach in which this can be achieved (Holden, 2001; Klopp \& Petretta, 2017).

There are several areas of uncertainty prior to starting this research study that warranted a pragmatic approach. First, it appears that the City of Toronto has not yet established a sustainability or sustainable development plan to unify the various individual initiatives relating to sustainability. Considering this, there is uncertainty regarding how many documents that relate to sustainability exist, if any. There may 
also be some challenges in acquiring municipal documents given the thirty-year period this study intends to cover. Accordingly, the format (i.e. electronic versus print) that these documents are available in has yet to be determined and may pose some challenges for analysis. Although this study seeks to use a systematic approach to document identification and selection, the success of this approach is contingent on the functionality of City of Toronto website search bar, and the characteristics of their document storage, archival, and retrieval processes. Finally, in the process of unpacking the semantics and linguistics of sustainable development, sustainability, its derivatives, it became apparent that there may be some difficult challenges to overcome in the analysis of sustainability discourse. Under these circumstances, this study necessitated the adoption of a pragmatist point of view.

\subsubsection{Narrative Policy Analysis}

Discourse theory maintains that actions, practices, objects, and communications are procured under specific social, cultural, and political circumstances which are unique to a particular point in time (Fisher, 2003). Given that discourse analysis and narrative analysis in particular, attends to meaning in context, it is a useful tool for the policy analyst because it allows one to address, adapt and communicate policy content that is often embedded with uncertainty and ambiguous meaning, and contradiction and confliction (Roe, 1992). What is evident in the literature on sustainability and sustainable development that which is also apparent in politics is the relationship between language and how problems are socially constructed.

Despite being rather imprecise, narratives are described as being distinguishable from other types of discourse in that they relay "stories", rather than providing a "description" or "study" (Kaplan, 1986). Narratives can be characterized by their use of distinct temporal events as a mechanism for formulate meaning. Considering that this research study covers sustainability policy over a specific time interval, from 1988 to 2018, adopting a narrative approach seems particularly relevant (McComas \& Shanahan, 1999) in discussing the findings of this research study.

Narrative policy analysis allows one to use the narrative to establish a broader understanding of policy issues, problems, and definitions, and in a way that avoids "grand theoretical aspirations" which is said to be characteristic of more traditional policy change research (McBeth et al., 2007, p. 88). In other words, these narratives represent the policy situation using an interpretative analysis as a means for including political, institutional, cultural, or other contextual factors.

The structure of the narrative, specifically in the context of public policy, is much like any other, containing a beginning, middle, and end: (i) the beginning represents the policy problem or situation; (ii) the middle represents the policy intervention; and (iii) the end covers the policy consequences or 
outcomes. In the process of formulating policy narratives, one is able to demonstrate how sequential policy narratives are comprised of diverging views, conflicting claims, and inconsistent responses to different interest groups (Fischer, 2003).

Described by Fisher (2003) but based on the works of policy analyst Emery Roe, narrative policy analysis comprised of four basic steps: (i) identifying the conventional or accepted stories dominating the policy problem; (ii) identifying any "counter stories" differing from or in opposition to, the dominant narrative; (iii) comparing these the first two narratives, the analyst attempts to establish a metanarrative to accommodate the differing points of view that surround the same policy problem; and (iv) the metanarrative is then assessed to determine if and how it reshapes the policy problem, particularly in a manner that is more accommodating to empirical policy-analytical tools (Fischer, 2003). Since narrative policy analysis provides a means in which one is able to analyze "highly uncertain and complex policy issues whose truth-value cannot be ascertained..." (Roe, 1989, p. 251), such as those that are sociotechnically complex and politically polarized (Fischer, 2003), it is relatively useful tool for delivering sustainability and sustainable development discourse. Expectantly, narrative policy analysis can be highly interpretive. The limitations to using an interpretative approach such as this, is discussed in the forthcoming limitations in Section 4.7.

\subsection{Study Sample Identification \& Selection}

Before detailing the processes associated with study sample identification, some characteristics of this study need to be discussed as they limit the types of documents that can be selected. Arguably, to capture sustainability and sustainable development discourse over time, a significant temporal span is required. Since sustainable development was first formally defined in the 1980s, this study selected the 30-year time span between 1988-2018, which ultimately limited what documents could be included in this study sample.

Considering land-use planning is a fundamental process to sustainable urban development (Dale \& Pierce, 1999; Hanna \& Slocombe, 2012), Toronto's Official Plan would be essential to this research study. However, during the temporal span selected, Toronto's governance system was restructured, resulting in geographical and functional changes to the City's public administration, including Official Plans. If this study were to include Official Plans between 1988-2018, it would have to consider the Official Plans of seven municipalities which no longer exist since the City amalgamated in 1998. The limitations this imposes on this research study are detailed in Section 4.7.

Documents authored by the City of Toronto or one of its municipal agencies is the first criteria for inclusion in this study. Preliminary database searches however, indicated that more specific criteria were 
necessary. Accordingly, this was narrowed further to include only City of Toronto Council documents, one Service Agency (Toronto Public Health) and one Partnered Agency (Toronto and Region Conservation Authority). These agencies were selected based on (i) their likelihood of having defined, conceptualized, and operationalized sustainability and sustainable development; and (ii) their relevance to sustainability of human-ecological systems. Both public health and conservation authorities remain fundamental in understanding human-ecological sustainability. All other documents, particularly those authored by City Corporations, Partnered Corporations, and Adjudicative Bodies were not included in this study.

The process of identifying documents for inclusion in this study was pragmatic due to several unknown circumstances that were unavoidable in this type of research study. These unknown circumstances specifically pertained to (i) how municipal documents are archived; (ii) the functionality of municipal search engines; (iii) the number of municipal databases and their accessibility; (iv) document formats (i.e. digital or paper format); and (v) the number of document relevant to sustainability or sustainable development.

Initially this study began by conducting an exploratory search of key words "sustainability" and “sustainable development" on the City of Toronto's website to identify key municipal documents pertaining to either concept. For the purposes of this research study, "key municipal documents" refers to secondary policy documents which are in part, vital to implementing the vision in the City of Toronto's Official Plan (City of Toronto, 2015). This research initially started with a priori protocol, similar to the ones used in systematic reviews of scholarly research journals. in attempt to systematically extract information regarding the frequency of these terms use. Unfortunately, there were several barriers to this approach that rendered it unsuitable for searching government databases for municipal documents. Sample selection was limited to municipal documents that were available and accessible publicly on the City of Toronto's website or through Ryerson University Library \& Achieves (RULA),, which is accessed through an institutional subscription provided by Ryerson University. Sample selection initially began by using the City of Toronto's search engine to filter out any document or webpage that contained the word "sustain". This search was conducted in February 2018. The search yielded 267 results, however whether this was reflective of the number of times "sustain" was used or the number of webpages it occurred on was unclear. Furthermore, it was also uncertain as to whether the search engine scanned the City of Toronto webpages and the documents contained within them. Given the number of results generated from this search, it is likely that the search engine only scanned the webpages and not the documents contained within them. 
Given this was an exploratory approach, each PDF document was downloaded, along with the corresponding webpage that it was found on. The 'find' function on Adobe Acrobat Reader was used to search "sustain" in each PDF document. Each webpage typically contained a summary of the PDF documents attached to that particular webpage. Considering this, the webpage contents were often duplicated content, but abbreviated, from the PDF documents contained within them. This process also suggested that 'sustain' was used more often than the number indicated by the search engine results. It was concluded that the City's search engine was insufficient in capturing the number of times sustain* occurred on each webpage, including within the PDF documents (i.e. reports, strategies) that they contained. Furthermore, the search did not yield any documents prior to 2009, although the City states that it should go further back than 2009. Given that the search only covered documents from 2009 to 2017, it only covered the terms of two municipal governments (i.e. Rob Ford, incumbent Mayor John Tory). Reports, strategies and communications from municipal governments prior to Rob Ford were absent on the City of Toronto's website, presumably because they were updated and/or archived.

Corporate Information Management Services of the Toronto City Clerk's Office was contacted via email (infomgmt@toronto.ca) to verify the functional abilities of the City's search engine. Through this correspondence, it was confirmed that the search function does not capture all City records, rather it predominantly yields information pertaining to divisional services and their contact points. In the absence of a municipal database that compressively captures reports, plans, and strategies that cover the 30year span of this study, standard systematic sampling could not be achieved. Thus, considerably less rigorous sample selection methods had to be used. To summarize the steps taken study sample selection, a workflow diagram is shown in Figure 4.

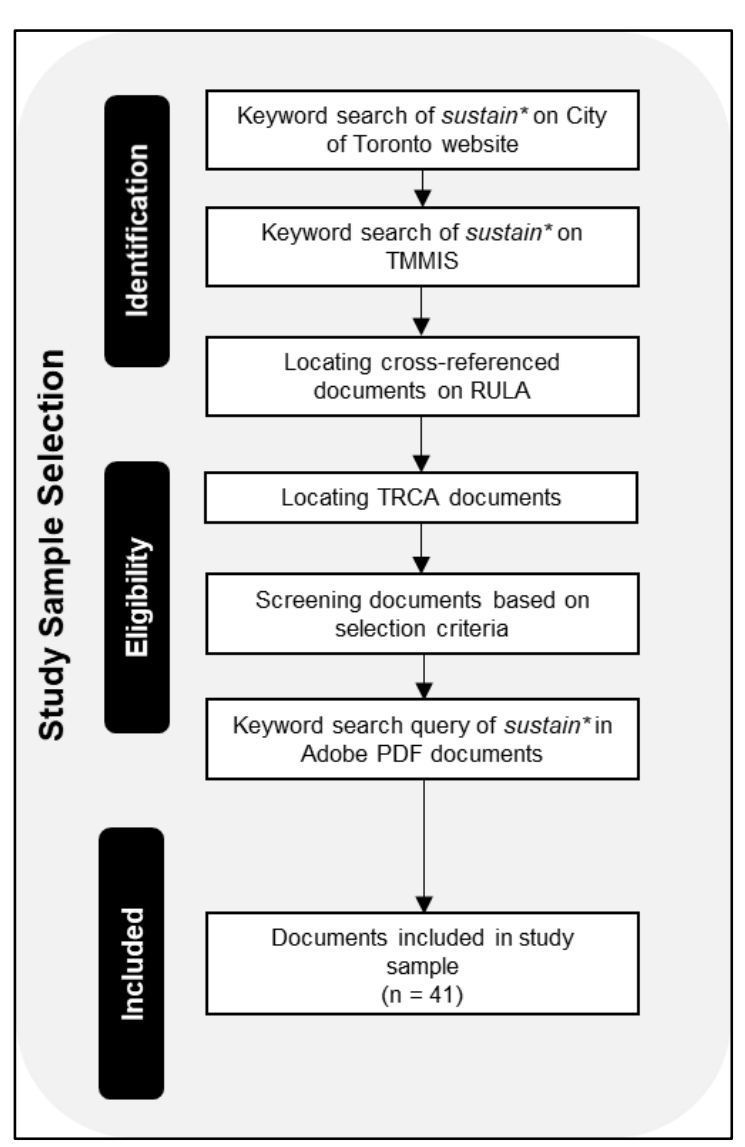

Figure 4. Work flow diagram for study sample selection.

Considering the circumstances noted above, an exploratory search of the City of Toronto's Meeting Management Information System ${ }^{\mathrm{TM}}$ (TMMIS) database (http://app.toronto.ca/tmmis/) was conducted because it contained records extending back to 1998. Documents in this database are classified in 
temporal intervals, allowing searches between 1998-2008 and 2008-2018. Searching "sustainability" yielded > 8,000 and 343 results, respectively; and "sustainable development" yielded > 700 and 112 results, respectively. These results were scanned until their relevance in respect to the document selection criteria began to decline considerably. It should be noted that this database primarily contained City Council documents and communications. Where key documents were mentioned in communications but not directly provided, an independent secondary search for them was conduced in TMMIS and RULA. Ultimately, TMMIS may not be as suitable for acquiring reports, plans, strategies, and guidelines but remained a valuable resource for understanding the chain of communications associated with the proposing, revising and adopting of reports, plans, strategies, and guidelines.

Given the time and logistical constraints of identifying documents that cover the 30 -year time span under investigation in this study, the study sample was selected using purposive sample selection, also referred to as convenience sampling. As its name suggests, purposive or convenience sampling allows researchers to identify or select their sample deliberately (Vogt, 2005), with some specific research goals or objectives in mind (Olsen et al., 2013). It is recognized that the use of purposive sampling means the study sample is exposed to unknown biases. The limitations of this sampling method are discussed in Section 4.7.

As mentioned earlier, "key municipal documents" refers to secondary policy documents which are in part, vital to implementing the vision in the City of Toronto's Official Plan (City of Toronto, 2015). For the purposes of this research study, documents were classified as key documents based on whether they were explicitly regarded as reports, strategies, plans, or guidelines. The results from the two exploratory searches were purposively sampled and the documents were selected based on the following criteria: (i) purpose or type of document (e.g. documents classified as reports, guidelines, or strategies/plans); (ii) the originating office (e.g. documents authored by City of Toronto, Toronto Public Health or TRCA); (iii) the presence of "sustain*” (e.g. derivative of 'sustain' used at least twice within body of document); (iv) publication date (e.g. published between 1988 and 2018); and (v) pertains to the entire spatial area of the City of Toronto (e.g. not site-specific). Documents that fulfilled the aforementioned criteria from the two exploratory searches were retained for the study sample. Since these two websites are the primary sites for accessing municipal documents online, the results of these searches were used as a starting point for sample selection. Through this process, several other documents were recognized as "key municipal documents" from having been cross-referenced in the sample identified from the two exploratory searches earlier.

In combination with purposive sampling of documents, an adapted version of referral sampling, also known as snowball sampling, was used to identify key municipal documents that had not been discovered 
from the first two exploratory document searches. Conventional referral sampling typically involves selecting a sample based on certain characteristics of research interest. Once the sample population is identified, participants are then asked to refer alike individuals to participate in the research study (Biernack \& Waldorf, 1981). In a similar manner, the sample identified from the two exploratory searches of "sustain" on the City of Toronto website and the TMMIS database was used to identify other key documents that they may have referred to as such, but which were not discovered in the initial exploratory search. Essentially, once the first group of documents were identified as eligible for inclusion, they were scanned for references to other key municipal documents that matched the same four criteria. The final list of documents included in this study sample are provided in Appendix A and B. Any documents that were cross-referenced but inaccessible through the City of Toronto website or TMMIS were accessed using RULA. While this process could not capture all municipal documents published in the last thirty years relating to sustainability and sustainable development, the procedure uncovers some documents that were otherwise unidentifiable through the first City of Toronto website search. Thirty-one documents included in the study sample were identified through the aforementioned processes, except for those authored by the TRCA. TRCA documents were not identified through the City of Toronto website searches likely because their website operates independently from City of Toronto's. TRCA documents were selected using the same five criteria from the database searches. Considering the study sample contains thirty-one documents thus far, only three documents were selected from TRCA, in particular high-level documents, such as The Living City® Report cards and strategic plan.

Currently there is no standard or optimal number for determining the number of documents to include in study samples like these. Therefore, the sample size was based on the need to balance of two necessities related the research questions of this study: (i) the need to obtain sufficient temporal coverage for the time span under consideration; and (ii) the need to maintain the relevance of the sample documents to sustainability or sustainable development as prescribed by the research question(s).

\subsection{Preprocessing Documents}

Once the study sample was confirmed, the documents were formatted for use in MAXQDA software. The steps involved in the preparing or preprocessing of the documents in this sample are shown in Figure 5. Three of the forty-one documents in the study sample were only available in paper format and had to be converted to digital form using a document scanner. Although these documents could be analyzed in their paper form, this research sought to maintain consistency in analyzing the documents in this study sample. This research study acknowledges copyright laws in Canada; accordingly, these three documents were converted into digital format for the sole purpose of this research. These three electronic files were only 
imported into the MAXQDA project file. Upon the completion of this thesis and in accordance with Ryerson University's Records Retention Schedule (RRS), the electronic PDF files will be irreversibly destroyed in a manner in which recovery is not possible.

After the documents were digitized, they were all imported into MAXQDA software for analysis. After importing the documents, it became apparent that some documents could not be read by MAXQDA software despite being in their original form. Both the TRCA and the City of Toronto had to be contacted to have the documents converted into Adobe Standard format for use in MAXQDA. Within MAXQDA documents were ascribed variables characterizing the documents in the study sample. Documents were classified in terms of the following: (i) document type (plan/strategy, report, guidelines); (ii) author and author type (division/department, partnered agency, management,

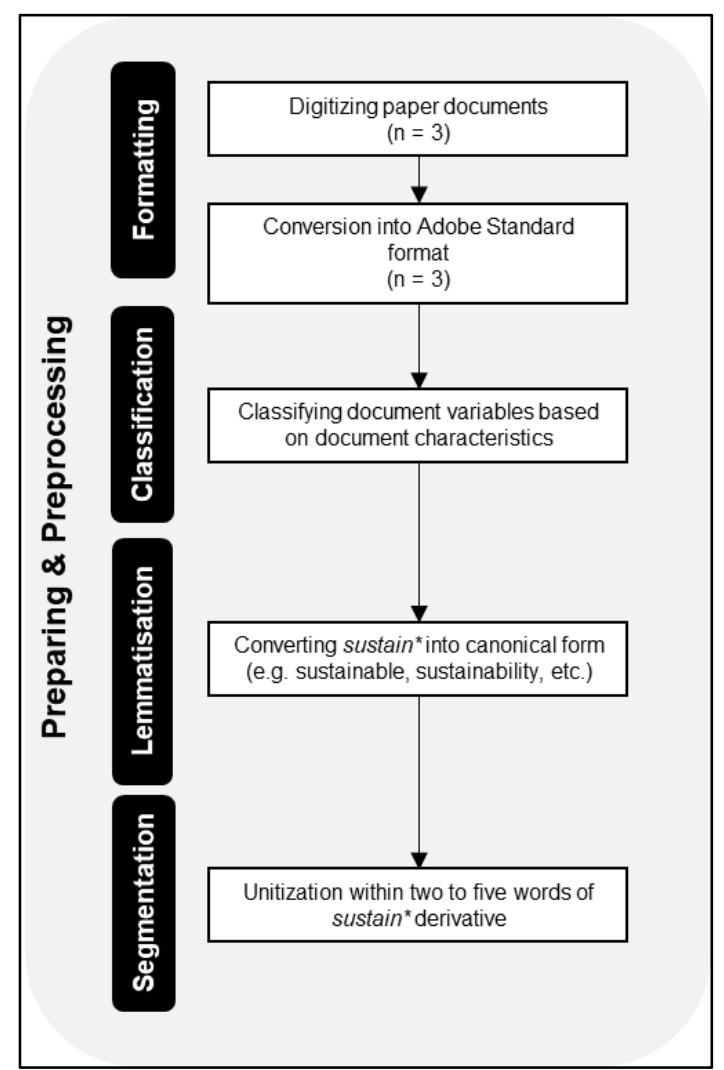

Figure 5. Work flow diagram of preprocessing and preparing documents for MAXQDA. service agency, committee); (iii) the incumbent mayor at the time of publication; and (iv) whether sustainability was included in the document title. The study sample distribution in terms of the author type and document type is provided in Appendix D and Appendix E, respectively. The distribution in terms of the incumbent mayor is also provided in Appendix G.

\subsection{Coding Documents for Analysis}

This research study is concerned with the policy discourse around a specific family of words (i.e. those that are derived from sustain) that which, as part of this study, were discovered as linguistically complex and diverse in their utilization, especially in policy discourse. Consequently, these circumstances have posed several challenges to coding for sustainability and sustainable development in the textual data. Accordingly, this research study argues that coding for sustainability-related language, if not based on systematic linguistic structure and function, is far to interpretative to be replicable unless a comprehensive and exhaustive coding outline is provided.

Reluctant to establish some systematic coding scheme (or codebook) that could confine the discourse on sustainability and sustainable development to boundaries (or thematic categories) that it does not 
necessarily represent or adhere to, this study decided to explore the use of verbatim coding, an approach that is more commonly used for qualitative interviews and open-ended surveys. This particular coding approach was employed due to several circumstances surrounding this research study: (i) the absence of secondary coders to evaluate the consistency and reliability of researcher coding; (ii) the interdependency of social, economic, and environmental components of sustainability and the lack of evidence-based research on the interdependencies and their potential classification, if even possible; and (iii) the limitations to classifying multi-word expressions according to sustainability dimensions.

The purpose of secondary coders is to evaluate the reliability of the researchers' categorization of text into codes (or categories), which is often conducted according to some a priori coding scheme. The process of coding necessitates that researchers make inferential judgements regarding what statements fall into which categories and apply these inferential judgements consistently throughout the text. Consider the frequently endorsed dimensions of sustainability dimensions - social, economic and environment. If statements are classified thematically according these dimensions, the researcher would have to make some inferential judgement as to whether the statement made pertains to social, economic, or environmental sustainability. While this coding scheme was considered for this research, a quick pilot study revealed that some multi-word expressions found in the study sample presented a considerable threat to coding reliability considering that this study employed an independent coder. For example, the ambiguity surrounding multi-word expressions such as "environmentally sustainable economic development" or "economically sustainable environmental development" make text classification according to social, economic, and environmental themes nearly impossible. With more than one coder, classifying multi-word expressions may be challenging without clear guidance in the coding scheme to account for ambiguous phrases such as these. Therefore, depending on the depth and detail in the coding scheme, the consistency of text classification can be highly variable.

For the above reasons, researchers may have two to three coders apply the same coding scheme to the entire text or a subset of the text to quantify the consistency of inter-coder inferences using statistical measures such as Krippendorff's alpha. This functions as a quality assurance mechanism for researchers working with qualitative data. In absence of secondary coders, this research study required a coding approach that limited the number of inferences made in coding textual data.

As previously earlier, this study considered functional linguistics as an alternative method for coding and analyzing textual data as it provided a means for systematically representing textual data according to a systematic linguistic structure. While this appeared to be a promising solution for reducing the number of inferences made by an independent researcher in coding textual data, the linguistic complexity of sustainability and its variants suggested that implementing a coding scheme like such, accurately and 
timely, would require linguistic expertise beyond what is available for this research study. The challenges to coding for sustainability and its variants using functional linguistics has been thoroughly detailed in the earlier sections of this study.

Despite the limitations of sentence-by-sentence coding, short and clear codes were needed given the size of the study sample which included forty-one documents. With that said, a lexical search of "sustain*" was conducted and the results were coded within 2-5 words of the occurrence of sustain or any of its lexical variants. Figure 6 briefly illustrates the steps of the coding process used. For the most part, coding within two to five words of the occurrence of "sustain*" permitted sufficient context in which the sustainability of what (i.e. person, place, or thing) could be identified. While challenges in verbatim sentence-bysentence coding were anticipated, efforts to identify an alternative approach that could accommodate the characteristics of this research study, and integrate both quantitative and qualitative analysis, were unsuccessful.

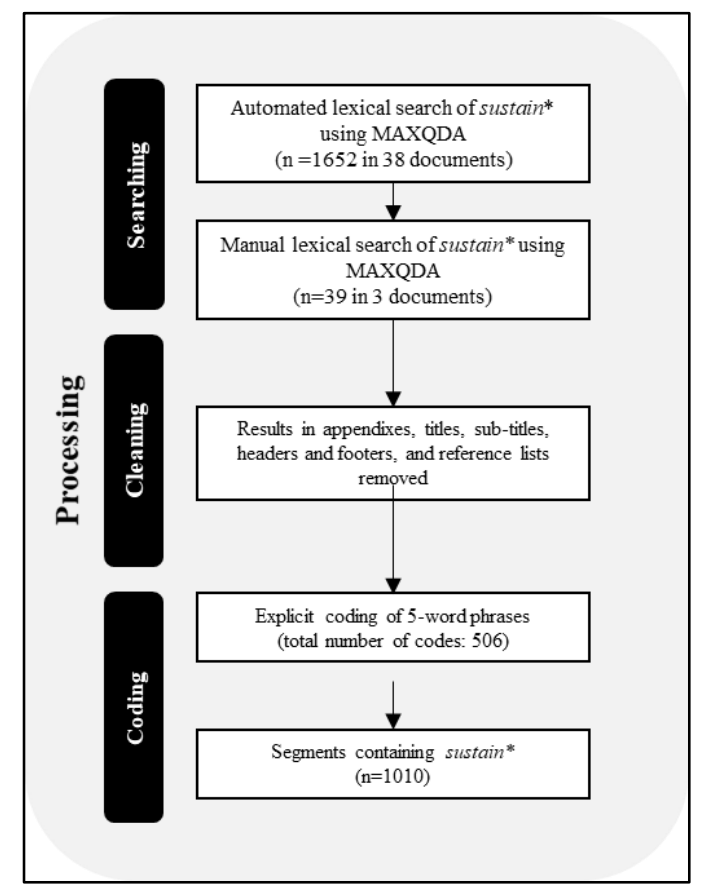

Figure 6. Work flow diagram of coding process employed using MAXQDA.

Providing a comprehensive discussion of different coding approaches that could be applied to the textual data in this study sample was necessary to achieve transparency in the methodological decisions made in this research which had to be pragmatically justified.

The explicit (or verbatim) coding of documents in this study sample produced 506 different codes. Essentially, this indicates that the City of Toronto used 506 multi-word expressions that contained some variant of sustainability. While some of these multi-word expressions indicated thematic similarities and differences, it should be noted that there were numerous expressions within these 508 codes that bared near-identical resemblance. During the coding process, there were some codes that were duplicated in verbatim that were then easily removed once coding was complete. In considering the occurrence of code duplication, this research found that the verbatim coding process produced many codes that appeared to be near-duplicates but perhaps not in the linguistic sense. These codes were reoccurring and nearly identical multi-word expressions, however, they often differed in terms of their word order, morphological structure, and presence of stop words; any of these circumstances could impact the semantic meaning of the discourse, as discussed in earlier sections. Some examples are shown in Table 2. 
Table 2. Comparison of similar multi-word expressions coded in study sample.

\begin{tabular}{ll}
\hline \multicolumn{1}{c}{ Similarity of Coded Multi-word Expression } \\
\hline Variation 1 & Variation 2 \\
\hline "environmental and sustainability issues" & "environmental sustainability issues" \\
"environmental and sustainability goal" & "environmental sustainability goal" \\
"information on sustainability" & "sustainability information" \\
"sustainable environmental pratices" & "environmentally sustainable pratices" \\
"manner that is more environmentally sustainable" & "environmentally sustainable manner" \\
"sustainability of toronto region" & "sustainable toronto region" \\
"sustainability of forest resource" & "forest sustainability" \\
\hline "Note: showing uncertainty related to inferences of meaning, specifically whether meaning changes fiom variant 1 to \\
variant 2
\end{tabular}

For the most part, stop-words (i.e. of, the, on, is, at, etc.) were retained within the codes; however, in a few cases where the expression exceeded 5 words, functionally redundant stop-words were removed. Nonetheless, this was strictly limited to only a few circumstances and done with an abundance of caution. Aside from these cases and despite the potential duplication, the codes remained verbatim. Without secondary coders, inferences regarding which stop words or morphological variations don't compromise meaning would call into question the reliability of this research. For this reason, this research study ceased to code the content any further. These explicit codes will be used for a broad quantitative assessment of the sustainability-related content, after which they will be used as the basis for guiding the narrative policy analysis to follow.

\section{FINDINGS, RESULTS AND DISCUSSION}

This section will first discuss some general trends found in the documents analyzed. Frequency and context are both important in analyzing the definitions, conceptualization, and operationalization of sustainability and sustainable development concepts. At the same time, one must use caution when interpreting these findings as the study sample selected is likely a confounding factor in the results and trends identified. For further information regarding the limitations of this study, please refer to Section 4.7 .

In general, the City of Toronto's explicit use of sustain, sustainable, and sustainability seems to be increasing over the last 30 years as shown in Figure 7. The same trend is observed for each variant of sustainability used. Overall, sustain* was found 1006 times in 41 documents. Of those 1006 occurrences, $51.39 \%$ were references to sustainable, $35.69 \%$ were references to sustainability, $10.34 \%$ were references to sustain, $1.49 \%$ were references to unsustainable, and $1.09 \%$ were self-sustaining. 
There several distinct peaks of use occurring in 2000, 2013, and 2016 as shown in Figure 7. There are several probable explanations for these peaks in use. The peak observed in 2000 is attributed to the City of Toronto's release of Clean, Green and Healthy: A Plan for an Environmentally Sustainable Toronto as it is the only document representing the year 2000. As observed in Table 3, this document contains the largest number of sustainability-related words for one document $(n=196)$, and the second largest for a single year (n=196). As the title suggests, the Environmental Plan (2000) was the first plan of its kind that is explicitly dedicated to Toronto's environmental sustainability and contains the most comprehensive plan in this study sample for operationalizing sustainability in City Council decisionmaking, which is detailed in Section 4.6.

The second largest peak in explicit use of sustainabilityrelated words is in 2013 as

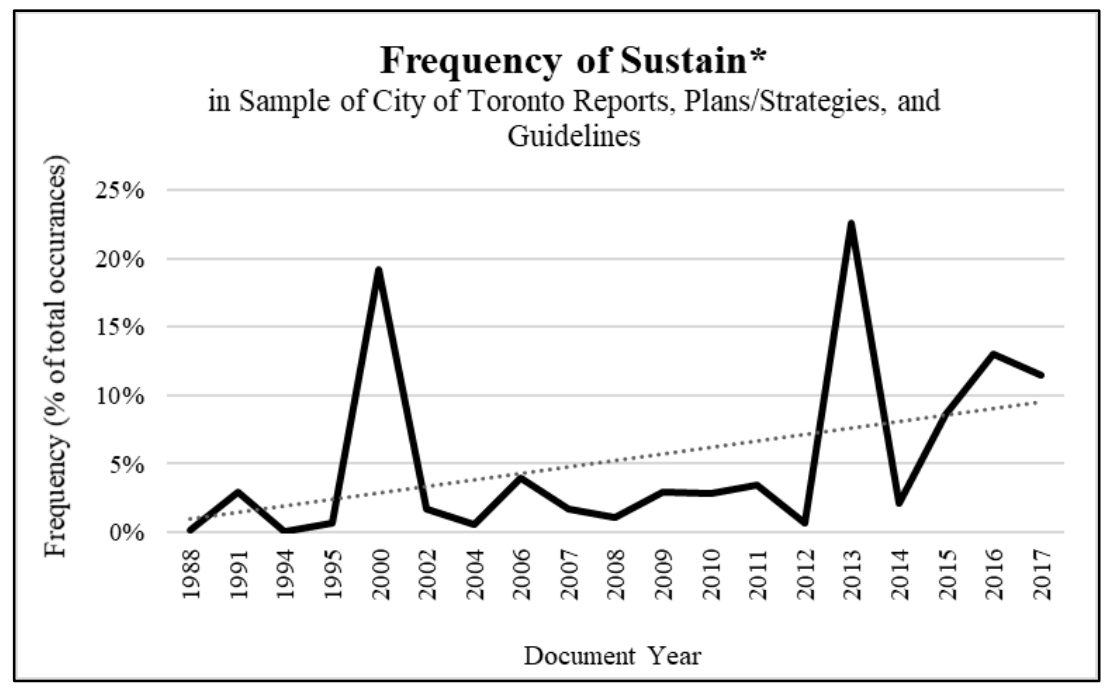

Figure 7. Frequency of sustain* in sample of City of Toronto reports, plans/strategies, and guidelines.

observed in Figure 7. This peak

in use reflects 9 different documents released in 2013, in particular, the TRCA's Building The Living City®; City of Toronto's Recreation Service Plan; Every Tree Counts: A Portrait of Toronto's Urban Forest; Collaborating for Competitiveness: A Strategic Plan for Accelerating Economic Growth and Job Creation in Toronto; Sustaining and Expanding the Urban Forest: Toronto's Strategic Forest Management Plan 2012-2022; City Planning Strategic Plan 2013-2018; Parks Plan 2013-2017; City of Toronto Strategic Actions 2013-2018; Next Stop Health: Transit Access and Health Inequities in Toronto. In contrast to the first peak in use observed in 2000, this peak accounts for the accumulation of sustainability-related words across nine documents in $2013(\mathrm{n}=230)$. 
Table 3. Study sample documents ranked based on absolute frequency of sustain*

\begin{tabular}{|c|c|c|c|c|}
\hline Year & Document Title & Author* & $\begin{array}{c}\text { Absolute } \\
\text { Frequency of } \\
\text { sustain }^{*}\end{array}$ & $\begin{array}{l}\text { Frequency } \\
\text { Rank }\end{array}$ \\
\hline 2000 & Environmental Plan: A Plan for an Environmentally Sustainable Toronto & $\mathrm{ETF} / \mathrm{CM}$ & 195 & 1 \\
\hline 2016 & The Living City Report Card 2016: A Progress Report on Environmental Sustainability in the Toronto Region & TRCA & 117 & 2 \\
\hline 2013 & Building the Living City 10-Year Strategic Plan 2013-2022 & TRCA & 82 & 3 \\
\hline 2013 & Sustaining \& Expanding the Urban Forest: Toronto's Strategic Forest Management Plan 2012-2022 & PFR & 43 & 4 \\
\hline 2013 & Parks Plan 2013-2017 & PFR & 38 & 5 \\
\hline 2006 & Making a Sustainable City Happen: The Toronto Green Development Standard & PD & 35 & 6 \\
\hline 2011 & The Living City Report Card: An Assessment of the Environmental Health of the Greater Toronto Area & TRCA & 35 & 7 \\
\hline 1990 & Environmental Backgrounder. Environmental Planning Issues and Concerns in the City of Toronto & PD & 32 & 8 \\
\hline 2017 & TransformTO: Climate Action for a Healthy, Equitable and Prosperous Toronto (Report 2) & TEO/EED & 32 & 9 \\
\hline 2015 & Toronto Environmental Progress Report 2015 & TEO/EED & 30 & 10 \\
\hline 2010 & Cultivating Food Connections: Toward a Healthy and Sustainable Food System for Toronto & PH & 29 & 11 \\
\hline 2017 & Parks and Recreation Facilities Master Plan (FMP) 2019-2038 & PFR & 28 & 12 \\
\hline 2015 & Long Term Waste Strategy & SWM & 26 & 13 \\
\hline 2013 & Every Tree Counts: A Portrait of Toronto's Urban Forest & PFR & 25 & 14 \\
\hline 2015 & From Concept to Commercialization: A Startup Eco-System Strategy for the City of Toronto & EDC & 23 & 15 \\
\hline 2009 & The Power to Live Green Toronto's Sustainable Energy Strategy & TEO/EED & 22 & 16 \\
\hline 2002 & City Council's Strategic Plan & $\mathrm{CM}$ & 20 & 17 \\
\hline 2014 & 2014 Performance Measurement and Benchmarking Report & $\mathrm{CM}$ & 18 & 18 \\
\hline 2017 & Toronto Ravine Strategy & PFR & 18 & 19 \\
\hline 2007 & Climate Change, Clean Air and Sustainable Energy Action Plan: Moving From Framework to Action Phase 1 & TEO/EED & 17 & 20 \\
\hline 2016 & TransformTO: Climate Action for a Healthy Equitable, and Prosperous Toronto (Report 1) & TEO/EED & 17 & 21 \\
\hline 2017 & Toronto Complete Streets Guidelines: Making Streets for People, Placemaking and Prosperity & $\mathrm{PD}$ & 16 & 22 \\
\hline 2013 & Strategic Actions 2013-2018 & $\mathrm{CM}$ & 14 & 23 \\
\hline 2013 & Collaborating for Competitiveness: A Strategic Plan for Accelerating Economic Growth and Job Creation & EDC & 13 & 24 \\
\hline 2008 & Ahead of the Storm Preparing Toronto for Climate Change & TEO/EED & 11 & 25 \\
\hline 2009 & Toronto Walking Strategy & TSD & 8 & 26 \\
\hline 1995 & State of the Environment Report: Metropolitan Toronto & PD & 7 & 27 \\
\hline 2012 & GrowTO Urban Agriculture Action Plan & PH & 7 & 28 \\
\hline 2004 & Our Common Grounds & PFR & 6 & 29 \\
\hline 2015 & TO Prosperity: Toronto Poverty Reduction Strategy & SDFA & 6 & 30 \\
\hline 2017 & Toronto Green Standard (TGS): New Mid to High-Rise Residential and All Non-Residential Development & PD & 6 & 31 \\
\hline 2013 & City Planning Strategic Plan 2013-2018 & PD & 5 & 32 \\
\hline 2017 & Toronto Pollinator Protection Strategy & TEO/EED & 5 & 33 \\
\hline 2017 & Toronto Green Streets Technical Guidelines (GSTG) & PD & 5 & 34 \\
\hline 2014 & Toronto Strong Neighbourhoods Strategy (TSNS) 2020 & SDFA & 4 & 35 \\
\hline 2017 & The City of Toronto Zero Emissions Building Framework & PD & 4 & 36 \\
\hline 2015 & A Climate of Concem: Climate Change and Health Strategy for Toronto & PH & 3 & 37 \\
\hline 1988 & Toronto: State of the Environment & $\mathrm{PH}$ & 2 & 38 \\
\hline 2013 & Recreation Service Plan 2013-2017 & PFR & 2 & 39 \\
\hline 2013 & Next Stop Health: Transit Access and Health Inequities in Toronto & PD & 2 & 40 \\
\hline \multirow[t]{2}{*}{2017} & Parkland Strategy: Growing Toronto Parkland - Phase 1 Report & PFR & 2 & 41 \\
\hline & & Total: & 1010 & \\
\hline
\end{tabular}

Despite this finding being relative to the number of documents included in the 2013 sample year, three of the documents contain some of the largest counts of sustainability-related words, those documents in particular are the TRCA's Building The Living City ${ }^{\circledR}(\mathrm{n}=82)$; Parks, Forestry and Recreation's Sustaining and Expanding the Urban Forest: Toronto's Strategic Forest Management Plan 2012-2022 (n=43); and Parks Plan 2013-2017 (n=38). Of particular interest is that the highest ranked documents based on absolute frequency are authored by departments or agencies that predominantly focus on the environment, 
specifically, the TRCA and Toronto's Parks, Forestry, and Recreation. The implications this may have for conceptualization of sustainability or sustainable development will be discussed in the section to follow.

Correspondingly, out of the four highest ranked documents based on absolute frequency of sustainabilityrelated words, three contain some variant of sustainability in their title. Nonetheless, including the word in the document title may be inconsequential as it was found in document titles where the term appeared considerably less prevalent in the body of the document. For instance, The Power to Live Green:

Toronto's Sustainable Energy Strategy (2009) ranked $25^{\text {th }}$ out of forty-one documents, based on absolute frequency, despite having the word sustainable in its title, as shown in Table 3. This document may indicate less rhetorical use as it focuses on energy initiatives that work towards sustainability, rather then attributing all its energy-related objectives and goals as sustainable. Similarly, Climate Change, Clean Air and Sustainable Energy Action Plan: Moving from Framework to Action referred to sustain* on 17 difference occasions and ranked $20^{\text {th }}$, also based on absolute frequency.

The explicit use of environment with sustain, sustainable, or sustainability, appears to have remained largely unchanged over the last thirty years. As shown in Figure 8, it appears that cooccurrences of environment and sustainability have slowly

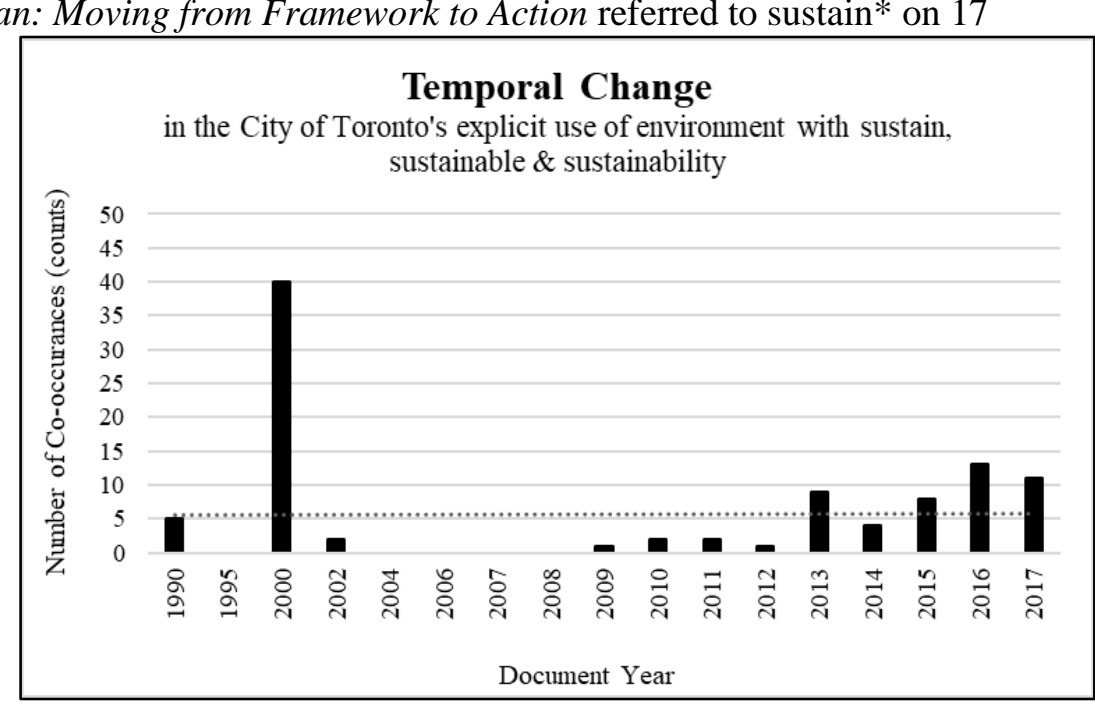

Figure 8. Number of times (counts) environment is explicitly used with sustain*.

began to increase since approximately 2013. It is important to mention that these are explicit occurrences of these terms, meaning it doesn't account for words that may be implicit of the environment such as, biodiversity, water, ecosystem, et cetera. Accordingly, explicit co-occurrences of sustain* and environment were absent in the four documents representing between 2004, 2006, 2007 and 2008. Upon further analysis however, some of these documents were found to refer to the environment implicitly by using terms which are indicative of the environment, for instance, "sustainable natural trails" and "sustainable urban forest" found in the Our Common Ground: Parks, Forestry and Recreation Strategic Plan (2004). 
When implicit environmental

terms are taken into

consideration, the opposite trend

is observed. Figure 9 in particular

shows that the co-occurrence of

explicit and implicit

environmental terms with

explicit use of sustain* appear to

be slowly increasing over the last

30 years. This incorporation of

implicit terms is largely

exploratory considering there is

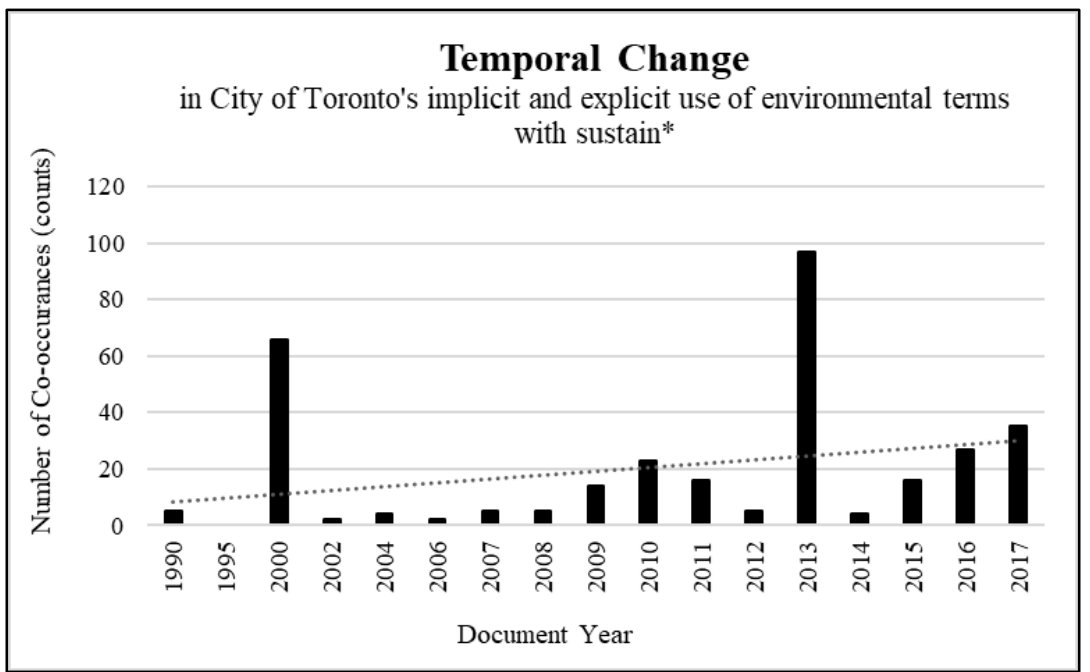

Figure 9. Number of times (counts) implicit and explicit environmental terms occur with sustain.

no mechanism for ensuring the quality control of these

inferences; in other words, what is implicit of

environment and what is not, could be up to

interpretation. Especially considering the environment

may refer broadly to the general surroundings or

specifically to the natural or living environment. To

explore the influence that implicit environmental

terms may have on the results of this study, implicit

environmental terms were included depending on

whether they represented any of the following: (i) life

or living organisms (i.e. physical entities that have

biological processes, such as plants, humans, and

other organisms); (ii) components or derived from

components of the Earth's biosphere (i.e. soil,

watershed, food, energy); or (iii) contained references

to "natural" or "green". For transparency, the list

terms considered to be implicit of the (natural)

environment terms are provided in Table 4.

These two contradictory trends dealing with explicit

and implicit references to the environment

demonstrate the importance of semantic relations in textual data analysis, specifically, the identification of

Table 4. Words classified as implicit of the natural environment.

\begin{tabular}{ll}
\hline & Words Implicit of Environment \\
\hline agriculture & natural cover \\
agri-food & natural ecosystems \\
biodiversity & natural elements \\
canopy cover & natural habitat corridors \\
climate actions & natural resource \\
drinking water & natural trails \\
ecological & park landscapes \\
energy & parkland \\
farming & parks \\
fish & pet traffic \\
food & planet \\
food system & plant \\
forest cover & pollinator populations \\
freshwater & soil \\
green infrastructure & solid waste \\
greenspace & species \\
groundwater & trails \\
habitat & tree canopy \\
honey bee colony & trees \\
landscape & urban drainage system \\
life & urban forest \\
liveable & vegetation \\
living & waste \\
living environment & water \\
living networks and systems & watershed \\
local garden projects & wildlife \\
natural cover & \\
\hline & \\
\hline
\end{tabular}


hypernyms and hyponyms, but synonyms as well. Identifying hypernyms and hyponyms would allow for the systematic classification environmental terms based on their linguistic relationship; a hypernym is the broader term and a hyponym is a specific instance of it, for example, geographical area is a hypernym of environment.

This same analysis was conducted for the concurrent, explicit use of sustain* and development, shown in Figure 10. Again, one must use caution when interpreting these results because this analysis only considered explicit use of development and doesn't include words that may be implicit of development, for instance, "buildings" may be considered as implicit of development.

Interestingly, this research found that the explicit use of sustain* and development has been

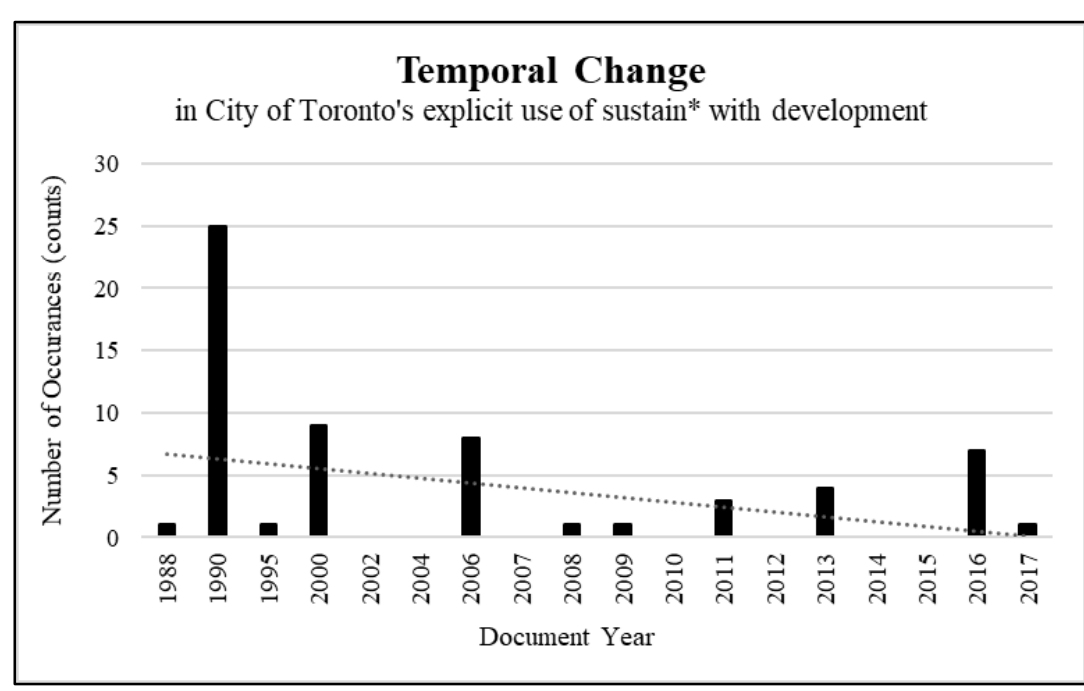

Figure 10. Number of times (counts) development is explicitly used with sustain*. decreasing over the last thirty years. Although if one were to consider words implicit of development, this may produce different results. Essentially, this research corroborates what scholars have argued before, specifically that word counts are ineffectual for elucidating context; and quantity doesn't necessarily indicate quality. Additionally, since several documents were issued in part, to provide the basis for environmental sustainability and sustainable development in Toronto, despite hardly acknowledging the terms, this research found that frequency isn't necessarily indicative of a document's relevance to these concepts either.

\subsection{Variation as Adjective and Noun}

This research also considered looking at lexical variation in attempt to elucidate how sustainability is used by the City of Toronto. Based on the sample of documents identified, sustain* was used most often as an adjective (sustainable) and noun (sustainability) by the City of Toronto. As mentioned in earlier, an adjective is a descriptive word that modifies (or qualifies) a noun (person, place, or thing). For instance, when "sustainable" precedes "energy" or "transportation", it essentially modifies the latter term. Arguably, one may consider this the formation of new concept, which in turn, would necessitate a definition and conceptual description of its own, especially if it were to be operationalized and measured. 
Of the 1006 occurrences of sustain* in this study sample, 517 were references to the adjective, sustainable; in other words, the City of Toronto characterized some persons, places, or things as "sustainable" 517 different times. The frequency of sustainable could warrant concern depending on whether these persons, places, or things are attributed as currently or prospectively sustainable (e.g. "sustainable future" or "investment in sustainable energy"). Since plans and strategies make up approximately $60 \%$ of the study sample and are presumably prospective in nature, it might indicate that attribution as sustainable was more prospective than current. If this were the case, it may also allude to more rhetorical use, in other words, the City may use the term simply because it "sounds good" and is marketable or persuasive. In any case, elucidating whether the City is referring to persons, places, or things as currently sustainable or prospectively sustainable would require further analysis.

Regarding sustainability, 359 of the 1006 occurrences of sustain* were explicit references to sustainability, as a noun. In the context of its utilization as a noun (more specifically, a mass noun), sustainability can be a thing on its own, but may also be employed as a compound noun in which the word preceding sustainability modifies its meaning (i.e. environmental sustainability, transportation sustainability, fiscal sustainability, global sustainability). The semantic function and meaning of sustain* is highly variable and depends on its use and arrangement in any given sentence. Considering the frequency of its use, extracting contextual components of discourse without distorting their meaning can be difficult.

In any case, it may be important to point out the nouns most frequently characterized as sustainable. These include "sustainable development", "sustainable city", "sustainable energy", "sustainable transportation system", "sustainable transportation modes", "sustainable urban forest", and "sustainable communities". These terms were found to be the most prevalent terms cooccurring alongside sustainable, each of which were found ten or more times across the forty-one documents in this sample as shown in Table 5. Similarly, "urban forest sustainability", "long-term sustainability", and "sustainability issues" appeared 17, 13, and 10 times, respectively. Given that occurrences of sustain* were coded in verbatim, there are likely other semantic variants of these themes within the data. As mentioned earlier, direct references to "environment" and "sustain*" were found in 98 different multi-word phrases. Again, this doesn't include words that may be synonymous with environment (i.e. natural ecosystem) or those that 
refer to specific environmental components, such as "sustaining freshwater resources", "sustain biodiversity", "sustain urban forest". Classifying words and their semantic relationships to other words should be done systematically, however given the absolute frequency of sustain* in this study sample this could not be achieved in a timely manner.

\subsection{Interchangeable use of Sustainability and Sustainable Development}

While some documents explicitly use sustainability or sustainable development, others refer to these concepts interchangeably. In some cases, other terminology is proposed as being representative of these concepts.

Toronto's Green Development Standard (TGS) (2006) for instance, refers to sustainability and sustainable development interchangeably. In particular, it suggests that sustainability was popularized by the WCED, but then provides the WCED's definition for sustainable
Table 5. Multi-word phrases containing nouns most frequently regarded as sustainable study sample.

\begin{tabular}{|c|c|c|}
\hline Code String & $\begin{array}{l}\text { Number of } \\
\text { Coded } \\
\text { Segments }\end{array}$ & $\begin{array}{c}\text { Number of } \\
\text { Documents with } \\
\text { Code String }\end{array}$ \\
\hline sustainable_de velopment & 24 & 7 \\
\hline sustainable_city & 20 & 11 \\
\hline sustainable_energy & 20 & 5 \\
\hline sustainable_food_system & 14 & 4 \\
\hline sustainable_transportation_system & 13 & 3 \\
\hline sustainable_modes_transportation & 12 & 5 \\
\hline sustainable_community_or_comm unities & 11 & 6 \\
\hline sustainable_urban_forest & 11 & 4 \\
\hline sustainable_ways & 9 & 4 \\
\hline sustainable_funding & 8 & 4 \\
\hline sustainable_buildings & 7 & 3 \\
\hline sustainable_transportation & 7 & 5 \\
\hline environm entally_sustainable_behaviour & 6 & 1 \\
\hline sustainable_city_region & 6 & 3 \\
\hline sustainable_community_building & 6 & 1 \\
\hline sustainable_commuting_options & 6 & 3 \\
\hline sustainable_food & 6 & 2 \\
\hline sustainable_future & 6 & 4 \\
\hline sustainable_parks & 6 & 1 \\
\hline sustainable_site_and_building_design & 6 & 4 \\
\hline sustainable_technologies & 6 & 3 \\
\hline sustainable_transportation_options & 6 & 3 \\
\hline sustainable_city_building & 5 & 1 \\
\hline sustainable_design & 5 & 3 \\
\hline sustainable_economic_growth & 5 & 1 \\
\hline
\end{tabular}
development thereafter. It also denotes the use of "green" in "Green Development Standard" as being associated with both concepts, sustainability and sustainable development.

Six documents acknowledge the WCED as having defined sustainable development, but only four documents make direct reference to the WCED in the body of the document, the remaining two are referred to in the documents reference list. The four documents that acknowledge the WCED's conceptualization of sustainable development in the body of the document were published in 1988, 1995, 2000, and 2006. The remaining two documents published in 2010 and 2016 use the term "sustainable development" and employ a Vancouver reference style (i.e. numbered system) to acknowledge the WCED in their reference list. In general, it appears that the number of documents acknowledging the WCED's role in defining sustainable development has been declining. However, this research also suggests that explicit cooccurrences of sustain* and development may be subsequently declining as well. 
The sheer frequency of sustain* in this 30-year study sample potentially suggests that sustainability and/or sustainable development is used more often as a rhetorical device than a clearly defined guiding principle that can be operationalized, despite being characterized as such. As outlined in the literature review above, it is by now generally accepted that such rampant use of the word - which is also prevalent in scholarly research on the subject - has profoundly diminished any meaning it contains, even its most fundamental sense of simply signifying that something can be or is maintained over an extended duration or without interruption.

As previously mentioned, the sample size included in this study makes the results difficult to summarize in a meaningful manner, especially considering its use over 1000 times. With that said, the following subsections will briefly discuss how sustainability, sustainable development, and some other prominent conceptions of sustainable, have been defined, conceptualized, and operationalized by the City of Toronto by the City of Toronto over the past 30 years.

\subsection{Defining Sustainability and Sustainable Development}

The distinction between defining, conceptualizing, operationalizing, and measuring can sometimes be unclear as each of these processes are not mutually exclusive of one another; rather they build upon each other. It also should be noted that this is not a one-way process either. While a definition is "a statement providing the exact meaning of a word or description of the nature, scope, or meaning of something", conceptualization is "the action or process of forming a concept or idea of something". In application, distinguishing definitions from conceptualizations and vice versa is unclear. For the purposes of this research then, definitions were distinguished by indication of meaning, such as "sustainability or sustainable development means..." or "defined as". It is acknowledged that there are other terms that can denote the presence of a definition in a proposition, however, for simplicity, all other characterizations that don't include "mean" were classified as conceptualizations. This section will also include acknowledgements of sustainable development as defined by the WCED's Brundtland Report because it is frequently recognized as being the most popularized definition.

In contrast to the documents that have acknowledged sustainable development as having been defined WCED, the Department of Public Health's 1988 report entitled Toronto: State of the Environment, which is the oldest document in this study sample, acknowledges the WCED's Brundtland Report in which sustainable development is defined, for seemingly different reasons. Instead of elaborating the meaning of sustainable development, the WCED's Brundtland Report is recognized for having identified a relationship between global economic growth and environmental quality. 
The magnitude of local- and trans-boundary chemical, physical, and biological pollution during this time was unprecedented, specifically throughout the 1960s, 70s and 80s when the consequences of global economic growth were being experienced first-hand. Accordingly, global economic growth and environmental quality dominated the political discourse for several decades. Perhaps Toronto's Department of Public Health interpreted sustainable development as a means for reconciling economic growth and environmental degradation in which a definitional debate may be redundant, especially if the environmental circumstances appear urgent (i.e. effecting human health) and few, if any other options had been presented for their reconciliation. Nonetheless, without providing the definition, the Department of Public Health (1988) espouses sustainable development as necessary for Toronto residents to maintain a "reasonable standard of living" (p. 1) that is unimpeded by environmental degradation.

Two years later, Toronto's Planning and Development Department (1990) published Environmental Backgrounder Part I: Environmental Planning Issues and Concerns in the City of Toronto. Despite all efforts to locate its complementary Environmental Backgrounder Part II: Analysis of Environmental Planning Policy in the City of Toronto on the City's website, TMMIS, and RULA, neither a paper or electronic copy could be located for inclusion in this research. It is likely that this document is held at the City of Toronto Archives, however based on the title results from an archival database search, this could not be confirmed. It is recognized that without considering Part II of this report series, the policy narrative will inevitably be incomplete; this should be kept in mind while interpreting this analysis.

Toronto's Planning and Development Department (1990) spent considerable time discussing the existence of a plethora of definitions and suggests the definitions do more to elucidate the political position of the author defining it, rather than the various qualities that sustainable development engenders. Clearly, the impacts of its definitional versatility and ambiguity on conceptualization and operationalization was already taking effect four years into its popularization by the WCED. This report in particular, is the only document that provides the complete WCED definition of sustainable development. Specifically, the document includes the WCED's specification that sustainable development is comprised of two key components: (i) the concept of "needs", in particular the essential needs of the world's poor, to which overriding priority should be given; and (ii) the idea of limitations imposed by the state of technology and social organization on the environments ability to meet present and future needs. Consequently, the document is the only to provide a comprehensive overview of the definitional and interpretational variability underlying the WCED definition of sustainable development. The report also suggests that the ambiguity surrounding its definition was potentially deliberate, in effect to favour political and diplomatic acceptability. In any case, Toronto's Planning and Development Department (1990) contends that its ambiguity can be both a strength and weakness. 
The Environmental Task Force's (ETF) which released Clean, Green and Healthy: A Plan for an Environmentally Sustainable Toronto in 2000, is also one of six documents recognizing the WCED as having defined sustainable development. While the ETF acknowledges the WCED's definition of sustainable development, it only provides the most frequently cited portion which doesn't specify the two components sustainable development is comprised of. In fact, it appears that the ETF incorrectly cites the WCED's definition, specifically quoting it as "economic [emphasis added] development that meets the needs...", when the original work states sustainable development as "development that meets the needs...". The addition of "economic" in this proposition of sustainable development, whether intentionally or not, ultimately changes the meaning of the statement and is unfortunately an incorrect representation of sustainable development as delineated by the WCED.

The ETF also provides a definition of sustainable development formulated by the World Bank "as development that passes on to future generations an equal or preferably enhanced stock of economic, natural, social, and human capital" (p. 50), but doesn't elaborate on what these forms of capital encompass. In between these two definitions however, the Environmental Plan (2000) shifts into its own definition of sustainability. While this may not be readily interpreted as a definition, it is characterized as such because the statement begins with "sustainability means...". Accordingly, sustainability is described as a conceptual lens for which economic, environmental, and societal implications can be addressed together as they are conventionally considered independently of one another. The Environmental Plan (2000) is structured in a way that suggests it uses sustainability and sustainable development interchangeably. Aside from this being indicated in the above paragraph, it is also signified from the concept of sustainable development being introduced under the subheading "About Sustainability". Toronto's Green Development Standard (TGS) (2006) acknowledges sustainable development as being popularized by the WCED, but similar to the ETF's Environmental Plan (2000), the TGS (2006) doesn't account for the two components that sustainable development is comprised of, specifying "needs" and the limits of technology. It suggests that the WCED's characterization of sustainable development is indicative of "two important tenets of sustainability; responsibility of one generation to the next and the interdependencies between social, economic, and ecological systems" (p. 4). Using the term "sustainability" to interpret the WCED's definition of sustainable development, as shown in the above statement, likely suggests the documents subsequent use of these concepts is interchangeable. The TGS (2006) also denotes that its use of "green" in the "Green Development Standard" as being associated with sustainability or sustainable development.

The remaining two documents published in 2010 and 2016, both employ a Vancouver reference style (i.e. numbered system) to acknowledge the WCED as the source of their definition. The first document is 
Toronto Public Health's Cultivating Food Connections: Toward a Healthy Sustainable Food System for Toronto which was published in 2010. The report recognizes that sustainability has many definitions but contends it fundamentally "refers to meeting the needs of the present without compromising the ability of future generations to meet their needs" (p. 14). Given that sustainability is defined using the WCED's definition of sustainable development, it would suggest that sustainability and sustainable development are also being used interchangeably. Finally, the last document to acknowledge the WCED as having introduced sustainable development is The Living City ${ }^{\circledR}$ Report Card 2016 by the TRCA. This document only refers to the WCED by placing a numerical citation after "the idea of sustainable development...". The report then describes how sustainable development has changed over the last 30 years, specifically how its management focus changes with new scale, but does not attempt to provide an explicit definition for the concept.

Out of the forty-one documents in this study sample, the aforementioned are the only explicit definitions of sustainable development, and by association appear to define sustainability as well. The interchangeable use of sustainability and sustainable development rendered the concepts indistinguishable from each other, despite their differences and semantic variability. Of the six documents that acknowledge the WCED Brundtland definition of sustainable development, only one includes the "two key components" specification regarding the limits of technology and needs of the world's poor.

Arguably, the two key components of sustainable development are fundamental for understanding what the WCED's Brundtland Report intentions were when they defined sustainable development and for accurately reflecting the definition which would reduce some of its ambiguity. However, as the Environmental Backgrounder Part I (1990) points out, even after acknowledging this specification, the Brundtland definition still produces a spectrum of views, whether intentional or not. Aside from the remaining documents excluding Brundtland's "two key components" specification and defining sustainability with the Brundtland definition of sustainable development, only one document erroneously referenced the definition incorrectly, specifically the ETF's Environmental Plan (2000). Lastly, each definition included some notion of current and future needs; and some specification regarding the social, economic, and environmental interdependencies.

\subsection{Conceptualizing Sustainability and Sustainable Development}

Conceptualizations of sustainability and sustainable development frequently corresponded with the division, department, office, or organizations mandate. It should be noted that a significant portion of the documents in this study sample are authored by a department or division containing some environmental mandate (i.e. TRCA; Environment and Energy Division; Parks, Forestry, and Recreation) which is shown in Appendix C. The first four documents in this study sample released in 1988, 1990, 1995, and 2000, are 
primarily focused on the natural environment. These documents were prepared by the Department of Public Health, the Planning Department, and an Environmental Task Force (ETF) established by the City Managers Office, respectively. Three of these documents refer to the WCED's sustainable development as detailed above, while the State of the Environment Report: Metropolitan Toronto (1995) is presented as the groundwork for which sustainability can be assessed moving forward.

Two these documents are state of the environment (SOE) reports and contain only a few references relating to sustainability. In particular, the Department of Public Health SOE (1988) contained only two, while the Planning Department's SOE (1995) contained five. If one were to look at only frequencies of sustain-related words (i.e. sustainable, sustainability, sustaining, etc.) these two documents would score considerable low in terms of the relevance to sustainability, given that the average number of sustainrelated words in this document sample is 24.54. Despite these two documents containing few references to the word's sustainability and sustainable, their intention of benchmarking environmental conditions in the City makes them pertinent to Toronto's sustainability, and environmental sustainability in particular; a sentiment both documents express.

Toronto's Department of Public Health's Toronto: State of the Environment Report (1988) was published one year after sustainable development was introduced by the WCED. In the report's executive summary, pre-1988 development is characterized as changing the face of the City, noting specific changes such as decommissioning and redeveloping industrial sites. At the same time, the City recounts their policy interventions, such as establishing "the first municipal environmental protection agency of its type in Canada"; and the actions taken to address site- and neighbourhood-specific environmental problems, such as lead contamination in soil, waterfront clean-ups, initiation of epidemiological investigations, and agreeing to "ensure environmentally sound development in the railway lands" (p. 1). This is the context provided before the Department of Public Health espouses sustainable development as a necessity, if Toronto residents are to maintain a "reasonable standard of living" (p. 1) that is unimpeded by environmental degradation. This is proceeded by recognizing the role the environment plays in health and well-being. Finally, the reports assert its account of environmental conditions is to help them "anticipate and mitigate the environmental impacts of growth and change" (p. 3), indicating that this is some sort of requisite of sustainable development. Considering this, the policy problem appears to be somewhere between economic growth and development and the impacts these processes have on the City's environmental quality. These are the circumstances the City suggests, necessitate sustainable development. Despite "sustainable development" and "to sustain" being the only explicit acknowledgements of sustainability, the executive summary is implicit in that reporting on environmental quality and quantity is fundamental for sustainable development. 
The report details, both quantitatively and qualitatively, the state of Toronto's environment which is specified as the interconnected system(s) of land, water, and air. This is followed by detailing initiatives, programs, policies, and regulations that have been implemented for mitigating the effects of environmental degradation in the City. The Department of Public Health (1988) presents environmental conditions in the City with considerable detail; for instance, quantitative air quality measures are provided (i.e. $\mathrm{SO}_{x}, \mathrm{CO}, \mathrm{NO}_{\mathrm{x}}$, etc.), but also supplemented with qualitative descriptions relating to the basic chemistry, source of pollutants, and potential impacts they have on human health. There are also several figures, tables, graphs, and maps throughout. Some notable graphs include commercial/industrial waste generation, emissions produced from residential, industrial, vehicles and incineration, and trends in traffic entering the city. Based on the circumstances detailed before and after introducing sustainable development, including the environmental conditions covered thereafter, sustainable development appears to be conceptualized as primarily dependant on environmental health, which perhaps corresponds with the report having been authored by the City's Medical Officer of Health, Dr. A. S. Macpherson.

Two years later, the City of Toronto Planning and Development Department (1990) published Environmental Backgrounder Part I: Environmental Planning Issues and Concerns in the City of Toronto. It should be noted that despite all efforts to locate its complementary Environmental Backgrounder Part II: Analysis of Environmental Planning Policy in the City of Toronto on the City's website, TMMIS, and RULA, neither a paper or electronic copy could be located for inclusion in this research. It is likely that this document is held at the City of Toronto Archives, however based on the title results from an archival database search, this could not be confirmed. It is recognized that without considering Part II of this report series, the policy narrative will inevitably be incomplete; this should be kept in mind while interpreting any analysis pertaining to this particular document.

The Environmental Backgrounder Part I (1990) begins by detailing the scientific background of environmental problems, particularly those relating to the quality and quantity of land, water, and air. In particular, it covers the historical context of global, local, and trans-boundary environmental issues, the dichotomy of views regarding these issues and sustainable development and discusses the role of environmental planning in mediating these complex environmental policy problems. The Planning and Development Department (1990) structured this document by designating a chapter to each biophysical system component (air, water, and land) and contains two final chapters, one entitled "Sustainable Development" and the other "The Environment and Environmental Planning". Based on the Planning and Development Department being the author of this document, it is reasonable to suggest that sustainable development is largely conceptualized from an urban planning perspective; that is, after the ambiguity 
and opposing views surrounding sustainable development are covered in notably more detail than any other document in this study sample.

The Environmental Backgrounder Part I (1990) finds sustainable development to be frequently "identified with rural rather than urban areas, and with developing countries rather than developed countries" (p. 97). This is possibly because the WCED had formulated sustainable development from a global perspective to address global environmental problems that were in part, the result of a globalizing economic system. The Planning and Development Department (1990) contends that the WCED's considerable focus on rural issues in less-developed countries inadvertently suggests that sustainable development has minimal value in western industrialized cities. As mentioned earlier, the WCED specifies that present and future needs is in reference to the "essential needs of the world's poor, to which overriding priority should be given", but it should also be noted that the document is largely centered on implementing sustainable development particularly in "developing countries". Considering Canada is one of the wealthiest countries in the world, the needs of its impoverished perhaps pale in comparison to those countries experience widespread destitution. The report also adds that the WCED's conceptualization of sustainable development is closely associated with social equity issues and women's issues, but aside from the aforementioned, does not elaborate beyond these points.

The Environmental Backgrounder (1990) describes how the "spectrum of interpretation" often ranges in terms of one's stance on economic and environmental matters. Consequently, the report typifies sustainable development from an ecological/environmental, business, and planning view. In any case, the City of Toronto (1990) contends that its frequent oversimplification and trivial characterization as "environmentally sustainable economic development" is an inaccurate and inadequate interpretation of sustainable development. The report continues on to detail "the consensus definition" of sustainable development, in particular the one formulated by the WCED, and its variable interpretations when applying the concept in a western industrialized city, such as Toronto. Toronto's City's Planning and Development Department (1990) describes sustainable development as having been proposed as "a fundamental principle of decision making for all people in all walks of life in all parts of the world" (p. 97). Before going into any definitions, the report spends considerable time discussing the existence of a plethora of definitions which do more to elucidate the political position of the author defining the concept, rather than clarifying the various qualities sustainable development evokes.

Toronto's City's Planning and Development Department (1990) characterizes sustainable development as being more applicable to individual developments and approving whether they are sustainable, rather than the sustainability of city life as a whole. It also asserts that validating a development as sustainable is highly variable; but delineates it is often dependant on three "ill-defined" interpretations: (i) "if it replaces 
any damaged environmental elements"; (ii) "if it is environmentally compatible"; or (iii) "if it is environmentally self sufficient" (City of Toronto, 1990, p. 99). Although the City of Toronto (1990) makes numerous assertions about how sustainable development is interpreted, it consistently maintains that these concepts are ill-defined, arguable, or frequently up to one's interpretation. It finally concludes with a quote from Canadian population ecologist William Rees (1989) insisting that the integration of social, economic, and environmental considerations into policy and planning is only politically viable when endorsed by those the policy and planning will impact most (i.e. through government, social institutions and private activities)

Five years after Environmental Backgrounder II was published, Metro Planning issued a State of the Environment Report: Metropolitan Toronto in 1995. The SOE report coincides with The Liveable Metropolis: The Official Plan of the Municipality of Metropolitan Toronto approved by Metropolitan Council in 1994. The 1995 SOE points to the new Official Plan as setting out policy for encouraging "sustainable urban community that is environmentally, economically, and socially healthy" (p. 77). It further clarifies in the subsection on "Refining Environmental Objectives" that Official Plan describes quality of life by means of sustainable community development which specifically "fosters a healthy environment, economic vitality, and social well-being" (p. 139). It also notes that these three qualities healthy environment, economic vitality, and social well-being - are what determine a healthy urban ecosystem. However, it makes clear that these three qualities must be in equilibrium to achieve the quality of life desired by the Official Plan.

Metropolitan Toronto (1995) employs an ecosystem-based approach for assessing sustainability, indicated by its adoption of the stress-condition-response framework to conceptualize and formulate their environmental reporting. The report is then positioned as a tool where environmental issues can be detailed, and progress towards environmental goals, objectives, and targets can be evaluated. After a broader assessment of the context surrounding this assertion of sustainable community development, the preceding subsection on "Information Gaps" and the succeeding subsection entitled "A Need for Monitoring" indicate that there are some quantitative challenges to realizing sustainable community development that warrant policy intervention, although this will be discussed in Section 4.5.

Metropolitan Toronto (1995) repeatedly states that its intent is to set the basis for future environmental reporting by presenting what environmental information is available and recommends what environmental information is still required for establishing comprehensive and consistent measures. Specifically describing these measures as "consistent and scientifically valid indicators of urban sustainability" (p. 140), which will help inform reporting, establish policies, and implement controls and other actions for sustaining and reconnecting Metro Toronto's natural ecosystem. In effect, this could 
improve conceptualization of sustainable development and sustainability and aid in its operationalization. Despite sustainability-related terminology only occurring seven times in the State of the Environment Report: Metropolitan Toronto (1995), it is clear that the discourse surrounding these instances has much to offer in terms of how sustainable community development can be conceptualized, operationalized, and measured.

It should be noted that between the State of the Environment Report: Metropolitan Toronto (1995) and the Clean, Green and Healthy: A Plan for an Environmentally Sustainable Toronto (2000), the system of governance in Toronto was restructured. More specifically, the two-tier metropolitan government was amalgamated to one create a single-tier municipality, known presently as the City of Toronto. Any limitations this restructuring may have on this research can be found in the limitations Section 4.7.

Consolidating the ecosystem stresses identified by the 1995 State of the Environment Report:

Metropolitan Toronto, along with two other reports not discovered in this sample selection, Clean, Green and Healthy: A Plan for an Environmentally Sustainable Toronto (2000) presents a strategy for moving towards "an environmentally sustainable Toronto", as its name suggests. Most notably, of the forty-one documents in this study sample, the ETF plan refers to sustainability more than any other document considered in this study. Specifically, sustainability-related terms were found on 196 different occasions in the plan which is undoubtably attributed to the peak in frequency observed in 2000 as shown in Figure 7.

The Environmental Plan (2000) describes sustainability as necessitating the simultaneous consideration of economic, social, and environmental components in policy decision-making. The report suggests that "a sustainability approach will ensure that decisions and strategic directions are based on:

- actions that simultaneously enhance social, economic and environmental conditions in both the short and long-term;

- minimizing environmental stress by taking preventive and precautionary approaches;

- saving financial resources by eliminating unwise subsidies for unsustainable activities; and

- institutional cooperation and coordination" (p. 50)

Nonetheless, the ETF declares there are many unanswered questions surrounding how to institutionalize sustainability approaches and measures their progress. The ETF covers environmental issues relating to local and regional sustainability, but to a much lesser extent then previous SOE reports in this study sample. In any case, the Environmental Plan uses Toronto's earlier SOE reports as a means for identifying issues relating to sustainability, and environmental sustainability in particular. Overall, the ETF's Environmental Plan (2000) primarily focuses on visioning a "sustainable Toronto", the ways in 
which this vision can be achieved, and the steps necessary for institutionalizing a sustainability approach to ultimately achieve a sustainable Toronto.

The Environmental Plan (2000) selected four thematic areas to help move the City of Toronto toward sustainability: (1) energy use; (2) transportation; (3) economic development; and (4) education and awareness. These appear to have been selected based on their relationship to sustainability and their policy-relevance The Environmental Plan (2000) was one of few documents that stressed the importance of establishing a vision for what a future "sustainable Toronto" would encompass. More specifically, the ETF sought to develop a "Sustainability Vision", "Sustainability Goal" and a set of "Environmental Principles" to guide the City towards sustainability. These were developed during a "Vision and Priority Setting workshop" attended by 100 participants which took place two years prior to releasing the plan.

Interestingly, the Environmental Plan (2000) details what Toronto might look like as a "world leader in sustainable urban living" by 2025 (p. 15). This vision describes the movement of people and wildlife through a system of natural corridors linking the City's greenspace, ravines, waterfront, and valleys. Neighbourhoods have been carefully redeveloped for mix-use, containing all the cultural, recreational, and employment needs for its residents. Development is concurrent with transit nodes and corridors. Transportation is described as "seamless" with active (i.e. walking, in-line skating, cycling) and public transportation being the most dominant modes of transportation in the City; it also contains regionally integrated transit system. Energy is increasingly generated from renewable sources and within the City's borders. Likewise, the amount of food being generated within the City's borders is growing steadily by utilizing allotments, yards and rooftop gardens. In this vision, the City of Toronto has naturalized its rivers that were previously encased in concrete and removed all non-essential dams by 2025 . Stormwater management has been a success, largely through numerous constructed stormwater ponds and wetlands in every neighbourhood. Contaminants are nearly undetectable in Toronto aquatic biota and sediment. Air quality advisors are no longer an issue in the City. Considering this consolidated vision of sustainable urban living prescribed by the Environmental Plan (2000), it may be the most ambitious conceptualization of urban sustainability in this study sample.

The Environmental Plan (2000) also provides "Environmental Principles" to accompany its environmental sustainability vision which are detailed in terms of (i) what to do; and (ii) how to do it. While the former is comprised of protecting, preventing, reducing, and restoring; the latter includes integrating, taking responsibility, and motivating. Each of these contain several points which appear to be the environmental principles it wishes to adopt. For example, "regenerate and naturalize degraded habitats and linked greenspaces" and "remediate contaminated soils, grounder, and sediments" are listed under "Restore". Another example is "integrate environmental factors, along with social and economic ones, 
into government, business, and personal decision-making" which is listed under "Integrate" (p. 19). These "Environmental Principles" are intended to guide the City's decision-making but how these are operationalized will discussed in Section 4.5

After contending there have been many attempts to define sustainability, Toronto's Green Development Standard (TGS) (2006) appears to adopt, in part, the WCED's conceptualization of sustainable development, and presents key principles that are fundamental in applying sustainability. Many of these principles contain similar sentiments that have already been identified in other documents in this study sample which were released prior to this one, such as the integration of social, economic, and environmental principles, intergenerational equity, consideration of human and natural capital, inclusion of all stakeholders, acknowledgement that natural resources are finite, and the precautionary principle. Many acknowledge the various attempts to define sustainability and prefer to delineate principles for guiding sustainability rather than producing another definition. The issue with using sustainability principles in place of a definition or even prior to its definition is that several questions may remain unanswered, specifically: (i) what should be sustained; (ii) who it should be sustained for; and (iii) for how long it should be sustained for. In the case of sustainable development, in addition to defining what is to be sustained, what is to be developed should be outlined as well.

Two documents in particular specify the temporal aspect of sustainability and/or sustainable development (i.e. how long it should be sustained). The ETF (2000) specifies sustainability means focusing on long term horizons (such as a generation ahead)" (p. 49) and contrasts this approach with conventional policymaking that predominantly focuses on fiscal years or terms of Council. Many delineate the temporal aspect of sustainability in terms of intergenerational equity, however this notion of intergenerational includes several generations; which is more than two but could also be five or seven generations into the future; accordingly, this would make operationalization difficult to plan for.

The TRCA's Building the Living City: 10-Year Strategic Plan 2013-2022 proposes a different temporal conception called seven generation sustainability". Originating from the Iroquois Confederacy, the concept requires one to "consider the impacts of decisions made today on our descendants seven generations into the future" (TRCA, 2013, p. 26). Such a principle delineates how long it should be sustained for, whether it be development or some other activity, and whom in the future it is being sustained for (i.e. seven generations into the future). If the City of Toronto is to conceptualize sustainability and/or sustainability development moving forward, it should establish consensus regarding the length of time they are planning for as it would have implications for its operationalization. 
This research found a reoccurring theme of conceptualizing a "sustainable city" rather than "sustainability" or "sustainable development". In addition to the Environmental Plan (2000), the Climate Change, Clean Air and Sustainable Energy Action Plan: Moving from Framework to Action (2007) contends that a sustainable city does not just include a clean and healthy environment but is also characterized by "strong community engagement", "a thriving economy", and "access to opportunity for all residents" (p.1). Conversely, Toronto's Walking Strategy (2009) insists that a sustainable city involves building and developing a city that allows for walking, cycling, and public transit to be the preferred mode of transportation. It denotes a "walkable city" or one that is "pedestrian friendly" as a sustainable city (p. 5).

Toronto Public Health's Cultivating Food Connections: Toward a Healthy Sustainable Food System for Toronto (2010) conceived a "sustainable food system" which prioritizes environmental protection. Specifically, one that allows for soil and water regeneration and is comprised of locally-sourced and seasonally-relevant foods with minimal packaging and advanced waste diversion. There are also social, economic, and cultural components to this sustainable food system. It features locally accessible food (i.e. allotments, yards and rooftop gardens) that are affordable, accessible by active transport (i.e. walking, biking), culturally-relevant and diverse in nutrition. Its important to note that this conceptualization of a "sustainable food system" has been conveyed in numerous other documents in this study sample, such as the Environmental Plan (2000), The Living City® Report Card (2011), GrowTO: An Urban Agriculture Action Plan for Toronto (2012), Building The Living City ${ }^{\circledR}$ (2013), The Living City® Report Card (2016).

Through public consultation processes, specifically those initiated for TransformTO Report 1 (2016), other conceptions of sustainable have emanated, for instance the notion of "sustainable lifestyles". Residents described "sustainable lifestyles" as those which are based on a sharing economy (i.e. sharing of infrequently used items), locally-sourced food, and work flexibility such as having the option to work from home to reduce transportation emissions.

These conceptions of sustainable, such as the sustainable food system, sustainable city, and sustainable lifestyle, among many others, maintain similar characteristics to those described in the vision for a sustainable Toronto in the Environmental Plan (2000). The same can be said for conceptions of sustainable transport and sustainable energy, despite explicit references to the Environmental Plan (2000), these conceptions also resemble those delineated by the ETF. Correspondingly, these various conceptions of "sustainable" are inevitable as society moves towards sustainability and/or sustainable development. Nonetheless, attributing every goal as "sustainable" should be done cautiously as operationalization requires rigorous planning and assessment to ensure the desired policy outcome is being achieved. It 
appears that the separation and fragmentation of these conceptions, specifically by department, industry, or service, has been increasing for the last decade or two, suggesting that it may be beneficial to connect these conceptions with some larger over-encompassing plan for sustainability in Toronto, similar to the preliminary framework provided by the ETF's Environmental Plan (2000). The most comprehensive descriptions of sustainability and sustainable development would likely be the Environmental Backgrounder II (1990) and Clean, Green and Healthy: A Plan for an Environmentally Sustainable Toronto (2000). Despite this, the SOE documents are invaluable to conceptualizing sustainability and sustainable development, which was shown in both of the aforementioned documents.

Not only were conceptualizations frequently based on mandate, but they were also scale dependant. While much emphasis was placed on accounting for changes in scale, documents often had to conceptualize either concept according to the spatial scale of their mandate. For instance, the Green Development Standard (2006) was concerned with building and site sustainability, whereas the Living City Report Card (2016) was concerned with regional sustainability which corresponds with their watershed mandate. This finding may indicate a need to combine these different conceptualizations, consolidating them into an overarching framework, which would allow one to identify what spatial scales remain unaccounted for.

\subsubsection{City Council Strategic Plans}

Toronto City Council's Strategic Plan (2002) appears to use sustainability in a more rhetorical sense, indicated by vision statements such as "Toronto is a clean, green, and sustainable City". Given that the Strategic Plan (2002) is intended to be a higher-level framework for City Council, such rhetorical uses may be expected. Sustainability is designated as a guiding principle whereby "[City Council] integrate[s] environmental, social, economic and fiscal perspectives into [their] actions” (p. 2). The Strategic Plan's (2002) thematic goals (social equity and inclusion, economic vitality, environmental sustainability, good governance and city building) are described as being reflective of "the scope and breadth of a sustainability framework" (p. 9) and indicative of a sustainable community outcome. The Strategic Plan makes numerous references to City Council's vision and goal of a "sustainable city". The Strategic Plan's (2002) explains that because its role is to improve social, economic, and environmental conditions in the City of Toronto, the concept of sustainability has been adopted as a guiding principle in this regard.

City Council's Strategic Plan (2002) does not elaborate on how sustainability is defined, conceptualized or operationalized as a guiding principle, at least beyond its delineation that it involves integrating social, economic, and environmental considerations into the actions of City Council. This could be for two reasons, one of which has already been mentioned and that has to do with this document being a highlevel strategic plan. Detailing the specifications in this regard may not be appropriate or warranted. The other reason may be that the Environmental Plan (2000) released two years prior, goes into considerable 
detail on how to operationalize sustainability in City Council's decision-making and specifically how to achieve the integration of social, economic, and environmental components into decision-making processes. At the time, the sustainability framework proposed by the ETF (2000) would have been in effect considering it had been adopted by City Council in 1999.

In the Strategic Plan's (2002) description of environmental sustainability as one of five thematic goals, similar sentiments are reiterated, for instance, environmental sustainability is delineated as "encompass[ing] principles of environmental balance and the integration of environmental considerations in our social and economic activities" (p. 3). Sustainability is also regarded in City Council's theme of "Good Governance" where they have listed "Organizational Sustainability" as being one of its goals. Organizational sustainability is described as having the necessary "legislative authority, financial tools and organizational structures and processes to undertake its responsibilities and achieve its goals... (p. 7). This proposition in particular reflects some of the decision-making challenges identified by the Environmental Plan (2000) two years earlier.

Sustainability in the context of fiscal or financial sustainability, however, is provided with much less ambiguity and presented as more of a policy challenge than a policy principle. It also accounts for almost half the references to sustainability in the Strategic Plan (2002). Sustainability, in this case, is applied in the most basic sense of being able to maintain something over a period of time, specifically City programs and infrastructure. It further specifies that maintenance of these programs and infrastructure is needed "without increasing debt or running down physical and financial assets" (p. 22). The City closes by emphasizing that adequate funding and appropriate use of funding continue to be a challenge in sustaining city operations and services.

In the City of Toronto's subsequent Strategic Plan released a decade later in 2013, environmental sustainability remains one of their "strategic themes" and is delineated with a proposition identical to the one provided in City Council's Strategic Plan's in 2002. Both Strategic Plans further specify that the theme or goal of environmental sustainability as including "environmental awareness", "environmental sustainability" and "environmental health". Environmental awareness refers to "awareness of environmental impacts results in active public participation in environmental improvements" (p. 6). Environmental sustainability is described in terms of "human activities and consumption are balanced with the environment's ability to absorb emissions and impacts" (p. 6). Lastly, environmental health is regarding "the health of residents is protected from environmental risks" (p. 6). An important question associated with this finding is whether the City of Toronto's vision, objectives, or strategic goals for environmental sustainability been revisited or evolved between 2002 and 2013 because according to this finding, it appears they have remained unchanged for the last decade. 


\subsection{Operationalizing Sustainability and Sustainable Development}

Operationalizing sustainability and sustainable development can be equally as obscure as the distinction between defining and conceptualizing. The operationalization of sustainable development is often conveyed in terms of the principles or values it engenders, processes it requires, specific activities it would include, policies it necessitates, and the information management and communication it involves. Some may consider the process of defining and conceptualizing as operationalization (i.e. operational definitions) because definitions and conceptual ideas are foundational in operationalization. For the purposes of this study however, operationalization refers more to the process of implementation or "putting it into practice", specifically how the definitions or conceptual frameworks of sustainability and sustainable development are put into practice in policy or decision-making.

The Department of Public Health's Toronto: State of the Environment Report (1988) and the Planning Departments State of the Environment Report: Metropolitan Toronto (1995) both suggest sustainability and sustainable development can't be operational without accounting for and improving our knowledge of environmental conditions, but specifically the quality and quantity of water, land, air, and living organisms, in Toronto and its surrounding area. Similar sentiments are still conveyed nearly thirty years later, specifically in the TRCA's The Living City® report cards released in 2011 and 2016. In any case, the lack of consistent, systematic, and coordinated data collection was frequently expressed as an institutional barrier in the operationalizing of sustainable development. In addition to the TRCA, operational issues emanating from inadequate environmental data are conveyed in the Environmental Plan (2000), Change is in the Air: Climate Change, Clean Air and Sustainable Energy Action Plan (2007), Ahead of the Storm: Preparing Toronto for Climate Change (2008), Parks Plan (2013), Every Tree Counts: A Portrait of Toronto's Urban Forest (2013), TransformTO: Climate Action for a Healthy Equitable, and Prosperous Toronto - Report \#1 (2016), for example. Most, if not all of these documents identify funding as being one of the most fundamental constraints to consistent, systematic, and coordinated data collection related to sustainability and sustainable development, and in particular environmental sustainability.

The City of Toronto (1990) doesn't discuss operationalization directly but does provide examples of activities that operationalize the concept of sustainable development, specifically from an environmental/ecological view. Some of these include continually accounting for and utilizing the entire life cycle of a product and the constant use of reliable sources of energy, however it doesn't specify what "reliable sources of energy" (p. 100) entails. The City of Toronto (1990) concludes with a quote from Canadian population ecologist William Rees (1989) who insists that operationalizing social, economic, 
and environmental considerations into policy and planning is only politically viable when it is endorsed by those it will impact most (i.e. through government, social institutions and private activities).

The ETFs Environmental Plan (2000) in particular, contains what might be the most comprehensive and elaborate plan for operationalizing sustainability in municipal decision-making than any other document in this study sample. Some of the broader recommendations for operationalization include education and outreach (i.e. formal integration of environmental sustainability in Ontario's curriculum), the establishment of policy working groups to share information and expertise (i.e. Education and Awareness Work Group, Green Economy Work Group, Energy Policy Working Group), private and public partnerships and sector-based sustainability programs (i.e. Better Buildings Partnerships, Industrial Energy Efficiency Program) (City of Toronto, 2000)

Of particular interest is Toronto's framework for governance and decision-making which the ETF characterizes as lacking "mechanisms or structures [necessary to] force the consideration of environmental, economic, and social aspects of issues together". Accordingly, environmental issues are frequently considered independently of social and economic ones (City of Toronto, 2000). Despite having acknowledged this barrier to operationalizing sustainability over 18 years ago, the integration of social, economic, and environment considerations remains the most common sustainability proposition in this study sample. However, only one other document hints to this as an issue, specifically the TRCA's The Living City ${ }^{\circledR}$ Report Card (2016) expresses the need to overcome conventional jurisdictional constraints to allow for non-traditional policy actors to be involved, such as non-governmental organizations and local business, among others. Accordingly, limitations of governance in implementing sustainability are apparent; accordingly, the ETF proposes a tentative governance framework which it specifically designed from an integrative sustainability approach.

The framework establishes several new positions for promoting, facilitating, and supporting sustainability in municipal decision making. It recommends the Chief Administrative Office be given the title of "Sustainability Lead" and appoint the position of "Sustainability Director", each position having distinct responsibilities for promoting, facilitating, and supporting sustainability in municipal decision making. It also suggests that a member of City Council be appointed the position of "Sustainability Advocate". The ETF propose the establishment of a "high-level Sustainability Roundtable" that includes representatives from all stakeholder areas, such as City Council Standing Committees, senior staff from municipal departments and divisions, representatives from the TRCA and the Board of Public Health, civic and public employee unions. These stakeholders should constitute only 50 per cent of the Sustainability Roundtable, the remainder comprises of community organizations "representing the environmental, social, and economic development communities" (p. 86). Lastly, the ETF advises that the City of Toronto 
create an "Environmental Auditor" to carry out duties such as producing annual reports, investigating the City's response to public complaints about their actions which contribute to environmental degradation, and develop audit methodologies which can be shared with provincial and federal counterparts. To ensure the sustainability decision-making interests of Toronto are represented in other levels of government, which the ETF regards as essential considering ecological systems don't conform to geopolitical boundaries, it recommends an "Inter-Governmental Environmental Advocate" be appointed from City Council.

The ETF contends that if the City of Toronto is to meet their goals, objectives, and targets in any circumstance, they must measure and report on their progress. Accordingly, the same is necessary for city's progress on integrating sustainability into decision-making. The report then continues to present a preliminary set of sustainability indicators but stresses that indicator development is an ongoing process as it should incorporate other stakeholders identified throughout the ETFs plan. In the final section on "Next Steps and Implementation", the ETF recognizes that its plan to move towards a "sustainable Toronto" is largely contingent on receiving adequate human and financial resources for its implementation. The Environmental Plan (2000) is ambitious considering the amount of human and financial resources it would necessitate for operationalization. Nonetheless, the ETF's Environmental Plan (2000) represents what may the earliest and largest contribution acknowledging what is required for operationalize sustainability in municipal decision-making. The ETFs sustainability framework was adopted by City Council on December 14th, 1999. As mentioned earlier, the Toronto's Sustainability Roundtable took over the ETFs mandate, although it was transferred to the Mayor's Roundtable on the Environment in 2003 and then not renewed for the 2007-2010 term of council. This perhaps represents decision-making that is largely based on terms of council rather than the longer-term.

For instance, the TGS (2006) consulted stakeholders regarding green building development and reported that the inclusion of LEED in the Toronto standard posed some implementation challenges, specifically noting that third-party verification can be expensive. Some developers also identified LEED as not locally oriented and favouring certain types of development (i.e. commercial development) (City of Toronto, 2006). Consequently, the Parks and Recreation Facilities Master Plan (2017) acknowledges that environmentally sustainable building methods can have higher initial costs but assert these methods have longer lasting returns as a result of operational savings. Similarly, Toronto's Strategic Forest Management Plan (2013) emphasizes that the effective maintenance, protection, planning and expansion of Toronto's urban forest cannot be achieved to its full potential without sufficient funding for "pest management, proactive maintenance, [and] natural area management” (p. 55). 
Some other documents reporting financial barriers to operationalizing sustainable solutions, include the TRCA (2011) who stressed the need for cooperative investment from all levels of government to fully implement a regional transportation system that would ensure the long-term sustainability of Toronto and its greater region. Moreover, the Long-Term Waste Strategy (2015) emphasizes the need for a sustainable funding model that will help maintain the current municipal waste management system while also developing new, presumably more sustainable projects. Similarly, Parks, Forestry and Recreation (2017) requires millions in investment to implement its Parks and Recreation Facilities Master Plan which identifies a maintenance backlog and expansion of current facilities as being its top priorities. The City of Toronto (2017) has also expressed that it tried to operationalize new waste diversion programs but cannot locate a financially viable and sustainable market for the diversion of certain materials such as shingles. Clearly, one of the largest barriers to operationalizing sustainability and/or sustainable development is securing funding. When the City is experiencing financial constraint delivering basic programs and services, often policy interventions relating to sustainability and/or sustainable seem more of a luxury than a necessity.

Another issue corresponding to financial limitations are human resource constraints, which depend on adequate financial resources to hire the necessary staff. For instance, Parks, Forestry and Recreation (2004) identifies the "need to reduce the forestry service order backlog to three to six months to properly sustain the existing trees in streets and parks (p. 35). Nearly a decade later, Parks, Forestry and Recreation (2013) contends that they have been trying to establish a more proactive forestry service since 2009, however since the "[human and financial] resources needed to implement such a program on a city-wide basis are currently not available", they are limited to largely reactive maintenance of Toronto's urban forest.

Similar to the jurisdictional constraints identified earlier, there are also constraints related to ownership, which can be especially challenging in urban areas. For instance, more than half of the City's urban forest is located on private property which makes operationalization of urban forest sustainability more challenging, especially when it comes to expanding current canopy cover, and thus can only be operationalized with the collective help of private land owners (City of Toronto, 2013c).

Despite the absence of a comprehensive sustainability or sustainable development framework for municipal governance, decision-making, knowledge mobilization, and the overall centralization of goals and initiatives, the City of Toronto has still made some notable progress implementation its conceptions of sustainability. In 2005, the TRCA initiated the Sustainable Technologies Evaluation Program (STEP) to support the uptake of "sustainable technologies and practices within a Canada context" by assessing where there are opportunities and/or barriers to the operationalization of sustainable technologies (TRCA, 
2013, p. 46). As mentioned earlier, during the development stages of the TGS (2006) the City of Toronto consulted stakeholders to determine what qualities are characteristics of a good building standard.

Developers expressed the need for graduated levels of attainment to ensure those who have less means to implement the standard aren't discouraged from implementation entirely. While the TGS (2006) initially started out as voluntary, it has since been operationalized into two tiers, Tier 1 being mandatory and Tier 2 being voluntary.

In 2007, the City of Toronto made a commitment to implement a pilot program for residential solar hot water heating and prepare several regulations regarding renewable energy generation. While in 2009 the City implemented the Queensway Sustainable Sidewalk Study where they piloted tree irrigation using filtered storm water (City of Toronto, 2013c), Moreover, despite some of the barriers Parks, Forestry and Recreation (2013) has encountered, they have still implemented numerous restoration and tree planning programs such as the Tree Seed Diversity Project and The Parkland Naturalization Program, among others. The Toronto Environmental Progress Report (2015) asserts that policies contained in the Official Plan have been contributing to greenhouse gas reductions "by ensuring compact, sustainable development, sustainable transportation, and protection of natural heritage and greenspace" (p. 7).

In many ways, the City, its agencies, and other stakeholders, have made considerable effort to preserve and restore natural heritage in Toronto and its regional area, and operationalize sustainability and sustainable development. However, there remains a need for concerted efforts to assure sustainability, sustainable development, and more specifically, environmental sustainability, are integrated into all decision-making of City Council.

The TRCA (2016) is one of few that acknowledge the ambitious objectives of plans and policies, perhaps similar to those outlined in the Environmental Plan (2000), as being difficult to put into practice. As identified in the operationalization of sustainability and sustainable development policy, this is likely due to a variety of reasons, but especially jurisdictional, financial, and otherwise human and knowledge resource-related constraints. The TRCA (2016) emphasizes that challenges in operationalizing sustainable development moving forward are substantial, in part, due to the way in which initiatives and investments are being tracked. Whether and how government initiatives and investments are influencing and working in terms of sustainability practices, processes, and outcomes, needs to be tracked and accounted for (TRCA, 2016). Since the TRCA (2016) proposes developing a tracking mechanism for sustainability, perhaps the City of Toronto should coordinate an initiative where the results for the City of Toronto can be compared with the larger GTA.

Arguably, most if not all the definitions of sustainability and/or sustainable development in this study sample, especially the ones regarding the WCED, are likely too broad and unspecific to fundamentally 
operationalize throughout all municipal decision-making. Conceptualizations where principles were identified in particular, provided considerably more details suggesting their operationalization might be more attainable. For instance, the TRCA acknowledges sustainable development as defined by the WCED but provides a conceptual framework for regional sustainability that corresponds with their current operational mandate and which is emphasized as a work-in-progress that will expand with improved monitoring, tracking, and private and public partnerships.

It is clear that the City of Toronto understands, at least for the most part, what changes are considered sustainable solutions, similar to those the City envisioned in the early 2000s. For instance, the City of Toronto formulated Green Streets Technical Guidelines in 2017 to ensure green infrastructure is incorporated in the development of Toronto's streets. Green infrastructure, sometimes referred to as bluegreen infrastructure, denotes a man-made landscape that developed more congruently with ecological processes. Specifically, it is design and development techniques that mitigates the impact of urban development on ecological and hydrological functions. For instance, permeable pavement, constructed wetlands, green roofs and green walls help to restore natural water cycles and improve water quality through the attenuation and infiltration of stormwater runoff (City of Toronto, 2017). Connecting greenspace through linking natural corridors allows for ecological succession and the safe passage of wildlife and has many human benefits by providing shade, greenspace, parks, trails, aesthetic pleasure, and has social and psychological benefits as well. The objective of Toronto Complete Streets Guidelines (2017) is to improve street connectivity for pedestrians and cyclists of all ages, while also providing greenspace and landscaping opportunities, and improving access to neighbourhood destinations. Lastly, as part of TransformTO (2017), Toronto's climate action strategy, the City is currently considering ways to establish low-carbon thermal energy networks using technologies such as sewer heat recovery, waste heat recovery, solar thermal collectors, and biogas utilization. Some examples that indicate the 
operationalization the ETF's vision for a sustainable Toronto in other municipal documents are summarized in Figure 11.

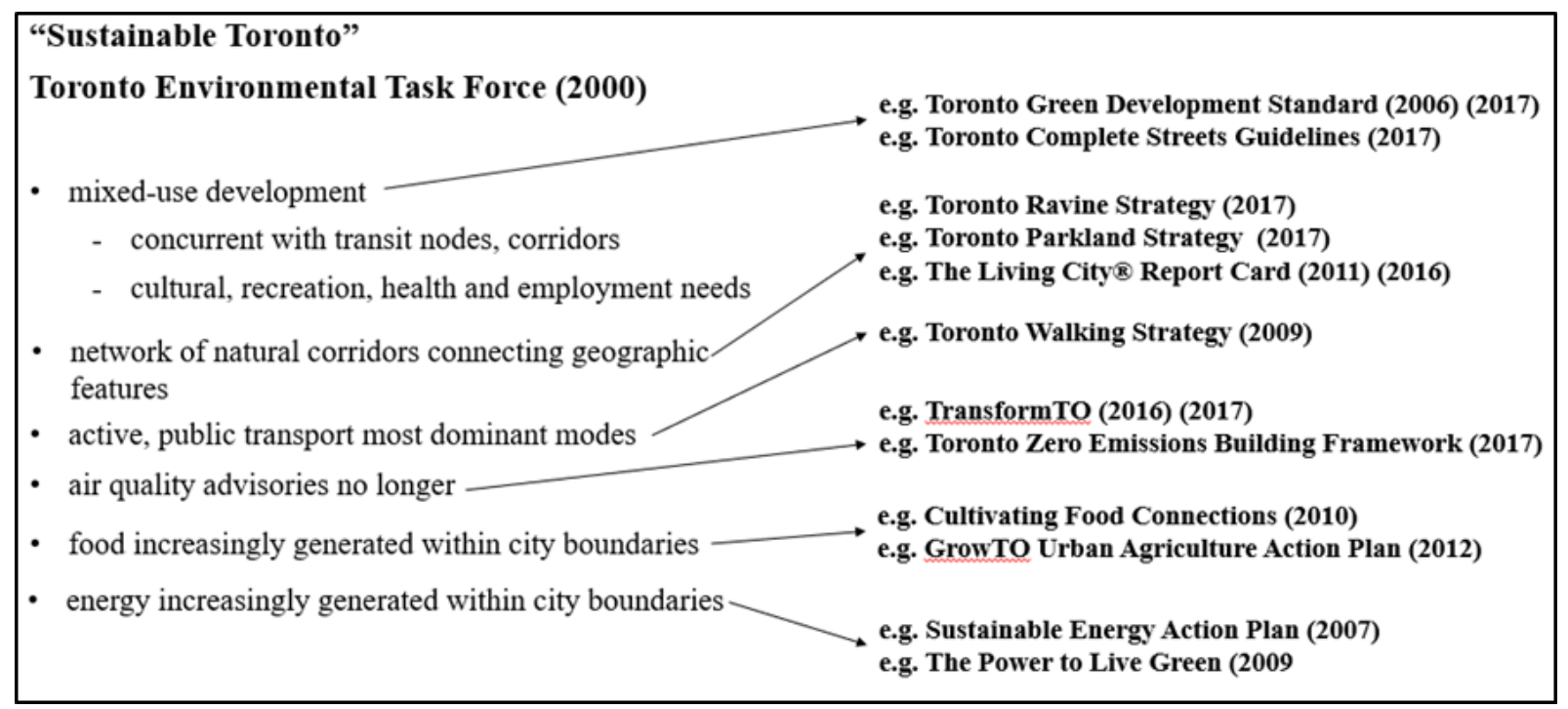

Figure 11. Example of documents that operationalize vision of "Sustainable Toronto 2020" described by the Environmental Task Force (2000).

Efforts to operationalize sustainable development are likely disproportionate across the City considering investment in these developments is often based on priority, sometimes referred to as "priority investment areas". While the City of Toronto is rather transparent in how these areas are selected (i.e. Toronto Ravine Strategy; Toronto Strong Neighbourhoods Strategy 2020), the formulation of selection criteria perhaps warrants public consultation. For instance, how are the needs of Toronto's most impoverished neighbourhoods taken into consideration during this prioritization? The City of Toronto already designates priority neighbourhoods based on its Neighbourhood Equity Index (NEI), but how are these neighbourhoods considered when prioritizing ravine restoration, green streets, and climate change mitigation, and other City initiatives alike.

Some consider measuring sustainability and sustainable development the process of making it operational. Certainly, measuring sustainability or sustainable development is part of its operationalization, however it is reasonable to suggest that measurement can only be operationalization when the data and method of assessment is consistent and sufficient for evidence-based policy changes. Nevertheless, evaluating and determining whether these policies, programs, and services are effectively sustainable will depend on the quality of the data and criteria they are measured against; perhaps this can act as the evidence base for which arguments can be made to keep the most effective and sustainable polices for longer than one or two council terms. 


\subsubsection{The Challenges of Scale}

One of the several reoccurring themes that were prevalent in this study sample was the condition of spatial scale. For instance, the TGS (2006) specifies its primary focus for sustainable development is at the building, site and neighbourhood scale. In contrast, Toronto Public Health's Cultivating Food Connections: Toward a Healthy and Sustainable Food System for Toronto and GrowTO Urban Agriculture Action Plan, released in 2010 and 2012 respectively, primarily focus on food sustainability at the neighbourhood scale, community scale, and to a lesser-extent, regional scale. Alternatively, the TRCA predominantly focuses on sustainability at the watershed scale, although it does operate several initiatives at the community and neighbourhood scale as well.

Notably, few documents addressed the conceptualization and operationalization of sustainability and sustainable development at the individual level. At the individual level, participants from TransformTO public consultations identified education, training, and incentives as some of the supports needed to help residents operationalize a sustainable lifestyle (City of Toronto, 2016). Nonetheless, the Environmental Plan (2000) does cover many ways to address sustainability at the individual level, such as incorporating environmental sustainability into the Ontario curriculum, and implementing widespread public education and outreach programs.

The TRCA often emphasizes issues of scale as it operates at several different levels. In particular, the TRCA (2013) noted that sustainability challenges are also challenges of scale, especially since sustainability issues are seldomly confined to jurisdictional boundaries, a single level of government, department, or agency, and often necessitates stakeholder engagement at different scales (i.e. community, neighbourhood, city, watershed). Accordingly, policy interventions that operationalize sustainable development at one spatial scale, may not have the same implications at another scale.The TRCA (2016) specifically identified "keep[ing] social and economic development within limits that the planet can sustain" as a major policy challenge. Subsequently asserting that after much examination of this problem at international and local levels, the regional scale appears to be the most appropriate for policy intervention.

On the other hand, the Toronto Strong Neighbourhoods Strategy (TSNS) (2014) expressed a need to change public policy to improve the planning and delivery of municipal services at the neighbourhood level and allow for more comprehensive assessment of policy consequences and outcomes at this scale. While designating spatial boundaries is necessary for organizing governance and operationalization of policy, there appears to be a need for greater consideration and collaboration across spatial scales when conceptualizing, operationalizing, and measuring sustainability and sustainable development in Toronto and its greater region. Especially considering each of these documents identified issues of 
operationalizing policy from a variety of different scales, such as building and site-specific, to community, neighbourhood, city, region and watershed scales.

Consider evaluating whether an action, process, or thing is sustainable without knowledge of the spatial area in which the action, process, or thing exists or is carried out. Even if we were to adopt the most basic definition of sustainability, being "able to be maintained at a certain rate or level", whether something can be maintained at a certain rate or level would depend on the amount of available space, among other spatial resource-dependent conditions. Spatial scale has remained at the forefront of scholar research on sustainability and sustainable development because of the implications it has for defining, conceptualizing, operationalizing, and measuring sustainability. For this reason, urban sustainability and sustainable development in general, is regarded as a spatially-explicit phenomena (Brelsford et al., 2017; Giddings et al., 2002; Huang et al., 2015).

\subsection{Conclusions}

This research corroborated what is already known regarding the practicality of word counts in mixed method research which questions the methodological rigour and quality of inferences they produce (Carney, 1972). This research found that the frequency of sustainability and/or sustainable development in municipal documents was not necessarily indicative of a document's relevance to either concept, nor did it convey any information regarding the context or use of these concepts, aside from the themes indicated from word cooccurrences. There is no optimal number for how frequent sustainability or sustainable should be used before it starts to lose meaning and act more as rhetorical device rather than some guiding principle. The discovery that fifty per cent of the time the City referred to some variant of sustainability was to attribute someone or something as sustainable could be concerning; however, further research is warranted to determine whether these references are regarding currently sustainable or prospectively sustainable.

The policy narrative analysis contained in this study uncovered several themes in the way sustainability and sustainable development is defined, conceptualized, and operationalized by the City of Toronto. It seems predominantly environment and development focused, however this finding is relative to the documents included in this study sample. This research found that despite poorly defined conceptions of sustainability and sustainable development, the application of these concepts seem partially understood, at least according to City's plans for mitigating the impacts of urban development on local ecological and hydrological process. When sustainability and/or sustainable development was recognized but not defined, it was found to be frequently described as integrating social, economic, and environmental considerations into the decision-making of the City and its agencies. While the interdependencies of social, economic, and environmental components of urban society are considered in some instances, 
especially in more recent documents such as, the Toronto Complete Streets Guidelines (2017) in particular, few actually provided examples of these interdependencies in a Toronto context. Regarding the temporal aspect of sustainability and sustainable development, only two documents propose ideas for how long sustainability should be planned for. Nonetheless, there are unsurmountable number of processes, programs, facilities and initiatives the City has identified as needing to be sustained, from economic development, start-up businesses, ecological and hydrological processes, to capital investments, public facilities and programs, among many others.

Lastly, the most unanswered questions pertain to the operationalization and measurement of sustainability and sustainable development in the City. Despite the City providing many examples of how its putting sustainable development into practice, discussions surrounding broader integration in municipal decisionmaking were considerably less absent in the last decade of this study sample. Furthermore, it appears the City of Toronto doesn't have any plans for measuring the policy consequences or outcomes of their initiatives in terms of their effectiveness towards sustainability and more specifically in terms of the social, economic, and environmental interdependencies they might impact.

Ultimately, this analysis found that coding textual data according to lexical morphology could only partially elucidate the ways in which these concepts were used, but still required more information to accurately account for the surrounding contextual discourse. Nonetheless, this approach could still be useful as a starting point for extracting discourse out of a large study sample while still maintain some functional linguistic structure.

\subsection{Limitations}

Certainly, there were many unavoidable limitations to this research, but one that is particularly confounding is the search strategy and sample selection. The challenges of sample selection pertaining to government documents, specifically at the municipal level were significant. The difficulties in locating some of the municipal documents contained in this study sample indicate that they are not easily accessible to the public despite being publicly available, while others were only discovered through RULA and/or available in paper format. The City of Toronto website appears to archive, either in the City of Toronto Archives or Toronto Public Library, all reports, strategies, and guidelines that are not pertinent to the incumbent governments work. The way in which these documents were stored by the City appeared fragmented and inconsistent, and ultimately prevented the systematic retrieval of earlier (pre-2009) municipal documents. In many ways this exemplified one of the many barriers to evidence-based policy making which necessitates a greater collaboration between scientists and policy makers. Clearly knowledge brokerage needs improvement if the work of academic communities is to benefit policy makers and for the effective collaboration among these two communities (Choi et al., 2005). 
Since purposive sampling was used to capture as many relevant documents as possible to cover the timespan under consideration, selection bias was inadvertently introduced into this study. Furthermore, with the sampling process used, it is highly likely that all records produced by the municipal government between 1988 and 2018 would not have an equal chance of being selected (i.e. non-random sampling). Therefore, the sample included in this study is not representative of all documents (reports, strategies, guidelines, plans) produced by municipal government from 1980-2018. With that said, it is recognized that some years may be overrepresented while others may be underrepresented.

Moreover, public administration is neither static over time or space. During the period of time being consideration in this study, Toronto's governance system was restructured, resulting in geographical and functional changes to city's public administration. Municipal governance in Canada is primarily determined by the provincial government, in this case, the Government of Ontario. Any changes to Toronto's municipal governance could change the delivery of public services such as recreation, infrastructure, zoning, and land-use planning, among other services. From 1954 to 1997, the Municipality of Metropolitan Toronto functioned as a two-tier metropolitan government (Sancton, 2005). By 1998 the Municipality of Metropolitan Toronto was required to amalgamate its constituent parts of Etobicoke, York, North York, East York, Old Toronto, and Scarborough, to create a single-tier municipality, known presently as the City of Toronto. Evidently, this changed Toronto's administrative and political boundaries. It is probable that municipal reporting requirements changed as well, perhaps in terms of the contents and geographical area the reports encompass. For consistency, this study wanted to ensure that sample documents pertained to the same spatial scale over time. The documents included in this sample that were published prior to amalgamation (pre-1998) were examined to ensure they were reporting on the same geographical area as present-day City of Toronto. Fortunately, these documents were produced by Metropolitan Toronto and their reporting encompassed the peripheral municipalities and thus is consistent with the spatial boundaries of present-day City of Toronto. Municipal reports, strategies, and other records pertaining to the governance of individual municipalities (Etobicoke, York, North York, East York, Old Toronto, and Scarborough), now constituents of the City of Toronto were consolidated and housed by the City of Toronto Archives (City of Toronto, n.d.).

As mentioned earlier, the City of Toronto's amalgamation made including Official Plan's in this document sample challenging, particularly because the study covers both pre- and post-amalgamation years. If this study were to include the City of Toronto's Official Plans between 1988-2018, it would encompass the Official Plan's of seven municipalities which no longer exist since the City amalgamated in 1998. Since land-use planning is a fundamental process to sustainable urban development (Dale \& Pierce, 1999; Hanna \& Slocombe, 2012), Toronto's Official Plan would have been a valuable resource in 
this study. It is possible that the Official Plan could have answered some of the uncertainties surrounding the conceptualization and operationalization described in Sections 4.3 to 4.5.

Also, it might be valuable to note that as a provincially-mandated document, Toronto's Official Plan must be consistent with the provincial policy statement and must not conflict, but conform with provincial plans (Ontario Planning Act, R.S.O. 1990, c. P.13, s. 26). With this in mind, the Official Plan may also be beneficial in clarifying the roles and responsibilities related to multi-level governance in Toronto, in which opportunities and barriers to operationalizing sustainable urban development could have been identified.

\section{CONCLUSIONS \& RECOMMENDATIONS FOR FUTURE RESEARCH}

This thesis covered the theoretical and conceptual history of sustainability and sustainable development in scholarly research, discussed the issues of ambiguity and contradicting interpretations, but ultimately found several challenges that remain consistent across these various interpretations. These challenges predominantly relate to temporal and spatial scales, limited understanding of social, economic, and environmental interdependencies, insufficient data regarding ecological conditions but perhaps social as well, constraints related to the integration of sustainable development into policy making processes, and challenges regarding collaboration, information sharing, and reporting.

The primary objective of this research was to investigate the way in which sustainability and sustainable development has been defined, conceptualized, and operationalized by the City of Toronto over the past 30 years. Sustainable development was first introduced in SOE reports as a means for reconciling economic growth and environmental degradation. By 2000, the City of Toronto began to use sustainability and sustainable development interchangeably and formulated a sustainability approach to operationalize in municipal decision-making. The City of Toronto continued to assert its sustainability approach its Strategic Plans throughout the following decade, however the initial approach as delineated in the Environmental Plan (2000), does not appear to have been revisited since its initial formulation. Nonetheless, various departments and agencies have continued to conceptualize other notions of sustainability such as sustainable lifestyles, sustainable city, sustainable transportation, sustainable energy, and sustainable partnerships, among many others. Although the City of Toronto provided broad and rather unspecific definitions of sustainability and sustainable development, it has continued efforts to operationalize throughout its agencies, and departmental plans and polices, as shown in Figure 11. Operationalization appeared in many forms depending on whether sustainability or sustainable development was being operationalized in environmental planning or accounting, municipal policy, Council or departmental decision-making processes, delivery of programs and services, building and site 
development, municipal policy, or regional, city, or environmental planning. While operationalization differs in each context, there were some consistent barriers to implementing sustainability and sustainable development.

One of the most dominant barriers to operationalizing sustainable development and sustainability in the City of Toronto relates to the fragmentation of environmental responsibility, data and information, across the City of Toronto and its greater region. This perhaps indicates an issue relating to collaboration and communication across multiple jurisdictions and scales, which remains difficult due to departmentspecific mandates, jurisdictional constraints and disparate governance and legal responsibilities.

The absence of SOE reports in the last two decades of this sample, potentially indicate that environmental information was more transparently communicated between 1988-2000. The TRCA appears to have taken on the role of SOE reporting, with considerable transparency, however as previously mentioned, the TRCA's jurisdiction encompasses a land area five times larger than the City of Toronto, managing 9 watersheds, including Toronto Islands and part of Lake Ontario's shoreline, and requires coordination with six different municipalities (TRCA, n.d). Arguably, relying on the TRCA to report on Toronto's environment, which is the most human-disturbed landscape in its jurisdiction, will inevitably have some consequences. Despite this, the TRCA remains to be the most valuable resource the City of Toronto has when it comes to environmental reporting.

Undoubtably, the City of Toronto has made considerable progress regarding sustainable development, however this was rather difficult to uncover using the linguistic methods employed in this study, especially when the City prefers using green development to refer to development that environmentally sustainable, among other interchangeable concepts. This research study spent considerable time discussing the importance of definitions but also their limitations. Consequently, there is no universal definition for sustainability or sustainable development nor should one exist, however ambiguity needs to be clarified. Such circumstance, however, shouldn't render these concepts inoperative or impractical, especially considering most words have more than one definition, some more ambiguous than others. Simply explaining how the terminology is being used, the context of its specific application, and perhaps delineating where begins and ends would likely suffice. Where a definition is borrowed, adapted, builtupon or otherwise used, it should be referenced accordingly. Research on sustainability and sustainable development has been ongoing for almost four decades since it was first introduced in 1980. It is important for governments, in particular municipal, provincial, and federal governments to have access to the most current research and be able to communicate, consult, and refer to the academic community as needed. 


\subsection{Information Management and Institutional Knowledge}

Since sustainable development and sustainability are forward-looking, there seems to be a tendency to over-emphasize the future aspects of these concepts. However, the knowledge and information required for sustainability and sustainable development must be retrospective, current, and prospective. Retrospective to ensure past decision-making is informing current improvements and changes. Information must be current because tracking and timely dissemination allows one to respond to unanticipated policy consequences in which changes can be made accordingly (Brandon \& Lombardi, 2011). Lastly, knowledge and information must be prospective, meaning institutions need to continue recognizing existing barriers to sustainability and sustainable development and identifying what processes, systems, or information they require to ensure evidence-based decisions are supporting sustainable development.

There were several examples in this study that indicate the City of Toronto may lack the institutional knowledge necessary for sustainable development. For instance, the Environmental Progress Report (2015) provides a list of plans, strategies, and policies relevant to Toronto's environmental progress, however the list of documents only begins in 2007 with the Environment \& Energy Division's Change is in the Air: Climate Change, Clean Air and Sustainable Energy Action Plan. Meanwhile, it omits the Environmental Task Force's Environmental Plan (2000). Since the list only includes plans, strategies, and policies, SOE reports from 1988 and 1995 were not included and neither was the Environmental Backgrounder II (1990). However, as the City of Toronto's only division exclusively dedicated to the environment, acknowledging, at least, the existence of these documents remains paramount as they have much information to offer in terms of the City of Toronto's environmental progress and environmental sustainability. The table included in Appendix B indicates that the first three documents in this study sample, specifically, the 1988 SOE report, 1990 Environmental Backgrounder II, and the 1995 SOE report have not been acknowledged in any other municipal document in this study sample since 2000. Similarly, the existence of the Environmental Plan (2000) also hasn't been acknowledged since 2006. There could be a variety of reasons for this, but there is little value in speculating. Certainly, the amalgamation of seven municipalities into one is going to be a major factor, especially since the first three documents were produced prior to amalgamation. Nonetheless, it has been twenty years since, and these documents have not yet been digitized.

The accessibility of information, especially information regarding the conditions of society, whether it be social, economic or environmental, past or current, should be readily accessible to citizens (Dale \& Pierce, 1999) for sustainable development to be operationalized in the City of Toronto. The City of Toronto needs to consider reflecting the works of earlier municipal governments in its current documents 
to ensure that institutional knowledge is carried forward. If the City of Toronto is truly progressing forward, there should be no reason not to carry this information forward, even if it is done using a footnote or appendix. On the other hand, if information is communicated less transparently today then thirty years ago, then it might explain why the first four documents are absent in the years that follow.

It is recommended that the City of Toronto reconsider its information management and retrieval processes to ensure its vast amount of resources (i.e. reports, data, maps, etc.) are consolidated into one database to assure efficient retrieval of information to inform municipal decision-making. Effective public policy decision-making is contingent on the quality of the information available for use (Innes, 1990). The currency of information is also fundamental to sustainable development considering the various actors involved, and the collaboration and coordination it requires. The apparent human and financial constraints expressed by City of Toronto departments and divisions is apparent in the currency of the municipal documents in this study sample. For instance, when this study sample was selected in January 2018, the most recent Environmental Progress Report from the Environment \& Energy Division was for 2015. Consequently, the Environmental Progress Report 2016 was released in September 2018, nearly two years after its reporting year. There was also a two-year lag in publishing the Performance Measurement and Benchmarking Report (2014) and likely others as well.

Humans, like any other organism, are only able to adapt and change in response to the information they obtain (Innes, \& Booher, 1999). This same principle applies in the dissemination of public information such as reports, policies, etc. When there is a two-year time lag in the dissemination of information, adaption and change can be expected to lag accordingly. If the City of Toronto is going to collaborate with universities, other levels of government, community organizations, and the private sector, to help operationalize sustainable development, it must ensure the information it collects and produces is conveyed in a timely manner, and especially if they are to respond to any unintended policy consequences. There may also be strengths in public discussions surrounding what quantitative and qualitative information is important (Innes, 1990). This process could be used as a mechanism for educating and informing the public and obtaining their support in the collection and dissemination of the information they find important to sustainable development and well-being.

Several recommendations have been made regarding the accessibility, organization, and chain of knowledge and information provided by the City of Toronto for sustainable development to be operationalized. There are also several recommendations regarding prospective knowledge and information needed for sustainability and sustainable development. Prospective in the sense of acknowledging current barriers and identifying what knowledge, information, or resources are needed to overcome these barriers to move sustainability and sustainable development forward in the most 
transparent manner possible. Arguably, some of the most valuable information this research has to offer the City of Toronto comes from challenges to operationalizing sustainability and sustainable development that were identified. Some of these include, restrictions associated with government mandates, limitations associated with jurisdictional responsibilities, constraints related to information flow and sharing, insufficient information for evidence-based environmental decision-making, and impediments to crossscale collaboration, just to name a few. Some of these, specifically issues related to mandates, jurisdictions, and impeded flows of information, are well-known barriers to sustainable development in Canadian public policy and have been for decades (Dale \& Pierce, 1999).

\subsection{Learning from Federal Sustainable Development Policy}

Three years after Rio, in 1995, the Government of Canada's Auditor General Act was amended under Prime Minister Jean Chrétien to include a requirement that all departments and agencies establish sustainable development strategies. Canada was one of the first countries to have a clear legal mandate for departments to develop a strategy process (Swanson et al., 2004). To monitor its implementation, the

office of the Commissioner of the Environment and Sustainable Development (CESD) was created and mandated to oversee how they would be meeting their objectives (Environment Canada, 2010). Contrary to the decentralized approached that Agenda 21 recommends, the Commissioner annually highlighted how this type of approach towards sustainable development in Canada was not meeting its intended consequence - a path towards sustainable development - and consistently cited the same reasons why. These ranged from a lack of central direction or strategy for sustainable development, insufficient monitoring and reporting, inadequate indicators of performance, untimely reporting (e.g. not within the timeframe to influence decision-making), vague goals, and overall fell short of a long-term approach (Thompson, 2009). Consequently, many of these issues are prevalent in operationalizing sustainable development at the municipal level. Even though there was a clear legal mandate in 1995 for federal departments to develop a sustainable development strategy, the lack of a national consensus as to how each would integrate it into current departmental processes led it to be ineffectual.

In 2007 Ron Thompson as the interim Commissioner of the Environment and Sustainable Development tabled a 10-year review and called on the government to change its approach (Environment Canada, 2010). The Commissioner cited that the strategy lacked incentive for departments to take environmental issues into account. He also mentioned that Canada's characterization of their approach to sustainable development as government-wide fell short in operation since it was only required for certain federal departments. In sum, sustainable development was much more of a separate reporting and monitoring process rather than a change in overall government decision-making (Thompson, 2009). The significant number of weaknesses in their approach to sustainable development continued to persist as they remained 
unfixed. In acknowledgement of the Commissioners findings, the Government of Canada enacted the Federal Sustainable Development Act (FSDA) of 2008, which saw Canada finally fulfilling its UN commitment to develop a national sustainable development strategy (Canadian Institute for Environmental Law and Policy, 2009).

The Sustainable Development Act, 2008 was formulated as the legal framework for producing a Federal Sustainable Development Strategy (FSDS) which includes sustainable development goals and targets for Canada. The Act mandates the Sustainable Development Office within the Department of the Environment where procedures, progress, and implementation of the FSDS could be monitored and complied as required. The Act instructs the Minister to appoint a Sustainable Development Advisory Council (SDAC) that is made up of one delegate from each province and territory, comprising of each of the following: Aboriginal peoples, non-governmental environmental organizations, organizations representative of business, and organizations representative of labour. Establishing an advisory panel comprised of diverse stakeholders was one of the several recommendations also made the Environmental Task Force in 2000, however in the case of the federal government, this is formally legislated. Overall, the Act is not very lengthy in detail, however it does have specific directives for the preparation, content, consultation, updating, scope of application, and regulation of the Act and the accompanying FSDS. The minimum content requirement for FSDS under the Act is that it must outline the federal sustainable development goals and targets while providing an implementation strategy and allocating a minister responsible for meeting each benchmark.

The basic principle of sustainable development in the Act is defined as ecologically efficient use of natural, social, and economic resources, correspondingly acknowledging the need to integrate environmental, economic, and social dimensions in all decision-making made by the government. Departments and agencies under the Act that are required to comply are derived from Schedule I of the Financial Administration Act, 1985. Nonetheless, compliance must be appropriate to their departmental or agency mandate. Currently, there are no regulations directly under the Act, albeit the Act does give permission to the Governor in Council to establish regulations for achieving any of the goals outlined in the Act.

The overall purpose of the Act is to provide a legal framework for developing and implementing the federal strategy with the intention of increasing overall transparency and accountability regarding environmental decision-making in federal government departments. Although a "whole-of-government" approach is emphasized in both the Act and the FSDS, as previously mentioned those who are required to report under the Act are only those listed under Schedule I of the Financial Administration Act. This includes 26 departments and agencies that are legally required to comply, while 15 comply voluntarily, 
and the remaining 177 don't participate. The 26 departments that are legally mandated have remained the same since its inception. The Government of Canada does not overtly detail as to why the Act only applies to those listed under Schedule I. After reviewing the Financial Administration Act, other than the distinction between Schedule I being federal departments in contrast to Schedule II being departmental corporations.

It reasonable to state that this narrow scope of application falls short of a government-wide approach. It leaves out departments and agencies that have potentially crucial decision-making capabilities for sustainable development in Canada. For example, the Canadian Environmental Assessment Agency, Infrastructure Canada, National Research Council Canada whom voluntarily participate, and the Canadian Transportation Agency, National Energy Board, and the Department of Intergovernmental Affairs whom are not required to participate at all. In terms of transparency, it appears that Environment and Climate Change Canada publicly releases the FSDS for each of 26 departments and agencies under the Act but not the ones that voluntarily comply. For example, the last report publicly provided by the Canadian Environmental Assessment Agency was for 2007-2009 while Canadian Northern Economic Development Agency doesn't seem to have provided one at all. Both whom participate voluntary and which have a potential decision-making capacity that could have implications for environment and sustainable development decision-making in Canada.

Bizikova and Swanson (2016) describe how the wording of the Act as a legal framework to "make environmental decision-making more transparent and accountable to Parliament", has a weak enforcement capacity. It overall lacks incentive and consequences for department and agency participation. Though there are no laws or regulations directly under the Sustainable Development Act other than the requirement for producing and reporting on a sustainable development strategy. It implies that departments and agencies are to instill the sustainable development framework in the laws and regulations (e.g. Canadian Environmental Protection Act (CEPA), 1999; Fisheries Act, 1985) of their own respective departments.

The scope of application, which to some extent depends on the goals and targets outlined in the FSDS is completely contingent on the capacity of the federal governments operational and financial resources (Findlay et al., 2010). For the most part, the FSDS goals are soft targets (e.g. clean energy, clean growth), but do include some harder sub-targets, short-term milestones (e.g. by 2017, 5\% of coastal and marine areas are conserved through networks of protected areas and other effective area-based conservation measures) and longer-term milestones (e.g. By 2030, reduce Canada's total GHG emission by 30\%, relative to 2005 emission levels). Given its broad scope of goals and targets, it is important to note that sustainable development is not merely about the formulation of pollution prevention or wilderness 
preservation policies (Dale \& Robinson, 1996). Rather it requires a fundamental change in the policy and policy making process that considers the intrinsically integrated and complex nature of both human society and the environment in governmental decision-making.

Ellis et al. (2010) conducted a case study on Canada's departmental sustainable development strategies and the effectiveness of the Act, concluding that there was a widespread lack of integration between the social, economic, and environmental goals. The research found that the out of all the federal sustainable development strategies, only 10 of the 42 included all three dimensions - economic, social, and environmental - in their goal statements (Ellis et al., 2010). Little is known about how the government internally prepared their departments for executing sustainable development strategies (e.g. communication networks, standard of procedures, financial and informational resources, etc.) and how they would identify the economic, social, and environmental dimensions of their decision-making. The Act itself not very lengthy in detail, although it does have specific directives for the preparation, content, consultation, updating, scope of application, and regulation of the Act and accompanying FSDS, it is inordinately brief in its description. It is valuable to note that this could present one of the major limitations to the successful implementation of the Act by federal departments.

Arguably, much of this partial and fragmentary application is associated with the fact that the Act emphasizes sustainable development goals that align with the current government mandate and not the reverse. Subsequently undermining the ability to achieve a sustainable development outcome. Although the Act demonstrated acknowledgement that decision-making in the federal government was on an unsustainable course, the significant driving issue which the Act intends to address - an unsustainable Canada - remains explicitly unacknowledged and unidentified in both the Act and the strategy (Findlay et al., 2010). Consequently, the Commissioner's 2015 annual audit findings found that the FSDS lacked contextual and cost information for almost 30 out of the 34 targets, was missing indications on whether targets were being met, and no explanations as to why progress is stagnant or the potential challenges of future progress. Most importantly, the FSDS did not present any information on the performance of integrating sustainable development into decision-making, which is the primary intention of the Sustainable Development Act in the first place. It also concluded that the 2015 report did not reflect the recommendations provided in the 2013 annual audit (Office of the Auditor General of Canada, 2016) Given the structure of Canada's Constitution, it is evident the circumstances for sustainable development has both barriers and bridges (Dale \& Robinson, 1996). The constitutional, fiscal, and administrative constraints internally imposed by this governmental structure are not fully understood (Balme \& Ye, 2014), and with that neither is its capacity for innovation, change, and ultimately operationalization of sustainable development. In any case, the intricacy of these internal relationships within government 
decision-making on environmental policy should not be underestimated. If governments are to benefit from their current constitutional, fiscal, and administrative circumstances, they need to explicitly identify these barriers and bridges to move forward on integrating sustainable development in decision-making. The City of Toronto and the Government of Ontario are highly encouraged to review and consult the Government of Canada and the Commissioner of Environment and Sustainable Development in particular, regarding the operationalization of sustainable development in government decision-making. The Government of Canada's integration of sustainable development in its federal departments and agencies has been far from successful, however this lack of success can be used as a learning opportunity for both the provincial and municipal governments in consideration of sustainable development moving forward. While this research recognizes that federal governance in Canada is completely different from its provincial and municipal counterparts, especially in terms of what they govern, all three levels of government are comprised of departments, agencies, and corporations, and they enact laws and operate public services. This research also acknowledges that municipal governments have the additional challenge of being the level of government closest to the public in terms of spatial proximity and interaction. However, if approached strategically, this proximity may be an asset for operationalizing sustainable development., rather than a challenge.

\subsection{Recommendations for Sustainable Development in Toronto}

This research encourages the (re)consideration of sustainable development and sustainability as framework for development, governance, and decision-making in the City of Toronto. Municipalities must move beyond the 'low-hanging fruit' of urban ecology if they are to be sustainable in the long-term (McDonnell \& Hahs, 2013). McDonnell and Hahs, (2013) refer to 'low-hanging fruit' as broad aggregate variables used in urban ecology such as land use and percentage of green space. Variables such as these have been used for the last 25 years to analyze patterns and predict biodiversity as a means for studying urban ecology. With urban populations growing rapidly however, these variables have been and will be insufficient in expanding our knowledge of urban ecology, producing ecologically-sound development, informing individual actions, preserving, and enhancing urban biodiversity, and in ultimately operationalizing urban sustainable development (McDonnell \& Hahs, 2013).

If the City of Toronto reconsiders sustainable development as a framework, this research recommends the following: (i) review the Federal Sustainable Development Act, 2008 including Bill C-57 amendments currently under review; (ii) research the operationalization of sustainable development in other municipalities or governments; (iii) recap the City's past definitions and conceptualizations of sustainability and sustainable development across its plans, reports, and polices considering the current sustainability-related initiatives currently in operation; (iv) conduct a systematic review of scholarly 
research pertaining to sustainable urban development in collaboration with local universities, and other stakeholders in the City; (v) format a widespread public consultation campaign for envisioning and operationalizing a sustainable Toronto; and (vi) appeal to provincial and federal governments to improve communication networks for information and data sharing. These are just some preliminary steps the City of Toronto can take to improve its defining, conceptualizing, operationalizing, and measuring of sustainability and sustainable development.

Research also suggests that Canada, and its provinces and municipalities would greatly benefit from human and financial resources that are devoted to learning from other countries (Dale \& Robinson, 1996). Experiencing similar regional challenges to sustainable development, Sweden has set a significant example by pursuing a comprehensive and integrated approach to sustainability (Findlay et al., 2010). As one of the most sustainable countries the world, it begun through the mechanism of a Sustainable Development unit within the prime minister's office, and by 2005 was functioning as a ministry of its own. Similarly, the European Commission highlights the characteristics of good governance but emphasizes that there are additional requirements when it comes to sustainability, including but not limited to "internalizing external costs and ensuring integration of policy considerations, evaluation of options and dealing with trade-offs" (Kemp et al., 2005, p. 18). Integrated decision-making requires regulatory support, for example, a minimum requirement for knowledge mobilization and networking with other jurisdictions and a mode at which this can be conducted in a publicly transparent and collaborative nature (e.g. conferences, commissions) - which is a common characteristic of the European Union.

All things considered, it is reasonable to suggest the City of Toronto would benefit considerably by integrating sustainable development into municipal decision-making. While there are certainly challenges to operationalizing sustainable development in the City, there is no reason to suggest it wouldn't be socially, politically, or technically feasible in Toronto. 


\section{APPENDICES}

\section{Appendix A: Study Sample Document Variables}

\begin{tabular}{|c|c|c|c|c|c|c|}
\hline ID & Year & Document Title & $\begin{array}{l}\text { Primary } \\
\text { Author }\end{array}$ & Author Type & Document Type & Pages \\
\hline 1 & 1988 & Toronto: State of the Environment & $\mathrm{PH}$ & Service Agency & Report & 87 \\
\hline 2 & 1990 & Environmental Backgrounder: Environmental Planning Issues and Concerns in the City of Toronto & PD & Division/Department & Report & 94 \\
\hline 3 & 1995 & State of the Environment Report: Metropolitan Toronto & $\mathrm{PD}$ & Division/Department & Report & 153 \\
\hline 4 & 2000 & Environmental Plan: A Plan for an Environmentally Sustainable Toronto & ETF/CM & Committee & Plan/Strategy & 130 \\
\hline 5 & 2002 & City Council's Strategic Plan & $\mathrm{CM}$ & Management & Plan/Strategy & 26 \\
\hline 6 & 2004 & Our Common Grounds & PFR & Division/Department & Plan/Strategy & 81 \\
\hline 7 & 2006 & Making a Sustainable City Happen: The Toronto Green Development Standard & PD & Division/Department & Guideline & 86 \\
\hline 8 & 2007 & Climate Change, Clean Air and Sustainable Energy Action Plan: Moving From Framework to Action Phase 1 & TEO/EED & Division/Department & Plan/Strategy & 15 \\
\hline 9 & 2008 & Ahead of the Storm: Preparing Toronto for Climate Change & TEO/EED & Division/Department & Plan/Strategy & 46 \\
\hline 10 & 2009 & The Power to Live Green: Toronto's Sustainable Energy Strategy & TEO/EED & Division/Department & Plan/Strategy & 32 \\
\hline 11 & 2009 & Toronto Walking Strategy & TSD & Division/Department & Plan/Strategy & 43 \\
\hline 12 & 2010 & Cultivating Food Connections: Toward a Healthy and Sustainable Food System for Toronto & $\mathrm{PH}$ & Service Agency & Report & 36 \\
\hline 13 & 2011 & The Living City Report Card: An Assessment of the Environmental Health of the Greater Toronto Area & TRCA & Partnered Agency & Report & 78 \\
\hline 14 & 2012 & GrowTO Urban Agriculture Action Plan & $\mathrm{PH}$ & Service Agency & Plan/Strategy & 22 \\
\hline 15 & 2013 & Building the Living City® 10-Year Strategic Plan 2013-2022 & TRCA & Partnered Agency & Plan/Strategy & 48 \\
\hline 16 & 2013 & Recreation Service Plan 2013-2017 & PFR & Division/Department & Plan/Strategy & 81 \\
\hline 17 & 2013 & Every Tree Counts: A Portrait of Toronto's Urban Forest & PFR & Division/Department & Report & 106 \\
\hline 18 & 2013 & Collaborating for Competitiveness: A Strategic Plan for Accelerating Economic Growth and Job Creation & EDC & Division/Department & Plan/Strategy & 50 \\
\hline 19 & 2013 & Sustaining \& Expanding the Urban Forest: Toronto's Strategic Forest Management Plan 2012-2022 & PFR & Division/Department & Plan/Strategy & 56 \\
\hline 20 & 2013 & City Planning Strategic Plan 2013-2018 & PD & Division/Department & Plan/Strategy & 80 \\
\hline 21 & 2013 & Next Stop Health: Transit Access and Health Inequities in Toronto & PD & Division/Department & Report & 37 \\
\hline 22 & 2013 & Parks Plan 2013-2017 & PFR & Division/Department & Plan/Strategy & 83 \\
\hline 23 & 2013 & Strategic Actions 2013-2018 & $\mathrm{CM}$ & Management & Plan/Strategy & 39 \\
\hline 24 & 2014 & 2014 Performance Measurement and Benchmarking Report & $\mathrm{CM}$ & Management & Report & 342 \\
\hline 25 & 2014 & Toronto Strong Neighbourhoods Strategy (TSNS) 2020 & SDFA & Division/Department & Plan/Strategy & 40 \\
\hline 26 & 2015 & From Concept to Commercialization: A Startup Eco-System Strategy for the City of Toronto & EDC & Division/Department & Plan/Strategy & 72 \\
\hline 27 & 2015 & Toronto Environmental Progress Report 2015 & TEO/EED & Division/Department & Report & 40 \\
\hline 28 & 2015 & Long Term Waste Strategy & SWM & Division/Department & Plan/Strategy & 104 \\
\hline 29 & 2015 & A Climate of Concern: Climate Change and Health Strategy for Toronto & $\mathrm{PH}$ & Partnered Agency & Plan/Strategy & 16 \\
\hline 30 & 2015 & TO Prosperity: Toronto Poverty Reduction Strategy & SDFA & Division/Department & Plan/Strategy & 62 \\
\hline 31 & 2016 & The Living City Report Card 2016: A Progress Report on Environmental Sustainability in the Toronto Region & TRCA & Partnered Agency & Report & 100 \\
\hline 32 & 2016 & TransformTO: Climate Action for a Healthy Equitable, and Prosperous Toronto (Report 1) & TEO/EED & Division/Department & Report & 75 \\
\hline 33 & 2017 & Toronto Green Standard (TGS): New Mid to High-Rise Residential and All Non-Residential Development & PD & Division/Department & Guideline & 20 \\
\hline 34 & 2017 & Toronto Complete Streets Guidelines: Making Streets for People, Placemaking and Prosperity & PD & Division/Department & Guideline & 168 \\
\hline 35 & 2017 & The City of Toronto Zero Emissions Building Framework & PD & Division/Department & Plan/Strategy & 118 \\
\hline 36 & 2017 & TransformTO: Climate Action for a Healthy, Equitable and Prosperous Toronto (Report 2) & TEO/EED & Division/Department & Report & 347 \\
\hline 37 & 2017 & Toronto Pollinator Protection Strategy & TEO/EED & Division/Department & Plan/Strategy & 34 \\
\hline 38 & 2017 & Toronto Green Streets Technical Guidelines (GSTG) & PD & Division/Department & Guideline & 36 \\
\hline 39 & 2017 & Toronto Ravine Strategy & PFR & Division/Department & Plan/Strategy & 54 \\
\hline 40 & 2017 & Parkland Strategy: Growing Toronto Parkland - Phase 1 Report & PFR & Division/Department & Plan/Strategy & 42 \\
\hline 41 & 2017 & Parks and Recreation Facilities Master Plan (FMP) 2019-2038 & PFR & Division/Department & Plan/Strategy & 103 \\
\hline
\end{tabular}




\section{Appendix B: Document Cross-References \& Reasons for Inclusion}

\begin{tabular}{|c|c|c|c|c|c|}
\hline ID & Year & Title & Document Owner & Reason for Incluson & Cross-ref \\
\hline 1 & 1988 & Toronto: State of the Environment & Metropolitan Toronto & $\begin{array}{l}\text { (i) references the sustainability of environment; } \\
\text { (ii) applies to spatial area of Toronto }\end{array}$ & 2,3 \\
\hline 2 & 1990 & $\begin{array}{l}\text { Environmental Backgrounder: Environmental Planning Issues and Concerns } \\
\text { in the City of Toronto }\end{array}$ & City of Toronto & $\begin{array}{l}\text { (i) references sustainable development chapter title; } \\
\text { (ii) capplies to spatial area of Toronto }\end{array}$ & 4 \\
\hline 3 & 1995 & State of the Environment Report: Metropolitan Toronto & Metropolitan Toronto & $\begin{array}{l}\text { (i) references the sustainability of environment; } \\
\text { (ii) applies to spatial area of Toronto }\end{array}$ & 4 \\
\hline 4 & 2000 & Environmental Plan: A Plan for an Environmentally Sustainable Toronto & City of Toronto & $\begin{array}{l}\text { (i) references sustainable in title; } \\
\text { (ii) applies to spatial area of Toronto }\end{array}$ & 7 \\
\hline 5 & 2002 & City Council's Strategic Plan & City of Toronto & $\begin{array}{l}\text { (i) references sustainability as guiding principle; } \\
\text { (ii) applies to spatial area of Toronto }\end{array}$ & 6,20 \\
\hline 6 & 2004 & Our Common Grounds & City of Toronto & $\begin{array}{l}\text { (i) references sustainability as guiding principle; } \\
\text { (ii) applies to spatial area of Toronto }\end{array}$ & $\begin{array}{l}7,9,16,22 \\
36,40,41\end{array}$ \\
\hline 7 & 2006 & $\begin{array}{l}\text { Making a Sustainable City Happen: The Toronto Green Development } \\
\text { Stand ard }\end{array}$ & City of Toronto & $\begin{array}{l}\text { (i) references sustainable in title; } \\
\text { (ii) applies to spatial area of Toronto }\end{array}$ & $\begin{array}{l}9,10,11,22, \\
36\end{array}$ \\
\hline 8 & 2007 & $\begin{array}{l}\text { Climate Change, Clean Air and Sustainable Energy Action Plan: Moving } \\
\text { From Framework to Action Phase } 1\end{array}$ & City of Toronto & $\begin{array}{l}\text { (i) references sustainable in title; } \\
\text { (ii) applies to spatial area of Toronto }\end{array}$ & $\begin{array}{l}9,19,27,29, \\
35,36,41\end{array}$ \\
\hline 9 & 2008 & Ahead of the Storm: Preparing Toronto for Climate Change & City of Toronto & $\begin{array}{l}\text { (i) references sustainability in relation to climate change; } \\
\text { (ii) applies to spatial area of Toronto }\end{array}$ & 10,27 \\
\hline 10 & 2009 & The Power to Live Green: Toronto's Sustainable Energy Strategy & City of Toronto & $\begin{array}{l}\text { (i) references sustainable in title; } \\
\text { (ii) applies to spatial area of Toronto }\end{array}$ & $27,32,35,36$ \\
\hline 11 & 2009 & Toronto Walking Strategy & City of Toronto & $\begin{array}{l}\text { (i) references strategy as contribution to sustainable city; } \\
\text { (ii) applies to spatial area of Toronto }\end{array}$ & $27,32,34,36$ \\
\hline 12 & 2010 & $\begin{array}{l}\text { Cultivating Food Connections: Toward a Healthy and Sustainable Food } \\
\text { System for Toronto }\end{array}$ & City of Toronto & $\begin{array}{l}\text { (i) references sustainable in title; } \\
\text { (ii) applies to spatial area of Toronto }\end{array}$ & 14,27 \\
\hline 13 & 2011 & $\begin{array}{l}\text { The Living City Report Card: An Assessment of the Environmental Health of } \\
\text { the Greater Toronto A rea }\end{array}$ & $\begin{array}{l}\text { City of Toronto; and } \\
\text { Government of Ontario }\end{array}$ & $\begin{array}{l}\text { (i) references environmental sustainability of regional area; } \\
\text { (ii) applies to spatial area of Toronto }\end{array}$ & 15,31 \\
\hline 14 & 2012 & GrowTO Urban Agriculture Action Plan & City of Toronto & $\begin{array}{l}\text { (i) references sustainability of urban agriculture; } \\
\text { (ii) applies to spatial area of Toronto }\end{array}$ & 27,30 \\
\hline 15 & 2013 & B uilding the Living City 10-Year Strate gic Plan 2013-2022 & $\begin{array}{l}\text { City of Toronto; and } \\
\text { Government of Ontario }\end{array}$ & $\begin{array}{l}\text { (i) references strategy as contribution to sustainable future; } \\
\text { (ii) applies to spatial area of Toronto }\end{array}$ & \\
\hline 16 & 2013 & Recreation Service Plan 2013-2017 & City of Toronto & $\begin{array}{l}\text { (i) references sustaining certain recreational activities; } \\
\text { (ii) applies to spatial area of Toronto }\end{array}$ & $22,40,41$ \\
\hline 17 & 2013 & Every Tree Counts: A Portrait of Toronto's Urban Forest & City of Toronto & $\begin{array}{l}\text { (i) references the sustainability of urban forest; } \\
\text { (ii) applies to spatial area of Toronto }\end{array}$ & $19,36,39$ \\
\hline 18 & 2013 & $\begin{array}{l}\text { Collaborating for Competitiveness: A Strategic Plan for Accelerating } \\
\text { Economic Growth and Job Creation in Toronto }\end{array}$ & City of Toronto & $\begin{array}{l}\text { (i) references sustainable economic growth to plan; } \\
\text { (ii) applies to spatial area of Toronto }\end{array}$ & $23,24,26,36$ \\
\hline 19 & 2013 & $\begin{array}{l}\text { Sustaining \& Expanding the Urban Forest: Toronto's Strate gic Forest } \\
\text { Management Plan 2012-2022 }\end{array}$ & City of Toronto & $\begin{array}{l}\text { (i) references sustaining in title; } \\
\text { (ii) applies to spatial area of Toronto }\end{array}$ & $\begin{array}{l}22,27,36,38 \\
40\end{array}$ \\
\hline 20 & 2013 & City Planning Strategic Plan 2013-2018 & City of Toronto & $\begin{array}{l}\text { (i) references sustainability of city planning; } \\
\text { (ii) applies to spatial area of Toronto }\end{array}$ & \\
\hline
\end{tabular}




\begin{tabular}{|c|c|c|c|c|c|}
\hline 21 & 2013 & Next Stop Health: Transit Access and Health Inequities in Toronto & City of Toronto & $\begin{array}{l}\text { (i) references sustainable as characteristic of healthy city; } \\
\text { (ii) applies to spatial area of Toronto }\end{array}$ & \\
\hline 22 & 2013 & Parks Plan 2013-2017 & City of Toronto & $\begin{array}{l}\text { (i) references the sustainability of park system; } \\
\text { (ii) applies to spatial area of Toronto }\end{array}$ & $\begin{array}{l}24,27,39 \\
40,41\end{array}$ \\
\hline 23 & 2013 & Strategic Actions 2013-2018 & City of Toronto & $\begin{array}{l}\text { (i) references environmental and fiscal sustainability; } \\
\text { (ii) applies to spatial area of Toronto }\end{array}$ & $27,28,40$ \\
\hline 24 & 2014 & 2014 Performance Measurement and Benchmarking Report & City of Toronto & $\begin{array}{l}\text { (i) references sustainability performance; } \\
\text { (ii) applies to spatial area of Toronto }\end{array}$ & \\
\hline 25 & 2014 & Toronto Strong Neighbourhoods Strategy (TSNS) 2020 & City of Toronto & $\begin{array}{l}\text { (i) references strategy for sustaining neighbourhoods; } \\
\text { (ii) applies to spatial area of Toronto }\end{array}$ & $\begin{array}{l}16,18,23, \\
24,26,36\end{array}$ \\
\hline 26 & 2015 & $\begin{array}{l}\text { From Concept to Commercialization: A Startup Eco-System Strategy for } \\
\text { the City of Toronto }\end{array}$ & City of Toronto & $\begin{array}{l}\text { (i) references the sustainability of entrepreneurship; } \\
\text { (ii) applies to spatial area of Toronto }\end{array}$ & \\
\hline 27 & 2015 & Toronto Environmental Progress Report 2015 & City of Toronto & $\begin{array}{l}\text { (i) references environmental sustainability; } \\
\text { (ii) applies to spatial area of Toronto }\end{array}$ & \\
\hline 28 & 2015 & Long Term Waste Strategy & City of Toronto & $\begin{array}{l}\text { (i) references environmental sustainability } \\
\text { (ii) applies to spatial area of Toronto }\end{array}$ & 31,32 \\
\hline 29 & 2015 & A Climate of Concern: Climate Change and Health Strategy for Toronto & City of Toronto & $\begin{array}{l}\text { (i) references need for sustainable food system; } \\
\text { (ii) applies to spatial area of Toronto }\end{array}$ & \\
\hline 30 & 2015 & TO Prosperity: Toronto Poverty Reduction Strategy & City of Toronto & $\begin{array}{l}\text { (i) references need for sustained poverty reduction; } \\
\text { (ii) applies to spatial area of Toronto }\end{array}$ & 25,36 \\
\hline 31 & 2016 & $\begin{array}{l}\text { The Living City Report Card 2016: A Progress Report on Environmental } \\
\text { Sustainability in the Toronto Region }\end{array}$ & $\begin{array}{l}\text { City of Toronto; } \\
\text { Government of Ontario }\end{array}$ & $\begin{array}{l}\text { (i) references environmental sustainability in title; } \\
\text { (ii) applies to spatial area of Toronto }\end{array}$ & \\
\hline 32 & 2016 & $\begin{array}{l}\text { TransformTO: Climate Action for a Healthy Equitable, and Prosperous } \\
\text { Toronto (Report 1) }\end{array}$ & City of Toronto & $\begin{array}{l}\text { (i) references need for sustainable options; } \\
\text { (ii) applies to spatial area of Toronto }\end{array}$ & 34,35 \\
\hline 33 & 2017 & $\begin{array}{l}\text { Toronto Green Standard (TGS): Making Sustainability Happen for New } \\
\text { Mid to High-Rise Residential and All Non-Residential Development }\end{array}$ & City of Toronto & $\begin{array}{l}\text { (i) references sustainability in title; } \\
\text { (ii) applies to spatial area of Toronto }\end{array}$ & $35,36,38,41$ \\
\hline 34 & 2017 & $\begin{array}{l}\text { Toronto Complete Streets Guidelines: Making Streets for People, } \\
\text { Placemaking and Prosperity }\end{array}$ & City of Toronto & $\begin{array}{l}\text { (i) references sustainable mode(s) of transportation; } \\
\text { (ii) applies to spatial area of Toronto }\end{array}$ & 36,38 \\
\hline 35 & 2017 & The City of Toronto Zero Emissions Building Framework & City of Toronto & $\begin{array}{l}\text { (i) references need for sustainable buildings; } \\
\text { (ii) applies to spatial area of Toronto }\end{array}$ & 36 \\
\hline 36 & 2017 & $\begin{array}{l}\text { TransformTO: Climate Action for a Healthy, Equitable and Prosperous } \\
\text { Toronto (Report 2: The Pathway to a Low Carbon Future) }\end{array}$ & City of Toronto & $\begin{array}{l}\text { (i) references need for sustainable energy; } \\
\text { (ii) applies to spatial area of Toronto }\end{array}$ & 34,35 \\
\hline 37 & 2017 & Toronto Pollinator Protection Strategy & City of Toronto & $\begin{array}{l}\text { (i) references sustaining pollinator species; } \\
\text { (ii) applies to spatial area of Toronto }\end{array}$ & 38 \\
\hline 38 & 2017 & Toronto Green Streets Technical Guidelines (GSTG) & City of Toronto & $\begin{array}{l}\text { (i) references environmentally sustainable street design; } \\
\text { (ii) applies to spatial area of Toronto }\end{array}$ & 34 \\
\hline 39 & 2017 & Toronto Ravine Strategy & City of Toronto & $\begin{array}{l}\text { (i) references sustainability of ravine use; } \\
\text { (ii) applies to spatial area of Toronto }\end{array}$ & $24,31,38,40$ \\
\hline 40 & 2017 & Parkland Strategy: Growing Toronto Parkland - Phase 1 Report & City of Toronto & $\begin{array}{l}\text { (i) references advancing environmental sustainability; } \\
\text { (ii) applies to spatial area of Toronto }\end{array}$ & 41 \\
\hline 41 & 2017 & Parks and Recreation Facilities Master Plan (FMP) 2019-2038 & City of Toronto & $\begin{array}{l}\text { (i) references environmental sustainability as priority; } \\
\text { (ii) applies to spatial area of Toronto }\end{array}$ & 24,40 \\
\hline
\end{tabular}


Appendix C: Study Sample Characteristics - Percentage (\%) of Documents by Primary Author

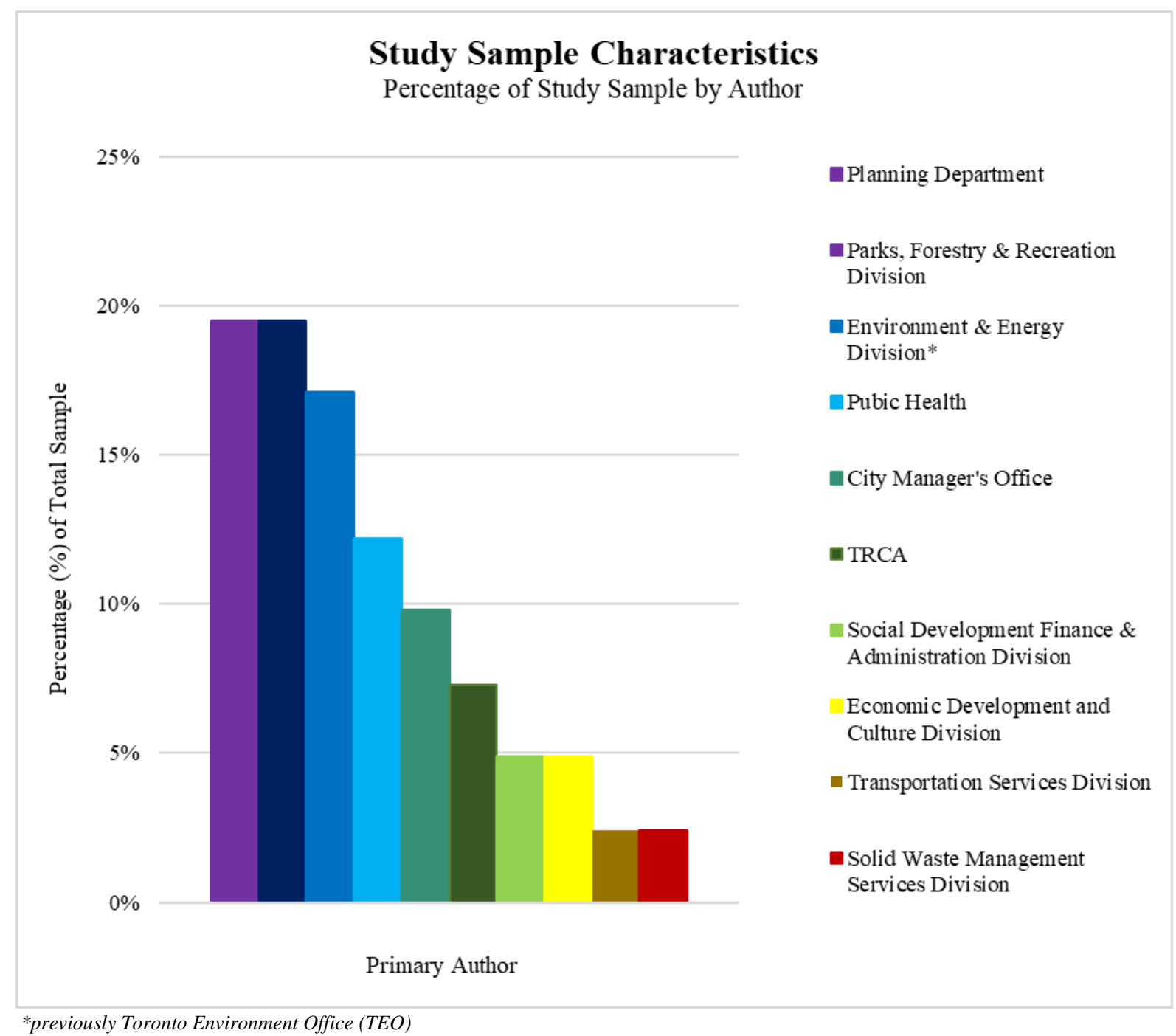

*previously Toronto Environment Office (TEO) 
Appendix D: Study Sample Characteristics - Percentage (\%) of Documents by Author Type

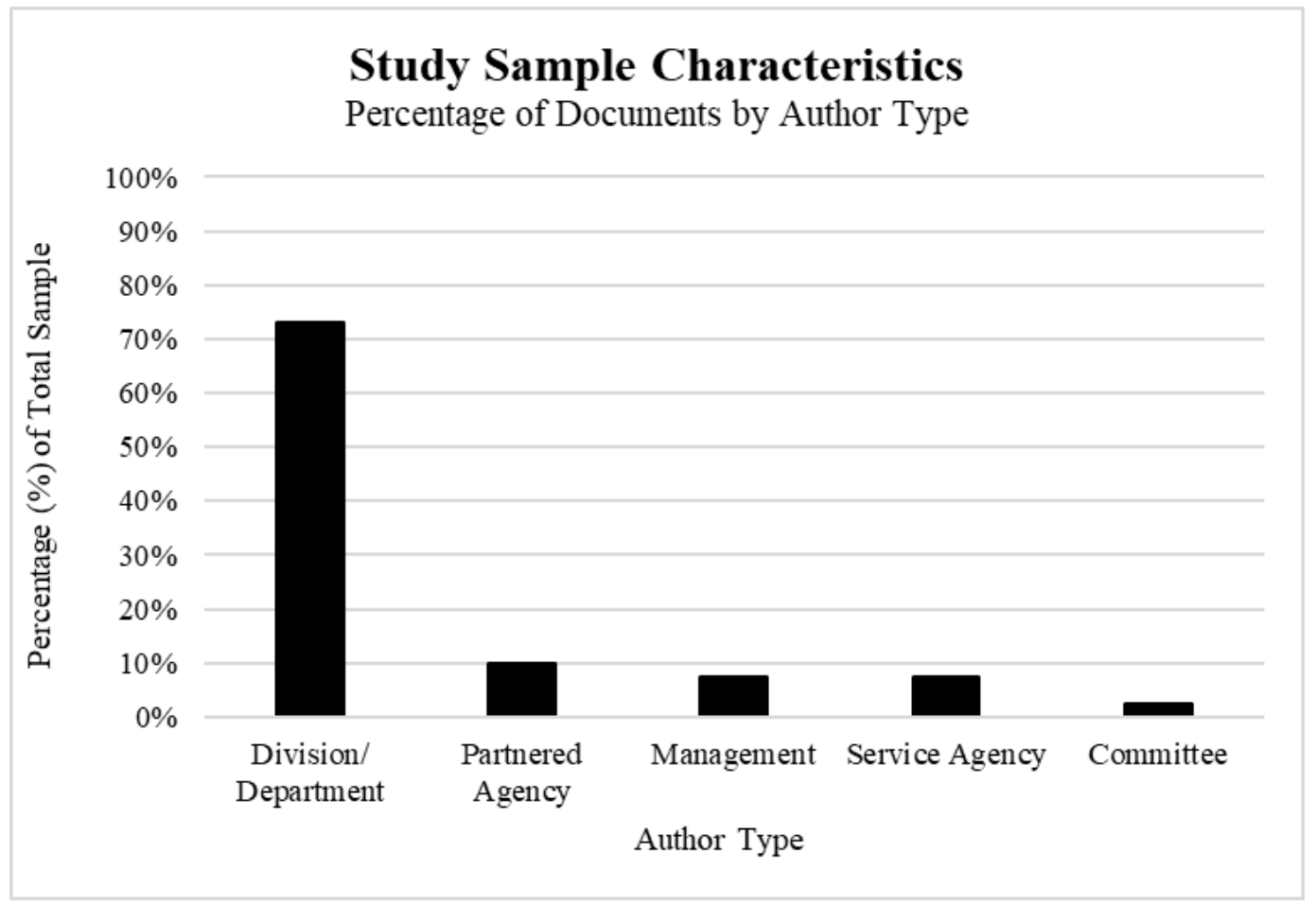


Appendix E: Study Sample Characteristics - Percentage (\%) of Sample by Document Type

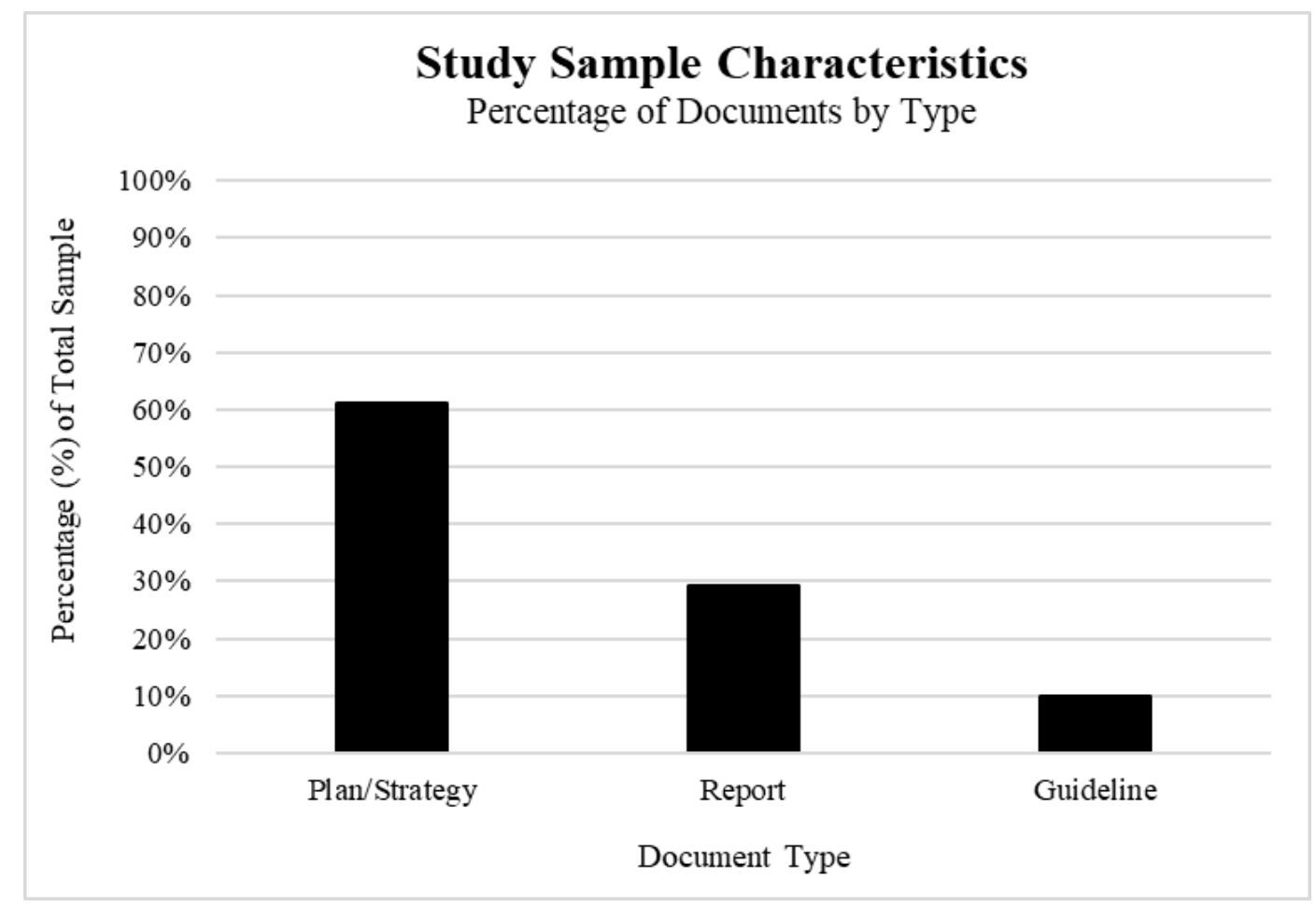


Appendix F: Study Sample Characteristics - Percentage (\%) of Sample with Sustain* in Title

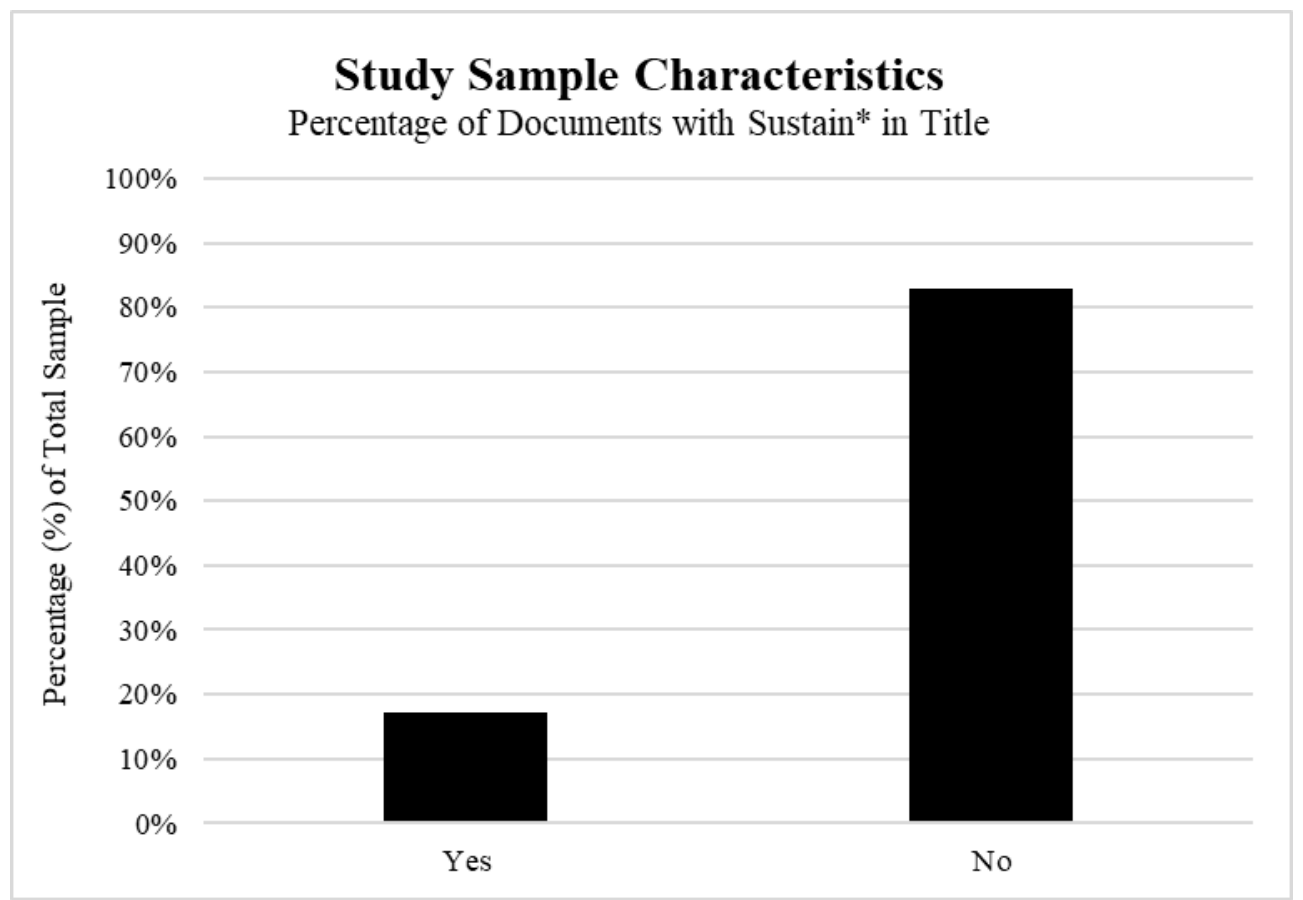


Appendix G: Study Sample Characteristics - Percentage (\%) of Sample by Mayor

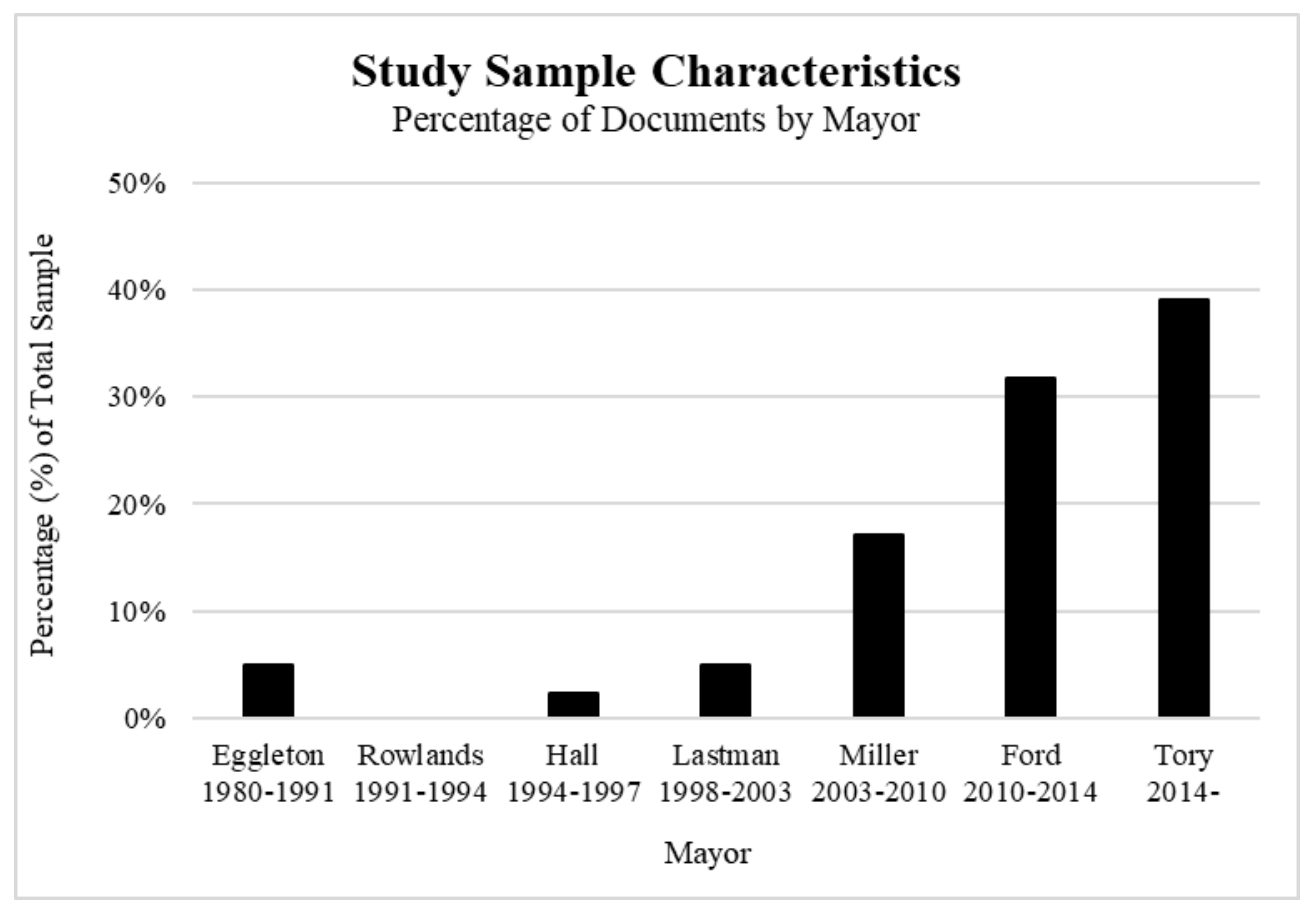

Note: denotes incumbent Mayor at the time of document publication 


\section{REFERENCES}

Amui, L. B. L. Jabbour, C. J. C., de Sousa Jabbour, A. B. L., \& Kannan, D. (2016). Sustainability as a dynamic organizational capability: a systematic review and a future agenda toward a sustainable transition. Journal of Cleaner Production, 142, 308-322. doi: 10.1016/j.jclepro.2016.07.103

Bassow, W. (1979). The Third World. Changing Attitude Toward Environmental Protection. The Annals of the American Academy of Political and Social Science, 444(1), 112-120. doi: $10.1177 / 000271627944400111$

Beck, A. C., Campbell, D., \& Shrives, P. J. (2010). Content analysis in environmental reporting research: Enrichment and rehearsal of the method in a British-German context. The British Accounting Review, 42(3), 207-222. doi: 10.1016/j.bar.2010.05.002

Begley, C. G. (2013). Six red flags for suspect work. Nature, 497, 433-434. doi: 10.1038/497433a

Bell, S. \& Morse, S. (2001). Breaking through the Glass Ceiling: who really cares about sustainability indicators? Local Environment, 6(3), 291-301. doi: 10.1080/1354983012007328 4

Berke, P. \& Manta, M. (1999). Planning for Sustainable Development: Measuring Progress in Plans. Lincoln Institute of Land Policy, 1-23. Retrieved from https://www.lincolninst.edu/sites/default/files/pubfiles/58_berkemanta99.pdf

Biely, K., Maes, D., \& Van Passel, S. (2018). The idea of weak sustainability is illegitimate. Environment, Development, and Sustainability, 20(1), 223-232. doi: 10.1007/s10668-016-9878-4

Biernacki, P., \& Waldorf, D. (1981). Snowball Sampling: Problems and Techniques of Chain Referral Sampling. Sociological Methods \& Research, 10(2), 141-163. doi: $10.1177 / 004912418101000205$

Biswas, M. R. \& Biswas, A. K. (1985). The global environment: Past, present and future. Resources Policy, 11(1), 25-42. doi: 10.1016/0301-4207(85)90017-0

Bizikova, L., \& Swanson, D. (2016, April 20). Towards a Strategy for Implementing the 2030 Agenda for Sustainable Development in Canada [Blog Post]. International Institute for Sustainable Development (IISD). Retrieved from https://www.iisd.org/blog/towards-strategy-implementing2030-agenda-sustainable-development-canada

Böhringer, C. \& Jochem, P. E. P. (2007). Measuring the immeasurable - A survey of sustainability indices. Ecological Economics, 63(1), 1-8. doi: 10.1016/j.ecolecon.2007.03.008 
Bolis, I., Morioka, S. N., \& Sznelwar, L. I. (2014). When sustainable development risks losing its meaning. Delimiting the concept with a comprehensive literature review and conceptual model. Journal of Cleaner Production, 83, 7-20. doi: 10.1016/j.jclepro.2014.06.041

Bolognesi, M., Pilgram, R., \& van den Heerik, R. (2017). Reliability in content analysis: The case of semantic feature norms classification. Behaviour Research Methods, 49(6), 1984-2001. doi: $10.3758 / \mathrm{s} 13428-016-0838-6$

Boschken, H. L. (2017). Aligning a Multi-Government Network with Situational Context: Metropolitan Governance as an Organizational Systems Problem. American Review of Public Administration, 47(2), 189-208. doi: 10.1177/0275074016668402

Boulding, K. E. (1966). The Economics of the Coming of Spaceship Earth. In H. Jarrett (Ed.), Environmental quality in a growing economy: essays from the Sixth RFF Forum. Baltimore, USA: Johns Hopkins Press

Brandon, P. S., \& Lombardi, P. L. (2011). Evaluating Sustainable Development in the Built Environment. Iowa, USA: Wiley-Blackwell

Brelsford, C. Lobo, J., Hand, J., \& Bettencourt, L. M. A. (2017). Heterogeneity and scale of sustainable development in cities. Proceedings of the National Academy of Science, 114(34), 8963-8968. doi: 10.1073/pnas. 1606033114

Brugmann, J. (1997). Is There a Method in Our Measurement? The use of indicators in local sustainable development planning. Local Environment, 2(1), doi: 10.1080/13549839708725512

Bruner, J. (1984). Pragmatics of Language and Language of Pragmatics. Social Research, 51(4), 969-984. Retrieved from https://www.jstor.org/stable/40970973

Butzer, K. W. (2012). Collapse, environment, and society. Proceedings of the National Academy of Sciences of the United States of America (PNAS), 109(10), 3632-3639. doi: 10.1073/pnas. 1114845109

Campagna, C., Guevara, D., \& Le Boeuf, B. (2017). Sustainable development as deus ex machina. Biological Conservation, 209, 54-61. doi: 10.1016/j.biocon.2017.01.016

Carney, T. F. (1972). Content Analysis: A Technique for Systematic Inference from Communications. Winnipeg, CA: University of Manitoba Press

Carson, R. (1962). Silent Spring. Cambridge, USA: Riverside Press 
Cartwright, L. E. (2000). Selecting Local Sustainable Development Indicators: Does Consensus Exist in their Choice and Purpose? Planning Practice \& Research, 15(12), 65-78. doi: $10.1080 / 713691874$

Canadian Institute for Environmental Law and Policy (CIELAP). (2009). CIELAP Brief on Implementation of the Federal Sustainable Development Act. 1-5. Retrieved from http://www.cielap.org/pdf/Brief_SDStrategy.pdf

Choguill, C. (2008). Developing sustainable neighbourhoods. Habitat International, 32(1), 41-48. doi: 10.1016/j.habitatint.2007.06.007

Choi, B. C. K., Pang, T., Lin, V., Puska, P., Sherman, G., Goddard, M., Ackland, M. J., Sainsbury, P., Morrison, H., \& Clottey, C. (2005). Can Scientists and Policy Makers Work Together? Journal of Epidemiology and Community Health, 59(8), 632-637. doi: 10.1136/jech.2004.031765

City of Toronto. (n.d.). Government Records. City of Toronto. Retrieved from https://www.toronto.ca/city-government/accountability-operations-customer-service/access-cityinformation-or-records/city-of-toronto-archives/whats-in-the-archives/government-records/

City of Toronto. (1990). Environmental Backgrounder, Environmental Planning Issues and Concerns in the City of Toronto (Part 1). Toronto, CA: City of Toronto Planning \& Development Department

City of Toronto. (2002). City Council's Strategic Plan. City of Toronto Chief Administrator's Office, 1-

24. Retrieved from https://www.toronto.ca/legdocs/mmis/2013/ex/bgrd/backgroundfile-61592.pdf

City of Toronto. (2004). Toronto Parks and Recreation Strategic Plan 2004: Our Common Grounds.

Centre for Local Research into Public Space (CELOS). Retrieved from

http://publiccommons.ca/library/docfiles/1651?instanceid=2125\&path=1810-\&perpage=30

City of Toronto. (2006). Making a Sustainable City Happen: The Toronto Green Development Standard.

City of Toronto. Retrieved from

https://www.toronto.ca/legdocs/2006/agendas/committees/ren/ren060710/it003.pdf

City of Toronto. (2008). Ahead of the Storm: Preparing Toronto for Climate Change. City of Toronto.

Retrieved from https://books.scholarsportal.info/en/read?id=/ebooks/ebooks0/gibson_cppc/2011$08-22 / 1 / 10478631$

City of Toronto. (2009a). The Power to Live Green: Toronto's Sustainable Energy Strategy. City of Toronto, 1-40. Retrieved from http://www.toronto.ca/legdocs/mmis/2009/ex/bgrd/backgroundfile-24947.pdf. 
City of Toronto. (2009b). Toronto Walking Strategy. City of Toronto. Retrieved from https://www.toronto.ca/wp-content/uploads/2017/10/9089-Pages-from-09-3410-WalkingStrategy.pdf.

City of Toronto. (2013). Collaborating for Competitiveness: A Strategic Plan for Accelerating Economic Growth and Job Creation in Toronto. City of Toronto. Retrieved from https://www.toronto.ca/city-government/data-research-maps/research-reports/economicdevelopment-reports/collaborating-for-competitiveness-implementation-actions/

City of Toronto. (2014). Toronto Strong Neighbourhoods Strategy (TSNS) 2020. City of Toronto.

Retrieved from https://www.toronto.ca/city-government/data-research-maps/researchreports/social-reports/toronto-strong-neighbourhoods-strategy-2020/

City of Toronto. (2015a). From Concept to Commercialization: A Startup Ecosystem Strategy for the City of Toronto (Attachment 1, Part A). City of Toronto. Retrieved from https://www.toronto.ca/wpcontent/uploads/2017/08/8f17-startup-eco-system-strategy.pdf.

City of Toronto. (2015b). Long Term Waste Management Strategy. City of Toronto. Retrieved from https://www.toronto.ca/services-payments/recycling-organics-garbage/long-term-wastestrategy/overview/

City of Toronto. (2015c). Toronto Environmental Progress Report 2015. City of Toronto. Retrieved from https://www.toronto.ca/wp-content/uploads/2017/08/8eb6-toronto-environmental-progress-report2015.pdf

City of Toronto. (2015d). TO Prosperity: Toronto Poverty Reduction Strategy. City of Toronto. Retrieved from https://www.toronto.ca/city-government/accountability-operations-customer-service/longterm-vision-plans-and-strategies/poverty-reduction-strategy/

City of Toronto. (2016). TransformTO: Climate Action for a Healthy Equitable, and Prosperous Toronto - Report \#1 (including Attachments A, B, C). City of Toronto. Retrieved from https://www.toronto.ca/services-payments/water-environment/environmentally-friendly-cityinitiatives/transformto/transformto-climate-action-strategy/transformto-reports-resources/

City of Toronto. (2017a). Toronto Facts. City of Toronto. Retrieved from https://www1.toronto.ca/wps/portal/contentonly?vgnextoid=57a12cc817453410VgnVCM100000 71d60f89RCRD 
City of Toronto. (2017b). Parkland Strategy: Growing Toronto Parkland (Phase 1 Report - November 2017). City of Toronto. Retrieved from https://www.toronto.ca/city-government/accountabilityoperations-customer-service/long-term-vision-plans-and-strategies/parkland-strategy/

City of Toronto. (2017c). Pollinator Protection Strategy: Draft Priorities and Actions. City of Toronto. Retrieved from https://www.toronto.ca/wp-content/uploads/2017/11/9819-Toronto-PollinatorStrategy-Booklet-Draft-Priorities-and-Actions-2017.pdf

City of Toronto. (2017d). Toronto Complete Streets Guidelines: Making Streets for People, Placemaking and Prosperity. City of Toronto. Retrieved from https://www.toronto.ca/servicespayments/streets-parking-transportation/enhancing-our-streets-and-public-realm/completestreets/complete-streets-guidelines/

City of Toronto. (2017e). Toronto Green Standard: Making a Sustainable City Happen. City of Toronto. Retrieved from https://www.toronto.ca/wp-content/uploads/2017/11/9297-City-PlanningToronto-Green-Standard-2017_MidHiRise_Standard.pdf

City of Toronto. (2017f). Toronto Green Streets Technical Guidelines (Version 1.0). City of Toronto. Retrieved from https://www.toronto.ca/services-payments/streets-parkingtransportation/enhancing-our-streets-and-public-realm/green-streets/

City of Toronto. (2017g). Toronto Ravine Strategy. City of Toronto. Retrieved from https://www.toronto.ca/city-government/accountability-operations-customer-service/long-termvision-plans-and-strategies/ravine-strategy/

City of Toronto. (2017h). TransformTO: Climate Action for a Healthy Equitable, and Prosperous Toronto - Report \#2 - The Pathway to a Low Carbon Future (including Attachments A, B, C). City of Toronto. Retrieved from https://www.toronto.ca/services-payments/waterenvironment/environmentally-friendly-city-initiatives/transformto/transformto-climate-actionstrategy/transformto-reports-resources/

City of Toronto City Manager's Office. (2013). City of Toronto Strategic Actions 2013-2018. City of Toronto. Retrieved from https://www.toronto.ca/city-government/accountability-operationscustomer-service/city-administration/city-managers-office/key-intiatives/strategic-actions/

City of Toronto City Manager's Office. (2014). 2014 Performance Measurement and Benchmarking Report. City of Toronto. Retrieved from https://www.toronto.ca/city-government/data-researchmaps/toronto-progress-portal/reports-on-how-toronto-is-doing/2014-pmbr/ 
City of Toronto Parks, Forestry and Recreation. (2012). The Recreation Service Plan 2013-2017. City of Toronto. Retrieved from https://www.toronto.ca/city-government/accountability-operationscustomer-service/long-term-vision-plans-and-strategies/recreation-service-plan/

City of Toronto Parks, Forestry and Recreation. (2013a). Every Tree Counts: A Portrait of Toronto's Urban Forest. City of Toronto. Retrieved from https://www.toronto.ca/businesseconomy/partnerships-sponsorships-donations/partner-2/parks-environment/every-tree-counts/

City of Toronto Parks, Forestry and Recreation. (2013b). Parks Plan 2013-2017. City of Toronto.

Retrieved from https://www.toronto.ca/wp-content/uploads/2017/08/9645-parks-plan-201317.pdf.

City of Toronto Parks, Forestry and Recreation. (2013c). Sustaining \& Expanding the Urban Forest: Toronto's Strategic Forest Management Plan. City of Toronto. Retrieved from https://www.toronto.ca/city-government/accountability-operations-customer-service/long-termvision-plans-and-strategies/strategic-forest-management-plan/

City of Toronto Parks, Forestry and Recreation. (2017). City of Toronto Parks and Recreation Facilities Master Plan 2019-2038. City of Toronto. Retrieved from https://www.toronto.ca/citygovernment/accountability-operations-customer-service/long-term-vision-plans-andstrategies/parks-and-recreation-facilities-master-plan/

Clarke T. (2002). Wanted: scientists for sustainability. Nature, 418(6900), 812-814. doi: $10.1038 / 418812 \mathrm{a}$

Cohen, M. (2017). A Systematic Review of Urban Sustainability Assessment Literature. Sustainability, 9(11), 2048-2064. doi: 10.3390/su9112048

Conceptualization. (2010). In A. Stevenson (Eds.), Oxford Dictionary of English (3 ${ }^{\text {rd }}$ ed.). Oxford University Press. doi: 10.1093/acref/9780199571123.001.0001

Connelly, S. (2007). Mapping Sustainable Development as a Contested Concept. Local Environment, 12(3), 259-278. doi: 10.1080/13549830601183289

Costanza, R. (1980). Embodied Energy and Economic Valuation. Science, 210(4475), 1219-1224. doi: 10.1126/science. 210.4475 .1219

Costanza, R., \& Patten, B. C. (1995). Defining and predicting sustainability. Ecological Economics, 15(3), 193-196. doi: 10.1016/0921-8009(95)00048-8

Costanza, R., d'Arge, R., de Groot, R., Farber, S., Grasso, M., Hannon, B., Limburg, K., Naeem, S., O’Neil, R. V., Paruelo, J., Raskin R. G., Sutton, P., \& van den Belt, M. (1997). The value of the 
world's ecosystem services and natural capital. Nature, 387(6630), 253-260. doi:

$10.1038 / 387253 \mathrm{a} 0$

Creemers, A., Don, J., \& Fenger, P. (2018). Some affixes are roots, others are heads. Natural Language \& Linguistic Theory, 36(1), 45-84. doi: 10.1007/s11049-017-9372-1

Creswell, J. W., \& Clark, V. L. P. (2011). Designing and Conducting Mixed Methods Research (2 $2^{\text {nd }}$ ed.). Los Angeles, USA: SAGE Publications Ltd.

Cucurachi, S., \& Sangwon, S. (2017). Cause-effect analysis for sustainable development policy. Environmental Reviews, 25(3), 358-379. doi: 10.1139/er-2016-0109

Dade, A., \& Hassenzahl, D. M. (2013). Communicating sustainability: A content analysis of website communications in the United States. International Journal of Sustainability in Higher Education, 14(3), 254-263. doi: 10.1108/IJSHE-08-2011-0053

Daily, G. C. (Eds). (1997). Nature's Services: Societal Dependence on Natural Ecosystems. Washington, USA: Island Press.

Dale, A. (2012). Introduction. In A. Dale, W. T. Dushenko, \& P. Robinson (Ed.), Urban Sustainability: Reconnecting Space and Place. Toronto, CA: University of Toronto Press

Dale, A., \& Pierce, J. T. (1999). Communities, Development, and Sustainability Across Canada. Vancouver, CA: UBC Press

Dale, A., \& Robinson, J. B. (1996). Achieving Sustainable Development. Vancouver, BC: UBC Press

Daly, H. E. (2009). Three Anathemas on Limiting Economic Growth. Conservation Biology, 23(2), 252253. doi: 10.1111/j.1523-1739.2009.01188.x

Daly, H. E. (1990). Toward some operational principles of sustainable development. Ecological Economics, 2(1), 1-6. doi: 10.1016/0921-8009(90)90010-R

Devall, B., \& Sessions, G. (1985). Deep Ecology. Salt Lake City, USA: Peregrine Smith Books.

Diamond, J. (1994). Ecological Collapses of Past Civilizations. Proceedings of the American Philosophical Society, 138(3), 363-370. Retrieved from https://www.jstor.org/stable/986741

Dictionary. (2010). In A. Stevenson (Eds), Oxford Dictionary of English ( $3^{\text {rd }}$ ed.). Retrieved from http://www.oxfordreference.com.ezproxy.lib.ryerson.ca/view/10.1093/acref/9780199571123.001. 0001/m_en_gb0212430?rskey=dgw8o3\&result=3

Dietz, T., Ostrom, E., \& Stern, P. C. (2003). The Struggle to Govern the Commons. Science, 302(5652), 1907-1912. doi: 10.1126/science. 1091015 
Duerr, W. A., Teeguarden, D. E., Christiansen, N. B., \& Guttenberg, S. (1979). Forest Resource Management: Decision-Making Principles and Cases. Philadelphia, PA: W. B. Saunders Company.

Ehrlich, P. (1968). The Population Bomb. New York, USA: Ballantine Books

Ehrlich, P. R., Ehrlich, A. H., \& Holdren, J. P. (1973). Human ecology: problems and solutions. San Francisco, USA: W. H. Freeman.

Ekins, P., Simon, S., Deutsch, L., Folke, C., \& De Groot, R. (2003). A framework for the practical application of the concepts of critical natural capital and strong sustainability. Ecological Economics, 44(2), 165-185. doi: 10.1016/S0921-8009(02)00272-0

Ellis, M., Gunton, T., \& Rutherford, M. (2010). A methodology for evaluating environmental planning systems: A case study of Canada. Journal of Environmental Management, 91, 1268-1277. doi: 10.1016/j.jenvman.2010.01.015

Elo, S., \& Kyngäs, H. (2008). The qualitative content analysis process. Journal of Advanced Nursing, 62(1), 107-115. doi: 10.1111/j.1365-2648.2007.04569.x

Engström, R., Nilsson, M., \& Finnveden, G. (2008). Which environmental problems get policy attention? Examining energy and agricultural sector policies in Sweden. Environmental Impact Assessment Review, 28(4), 241-255. doi: 10.1016/j.eiar.2007.10.001

Environment Canada. (2010). Planning for a Sustainable Future: A Federal Sustainable Development Strategy for Canada 2010-2013. Government of Canada, 1-92. Retrieved from http://www.ec.gc.ca/dd-sd/default.asp?lang=En\&n=7550fb51-1

Fallan, E. (2016). Environmental Reporting Regulations and Reporting Practices. Social and Environmental Accountability Journal, 36(1), 34-55. doi: 10.1080/0969160X.2016.1149300

Findlay, C. S., Benidickson, J., Benevides, H., \& Sloan, K. K. (2010). Sustainability Lost: Comments On "Planning for a Sustainable Future: A Federal Sustainable Development Strategy for Canada". Journal of Environmental Law and Practice, 22(1), 77-86. Retrieved from https://papers.ssrn.com/sol3/papers2.cfm?abstract_id=2272699

Fisher, F. (2003). Reframing Public Policy: Discursive Politics and Deliberative Practices. Oxford Scholarship Online. doi: 10.1093/019924264X.001.0001

Fleig, A., \& Tosun, J. (2017). Political Parties' Rhetoric Signaling of Sustainable Development. Sustainable Development, 25(5), 431-442. doi: 10.1002/sd.1672 
Ford, M. A., Davis, M. H., \& Marslen-Wilson, W. D. (2010). Derivational morphology and base morpheme frequency. Journal of Memory and Language, 63(1), 117-130. doi: 10.1016/j.jml.2009.01.003

Franks, T. R. (1996). Managing Sustainable Development: Definitions, Paradigms, and Dimensions. Sustainable Development, 4(2), 53-60. doi: 10.1002/(SICI)1099-1719(199608)4:2<53::AID$\mathrm{SD} 41>3.0 . \mathrm{CO} ; 2-\mathrm{F}$

Franzosi, R., Doyle, S., McClelland, L. E., Rankin, C. P., \& Vicari, S. (2013). Quantitative narrative analysis software options compared: PC-ACE and CAQDAS (ATLAS.ti, MAXqda, and NVivo). Quality \& Quantity, 47(6), 3219-3247. doi: 10.1007/s11135-012-9714-3

Freedman, L. P., Cockburn, I. M., \& Simcoe, T. S. (2015) The Economics of Reproducibility in Preclinical Research. PLOS Biology, 13(6). doi: 10.1371/journal.pbio.1002165

Fritze, R. H. (1989). The Oxford English Dictionary: A Brief History. Reference Services Review, 17(3), 61-70. doi: 10.1108/eb049065

Fu, Y., \& Zhang, X. (2017). Trajectory of urban sustainability concepts: A 35-year bibliometric analysis. Cities, 60, 113-123. doi: 10.1016/j.cities.2016.08.003

Gan, X., Fernandez, I. C., Guo, J., Wilson, M., Zhao, Y., Zhou, B., \& Wu, J. (2017). When to use what: Methods for weighting and aggregating sustainability indicators. Ecological Indicators, 81, 491502. doi: https://doi.org/10.1016/j.ecolind.2017.05.068

Gibbs, G. R. (2007). Qualitative Research kit: Analyzing qualitative data. London, England: SAGE Publications Ltd. doi: 10.4135/9781849208574

Gibson, R. B. (2006). Sustainability assessment: basic components of a practical approach. Impact Assessment and Project Appraisal, 24(3), 170-182. doi: 10.3152/147154606781765147

Giddings, B. Hopwood, B., \& O’Brian, G. (2002). Environment, Economy, and Society: Fitting them together into Sustainable Development. Sustainable Development, 10(4), 187-196. doi:10.1002/sd.199

Given, L. M. (2008). The SAGE Encyclopedia of Qualitative Research Methods. doi: $10.4135 / 9781412963909$

Geisler, C. (2018). Coding for Language Complexity: The Interplay Among Methodological Commitments, Tools, and Workflow in Writing Research. Written Communication, 35(2), 215 249. doi: $10.1177 / 0741088317748590$ 
Georgescu-Roegen, N. (1975). Energy and Economic Myths. Southern Economic Journal, 41(3), $347-$ 381. doi: $10.2307 / 1056148$

Goodland, R., \& Daly, H. (1996). Environmental Sustainability: Universal and Non-Negotiable. Ecological Applications, 6(4), 1002-1017. doi: 10.2307/2269583

Government of Canada. (2008). Federal Sustainable Development Act (S.C. 2008, c. 33). Minister of Justice. Retrieved from http://laws-lois.justice.gc.ca/eng/acts/F-8.6/

Government of Canada. (2016). Achieving a Sustainable Future: A Federal Sustainable Development Strategy. Environment and Climate Change Canada, 1-88. Retrieved from http://fsdssfdd.ca/index.html\#/en/intro/

Government of Canada. (1985). Financial Administration Act (R.S.C., 1985, c. F-11). Minister of Justice. Retrieved from http://laws-lois.justice.gc.ca/eng/acts/f-11/page-1.html\#h

Graham, D. A., Vanos, J. K., Kenny, N. A., \& Brown, R. D. (2016). The relationship between neighbourhood tree canopy cover and heat-related ambulance calls during extreme heat events in Toronto, Canada. Urban Forestry and Urban Greening, 20, 180-186. doi: https://doi.org/10.1016/j.ufug.2016.08.005

Graneheim, U. H., Lindgren, B., \& Lundman, B. (2017). Methodological challenges in qualitative content analysis: A discussion paper. Nurse Education Today, 56, 29-34. doi: 10.1016/j.nedt.2017.06.002

Gray, J. H., \& Densten, I. L. (1998) Integrating Quantitative and Qualitative Analysis Using Latent and Manifest Variables. Quality \& Quantity, 32(4), 419-431. doi: 10.1023/A:1004357719066

Greckhamer, T., \& Cilesiz, S. (2014). Rigor, Transparency, Evidence, and Representation in Discourse Analysis: Challenges and Recommendations. International Journal of Qualitative Methods, 13(1), 422-433. doi: 10.1177/160940691401300123

Greene, J. C., Caracelli, V. J., \& Graham, W. F. (1989). Toward a Conceptual Framework for MixedMethod Evaluation Designs. Educational Evaluation and Policy Analysis, 11(3), 255-274. doi: $10.2307 / 1163620$

Grimmer, J. \& Stewart, B. M. (2013). Text as Data: The Promise and Pitfalls of Automatic Content Analysis Methods for Political Texts. Political Analysis, 21(3), 267-297. doi: 10.1093/pan/mps028

Hagoort, P., Hald, L., Bastiaansen, M., \& Petersson, K. M. (2004). Integration of World Meaning and Word Knowledge in Language Comprehension. Science, 304(5669), 438-441. doi: 10.1126/science. 1095455 
Hák, T., Kovanda, J., \& Weinzettel, J. (2012). A method to assess the relevance of sustainability indicators: Application to the indicator set of the Czech Republic's Sustainable Development Strategy. Ecological Indicators, 17, 46-57. doi: 10.1016/j.ecolind.2011.04.034

Hanna, K., \& Slocombe, D. S. (2012). Mapmaking as Placemaking: Building Social Capital for Urban Sustainability. In A. Dale, W. T. Dushenko, \& P. Robinson (Eds), Urban Sustainability: Reconnecting Space and Place (pp. 29-50). Toronto, CA: University of Toronto Press

Hardin, G. (1968). The Tragedy of the Commons. Science, 162(3859), 1243-1248. doi: 10.1126/science.162.3859.1243

Hardin, G. (1970). To Trouble a Star: The Cost of Intervention in Nature. Bulletin of the Atomic Scientists, 26(1). doi: 10.1080/00963402.1970.11457756

Hardin, G. (1998). Extensions of "The Tragedy of the Commons". Science, 280(5364), 682-683. doi: $10.1126 /$ science. 280.5364 .682

Hartmuth, G., Huber, K., \& Rink, D. (2008). Operationalization and Contextualization of Sustainability at the Local Level. Sustainable Development, 16(4), 261-270. doi: 10.1002/sd.377

Heal, G. (2012). Reflections-Defining and Measuring Sustainability. Review of Environmental Economics and Policy, 6(1), 147-163. doi: 10.1093/reep/rer023

Holden, M. (2001). Uses and abuses of urban sustainability indicator studies. Canadian Journal of Urban Research, 10(2), 217-236. Retrieved from http://www.jstor.org/stable/44320668

Holling, C. S. (1973). Resilience and Stability of Ecological Systems. Annual Review of Ecology and Systematics, 4(1), doi: 10.1146/annurev.es.04.110173.000245

Hoornweg, D. Hosseini, M., Kennedy, C., \& Behdadi, A. (2016). An urban approach to planetary boundaries. Ambio, 45, 567-580. doi: 10.1007/s13280-016-0764-y

Hopkins, D. J., \& King, G. (2010). A Method of Automated Nonparametric Content Analysis for Social Science. American Journal of Political Science, 54(1), 229-247. doi: 10.1111/j.15405907.2009.00428.x

Hotelling, H. (1931). The Economics of Exhaustible Resources. Journal of Political Economy, 39(2), 137-175). doi: 10.1086/254195

Howes, M., Wortley, L., Potts, R., Dedekorkut-Howes, A., Serrao-Neumann, S., Davidson, J., Smith, T., \& Nunn, P. (2017). Environmental Sustainability: A Case of Policy Implementation Failure? Sustainability, 9(2), 165-190. doi: http://dx.doi.org.ezproxy.lib.ryerson.ca/10.3390/su9020165 
Huang, L. Wu, J., \& Yan, L. (2015). Defining and measuring urban sustainability: a review of indicators. Landscape Ecology, 30(7), 1175-1193. doi: 10.1007/s10980-015-0208-2

Innes, J. E. (1990). Knowledge and Public Policy: The Search for Meaningful Indicators. New Brunswick, US: Transaction Publishers

Innes, J. E., \& Booher, D. E. (1999). Consensus Building and Complex Adaptive Systems: A Framework for Evaluating Collaborative Planning. Journal of the American Planning Association, 65(4), 412-423. doi: 10.1080/01944369908976071

Intergovernmental Panel on Climate Change (IPCC). (2013). Climate Change: The Physical Basis Summary for Policymakers. IPCC, 1-27. Retrieved from http://www.ipcc.ch/report/ar5/wg1/

International Council for Local Environmental Initiatives (ICLEI). (1996). The Local Agenda 21 Planning Guide: An Introduction to Sustainable Development Planning. International Development Research Centre (IDRC), 1-207. Retrieved from https://www.idrc.ca/en/book/local-agenda-21planning-guide-introduction-sustainable-development-planning

International Institute for Applied Systems Analysis (IIASA). (1986). Sustainable Development of the Biosphere. Retrieved from http://pure.iiasa.ac.at/id/eprint/2751/

International Union for Conservation of Nature and Natural Resources (IUCN). (1980). World Conservation Strategy: Living Resource Conservation for Sustainable Development. Retrieved from https://portals.iucn.org/library/sites/library/files/documents/WCS-004.pdf

Johnson, R. B., Onwuegbuzie, A. J., \& Turner, L. A. (2007). Toward a Definition of Mixed Methods Research. Journal of Mixed Methods Research, 1(2), 112-133. doi: 10.1177/1558689806298224

Kaplan, T. J. (1986). The Narrative Structure of Policy Analysis. Journal of Policy Analysis and Management, 5(4), 761-778. doi: 10.2307/3324882

Kates, R. W., Parris, T. M., \& Leiserowitz, A. A. (2005). What is sustainable development? Goals, Indicators, Values, and Practice. Environment: Science and Policy for Sustainable Development, 47(3), 8-21. doi: 10.1080/00139157.2005.10524444

Kemp, R., Parto, S., \& Gibson, R. B. (2005). Governance for sustainable development: moving from theory to practice. International Journal of Sustainable Development, 8(1/2), 12-30. DOI: 10.1504/IJSD.2005.007372 
Klauer, B. (1999). Defining and achieving sustainable development. International Journal of Sustainable Development \& World Ecology, 6(2), 114-121. doi: 10.1080/13504509909470000

Klopp, J. M., \& Petretta, D. L. (2017). The urban sustainable development goal: Indicators, complexity and the politics of measuring cities. Cities, 63, 92-97. doi: 10.1016/j.cities.2016.12.019

Krippendorff, K. (2004). Content Analysis: An Introduction to Its Methodology (2 ${ }^{\text {nd }}$ Ed.). California, USA: SAGE Publications, Inc.

Lasswell, H. D., \& Leites, N. (1968). Language of politics: studies in quantitative semantics. Cambridge, USA: The MIT Press

Lélé, S. M. (1991). Sustainable development: A critical review. World Development, 19(6), 607-621. doi: 10.1016/0305-750X(91)90197-P

Li, F., Liu, X., Hu, D., Wang, R., Yang, W., Li, D., \& Zhao, D. (2009). Measurement indicators and an evaluation approach for assessing urban sustainable development: A case study for China's Jining City. Landscape and Urban Planning, 90(3), 134-142. doi: 10.1016/j.landurbplan.2008.10.022

Liberman, A. (1994). An Analytic Dictionary of English Etymology. Dictionaries: Journal of the Dictionary Society of North America, 15(1), 1-29. doi: 10.1353/dic.1994.0008

Lipinski, B., Hanson, C., Lomax, J., Kitinoja, L., Waite, R., \& Searchinger, T. (2013). Working Paper: Reducing Food Loss and Waste. World Resources Institute, 1-40. Retrieved from https://www.wri.org/sites/default/files/reducing_food_loss_and_waste.pdf

Lotka, A. J. (1925). Elements of Physical Biology. Baltimore, USA: Williams \& Wilkins Company.

Luederitz, C., Lang, D. J., \& Wehrden, H. V. (2013). A systematic review of guiding principles for sustainable urban neighborhood development. Landscape and Urban Planning, 118, 40-52. doi: 10.1016/j.landurbplan.2013.06.002

Lumley, S., \& Armstrong, P. (2004). Some of the Nineteenth Century Origins of the Sustainability Concept. Environment, Development and Sustainability, 6(3), 367-378. doi: 10.1023/B:ENVI.0000029901.02470.a7

Maclaren, V. W. (1996). Urban Sustainability Reporting. Journal of the American Planning Association, 62(2), 184-202. doi: 10.1080/01944369608975684

Macpherson, A. S. (1988). Toronto: State of the Environment Report. Toronto, ON: City of Toronto Department of Public Health 
Mahon, N. Crute, I., Simmons, E., \& Islam, M. M. (2017). Sustainable intensification - “oxymoron” or “third-way"? A systematic review. Ecological Indicators, 74, 73-97. doi:

10.1016/j.ecolind.2016.11.001

Malthus, T. R. (1798). An Essay on the Principle of Population. London, UK: J. Johnson

Manulak, M. W. (2015). Multilateral solutions to bilateral problems: The 1972 Stockholm conference and Canadian foreign environmental policy. International Journal, 70(1), 4-22. doi: $10.1177 / 0020702014546338$

Martin, B., \& Ringham, F. (2006). Key terms in semiotics. New York, USA: Bloomsbury Academic

MAXQDA Analytics Pro (Release 18.1.1) [Computer Software]. (2018). Retrieved from https://www.maxqda.com/

McBeth, M. K., Shanahan, E. A., Arnell, R. J., \& Hathaway, P. L. (2007). The Intersection of Narrative Policy Analysis and Policy Change Theory. The Policy Studies Journal, 35(1), 87-108. doi: 10.1111/j.1541-0072.2007.00208.x

McComas, K., \& Shanahan, J. (1999). Telling Stories About Global Climate Change: Measuring the Impact of Narratives on Issue Cycles. Communication Research, 26(1), 30-57. doi: $10.1177 / 009365099026001003$

McDonnell, M. J., \& Hahs, A. K. (2013). The future of urban biodiversity research: Moving beyond the 'low-hanging fruit'. Urban Ecosystems, 16(3), 397-409. doi: 10.1007/s11252-013-0315-2

McGuirk, P., Dowling, R., Brennan, C., \& Bulkeley, H. (2015). Urban Carbon Governance Experiments: The Role of Australian Local Governments. Geographical Research, 53(1), 39-52. doi: $10.1111 / 1745-5871.12098$

Meadows, D. H., Meadows, D. L., Randers, J., \& Behrens III, W. W. (1972). The Limits to Growth: A Report for the Club of Rome's Project on The Predicament of Mankind. New York, USA: Universe Books

Mebratu, D. (1998). Sustainability and sustainable development: Historical and conceptual review. Environmental Impact Assessment Review, 18(6), 493-520. doi: 10.1016/S0195-9255(98)00019-5

Mueller, C. M. (2004). Conceptualization, Operationalization, and Measurement. In M. S. Lewis-Beck, A. Bryman \& T. F. Liao (Ed), The SAGE Encyclopedia of Social Science Research Methods. doi: $10.4135 / 9781412950589$ 
Municipality of Metropolitan Toronto. (1994). Metropolitan Waterfront Plan. Toronto \& Region Conservation Authority, 1-94. Retrieved from http://trca.on.ca/trca-useruploads/MetropolitanWaterfrontPlan.pdf.

Municipality of Metropolitan Toronto. (1995). The State of the Environment Report: Metropolitan Toronto. Toronto, CA: Metropolitan Toronto Planning Department

Moore, F. C. (2011). Toppling the Tripod: Sustainable Development, Constructive Ambiguity, and the Environmental Challenge. Consilience: The Journal of Sustainable Development, 5(1), 141-150. Retrieved from http://www.jstor.org/stable/26167807

National Oceanic and Atmospheric Administration (NOAA). (n.d.). Trends in Atmospheric Carbon Dioxide. United States Department of Commerce. Retrieved from https://www.esrl.noaa.gov/gmd/ccgg/trends/full.html

Neuendorf, K. A. (2002). The Content Analysis Guidebook. California, USA: SAGE Publications, Inc.

Neumayer, E. (2010). Weak versus Strong Sustainability. MA, USA: Edward Elgar Publishing Inc.

Norton, R. K. (2008). Using content analysis to evaluate local master plans and zoning codes. Land Use Policy, 25(3), 432-454. doi: 10.1016/j.landusepol.2007.10.006

Office of the Auditor General of Canada. (2016). Report 4-Review of the 2015 Progress Report of the Federal Sustainable Development Strategy. Government of Canada. Retrieved from http://www.oag-bvg.gc.ca/internet/English/parl_cesd_201610_04_e_41674.html\#hd2c

Olsen, R. B., Orr, L. L., Bell, S. H., \& Stuart, E. A. (2013). External Validity in Policy Evaluations that Choose Sites Purposively. Journal of Policy Analysis and Management, 32(1), 107-121. doi: 10.1002/pam.21660

Open Science Collaboration. (2015). Estimating the Reproducibility of Psychological Science. Science, 349(6251). doi: 10.1126/science.aac4716

Organisation for Economic Co-operation and Development (OECD). 2001. OECD Environmental Indicators: Towards Sustainable Development. OECD, 1-141. Retrieved from www.oecd.org/site/worldforum/33703867.pdf

Ortloff, C. R. (2005). The Water Supply and Distribution System of the Nabataean City of Petra (Jordan), 300 BC-AD 300. Cambridge Archaeological Journal, 15(1), 93-109. doi: $10.1017 /$ S0959774305000053 
Parris, T. M., \& Kates, R. W. (2003). Characterizing a sustainability transition: Goals, targets, trends, and driving forces. Proceedings of the National Academy of Sciences of the United States of America, 100(14), 8068-8073. doi: 10.1073/pnas.1231336100

Pearce, D. (1988). Economics, equity and sustainable development. Futures, 20(6), 598-605. doi: 10.1016/0016-3287(88)90002-X

Perey, R. (2014). Organizing Sustainability and the Problem of Scale: Local, Global, or Fractal? Organization and Environment, 27(3), 215-222. doi: 10.1177/1086026614546363

Pezzoli, K. (1997). Sustainable development literature: A transdisciplinary overview of the literature. Journal of Environmental Planning and Management, 40(5), 549-574. doi: $10.1080 / 09640569711949$

Popping, R., \& Roberts, C. W. (2015). Semantic text analysis and the measurement of ideological developments within fledgling democracies. Social Science Information, 54(1), 23-37. doi: $10.1177 / 0539018414553865$

Princeton University. (2010). WorkNet ${ }^{\circledR}$ A Lexical Database for English. Princeton University. Retrieved from https://wordnet.princeton.edu/

Rallis, S. F. (2018). Conceptual Framework. In B. B. Frey (Ed), The SAGE Encyclopedia of Educational Research, Measurement, and Evaluation. doi: 10.4135/9781506326139

Rees, W., \& Wackernagel, M. (1996). Urban Ecological Footprints: Why Cities Cannot be Sustainableand Why they are a Key to Sustainability. Environmental Impact Assessment Review, 16(4), 223248. doi: 10.1016/S0195-9255(96)00022-4

Roberts, C. W., \& Popping, R. (1993). Computer-supported Content Analysis: Some Recent Developments. Social Science Computer Review, 11(3), 283-291. doi: $10.1177 / 089443939301100302$

Roberts, C. W. (2000). A Conceptual Framework for Quantitative Text Analysis. Quality \& Quantity, 34(3), 259-274. doi: 10.1023/A:1004780007748

Robinson, J. (2004). Squaring the circle? Some thoughts on the idea of sustainable development. Ecological Economics, 48(4), 369-384. doi: 10.1016/j.ecolecon.2003.10.017

Robinson, J. G. (2006). Conservation Biology and Real-World Conservation. Conservation Biology, 20(3), 658-669. doi: 10.1111/j.1523-1739.2006.00469.x 
Rockström, J. (2009). A safe operating space for humanity. Nature, 461(7263), 472-475. doi:

$10.1038 / 461472 \mathrm{a}$

Roe, E. (1989). Narrative Analysis for the Policy Analyst: A Case Study of the 1980-1982 Medfly Controversy in California. Journal of Policy Analysis and Management, 8(2), 251-273. doi: $10.2307 / 3323382$

Roe, E. (1992). Applied Narrative Analysis: The Tangency of Literary Criticism, Social Science and Policy Analysis. New Literary History, 23(3), 555-581. doi: 10.2307/469220

Rogers, P. P., Jalal, K. F., \& Boyd, J. A. (Eds.). (2008). An Introduction to Sustainable Development. Virginia, US: Earthscan

Røpke, I. (2004). The early history of modern ecological economics. Ecological Economics, 50(3), 293 314. doi: 10.1016/j.ecolecon.2004.02.012

Roseland, M. (2000). Sustainable community development: integrating environmental, economic, and social objectives. Progress in Planning, 54(2), 73-132. doi: 10.1016/S0305-9006(00)00003-9

Sakieh, Y., Amiri, B. J., Danekar, A., Feghhi, J., \& Dezhkam, S. (2015). Scenario-based evaluation of urban development sustainability: an integrative modeling approach to compromise between urbanization suitability index and landscape pattern. Environment, Development, and Sustainability, 17(6), 1343-1365. doi: 10.1007/s10668-014-9609-7

Salas-Zapata, W. A., Rios-Osorio, L. A., \& Cardona-Arias, J. A. (2017). Methodological characteristics of sustainability science: a systematic review. Environment, Development, and Sustainability, 19(4), 1127-1140. doi: 10.1007/s10668-016-9801-z

Sancton, A. (2005). The Governance of Metropolitan Areas in Canada. Public Administration and Development, 25(4), 317-327. doi: 10.1002/pad.386

Saxe, D. (2017). Good Choices, Bad Choices: Environmental Rights and Environmental Protection in Ontario. Environmental Commissioner of Ontario (ECO). Retrieved from https://eco.on.ca/reports/2017-good-choices-bad-choices/

Schmelzer, M. (2017). 'Born in the corridors of the OECD': the forgotten origins of the Club of Rome, transnational networks, and the 1970s in global history*. Journal of Global History, 12, 26-48. doi: $10.1017 / \mathrm{S} 1740022816000322$

Shaker, R. R. (2015). The spatial distribution of development in Europe and its underlying sustainability correlations. Applied Geography, 63, 304-314. doi: 10.1016/j.apgeog.2015.07.009 
Sharifi, A., \& Murayama, A. (2015). Viability of using global standards for neighbourhood sustainability assessment: insights from a comparative case study. Journal of Environmental Planning and Management, 58(1), 1-23. doi: 10.1080/09640568.2013.866077

Singh, R. K., Murty, H. R., Gupta, S. K., \& Dikshit, A. K. (2012). An overview of sustainability assessment methodologies. Ecological Indicators, 15, 281-299. doi:

10.1016/j.ecolind.2011.01.007

Soddy, F. (1933). Wealth, Virtual Wealth, and Debt: The Solution of the Economic Paradox. London, UK: Britons Publishing Company.

Solow, R. M. (1974). Intergenerational Equity and Exhaustible Resources. The Review of Economic Studies, 41, 29-45. doi: 10.2307/2296370

Statistics Canada. (2016). Human Activity and the Environment 2015 - The Changing Landscape of Canadian Metropolitan Areas. Government of Canada. Retrieved from http://www.statcan.gc.ca/access_acces/alternative_alternatif.action?l=eng\&loc=/pub/16-201x/16-201-x2016000-eng.pdf

Statistics Canada. (2017). Census Profile, 2016 Census. Government of Canada. Retrieved from http://www12.statcan.gc.ca/census-recensement/2016/dp-pd/prof/index.cfm?Lang=E

Stavins, R. N. (2011). The Problem of the Commons: Still Unsettled after 100 Years. The American Economic Review, 101(1), 81-108. doi: 10.1257/aer.101.1.81

Stuart, J., Collins, P., Alger, M., \& Whitelaw, G. (2016). Embracing sustainability: the incorporation of sustainability principles in municipal planning and policy in four mid-sized municipalities in Ontario, Canada. Local Environment, 21(2), 219-240. doi: 10.1080/13549839.2014.936844

Self-sustaining. (2010). In A. Stevenson (Eds.), Oxford Dictionary of English (3 ${ }^{\text {rd }}$ ed.). Oxford University Press. doi: 10.1093/acref/9780199571123.001.0001

Sustain. (2010). In A. Stevenson (Eds.), Oxford Dictionary of English (3 $3^{\text {rd }}$ ed.). Oxford University Press. doi: 10.1093/acref/9780199571123.001.0001

Sustain. (1996). In T. F. Hoad (Eds.), The Concise Oxford Dictionary of English Etymology. Oxford University Press. doi: 10.1093/acref/9780192830982.001.0001

Sustainability. (2010). In A. Stevenson (Eds.), Oxford Dictionary of English (3 ${ }^{\text {rd }}$ ed.). Oxford University Press. doi: 10.1093/acref/9780199571123.001.0001 
Sustainable. (2010). In A. Stevenson (Eds.), Oxford Dictionary of English (3 ${ }^{\text {rd }}$ ed.). Oxford University Press. doi: 10.1093/acref/9780199571123.001.0001

Sustainable development. (2010). In A. Stevenson (Eds.), Oxford Dictionary of English ( $3^{\text {rd }}$ ed.). Oxford University Press. doi: 10.1093/acref/9780199571123.001.0001

Sustainably. (2010). In A. Stevenson (Eds.), Oxford Dictionary of English (3 ${ }^{\text {rd }}$ ed.). Oxford University Press. doi: 10.1093/acref/9780199571123.001.0001

Swanson, D., Pintér, L., Bregha, F., Volkery, A., \& Jacob, K. (2004). National Strategies for Sustainable Development: Challenges, Approaches and Innovations in Strategic and Co-ordinated Action. International Institute for Sustainable Development and Deutsche Gesellschaft für Technische Zusammenarbeit (GTZ) GmbH, 1-54. Retrieved from https://www.iisd.org/pdf/2004/measure_nat_strategies_sd.pdf

Thompson, R. (2007). The Commissioner's Perspective - 2007. Office of the Auditor General of Canada, 1-15. Retrieved from http://www.oagbvg.gc.ca/internet/English/parl_cesd_200710_e_26831.html

Toronto and Region Conservation Authority (TRCA). (n.d.). Jurisdiction and Participating Municipalities. TRCA. Retrieved from https://trca.ca/about/jurisdiction-and-participating-municipalities/

Toronto and Region Conservation Authority (TRCA). (2011). The Living City Report Card 2011: An Assessment of the environmental health of the Greater Toronto Area. Greater Toronto Civic Action Alliance. Retrieved from https://www.civicaction.ca/wp.../1771_LC_GGT_PartnershipReport_rev9_low_res.pdf

Toronto and Region Conservation Authority (TRCA). (2013). Building The Living City®: 10-Year Strategic Plan 2013-2022. TRCA, 1-48. Retrieved from https://trca.ca/about/governancereports/building-the-living-city-10-year-strategic-plan-2013-2022/

Toronto and Region Conservation Authority (TRCA). (2016). The Living City® Report Card 2016: A progress report on environmental sustainability in the Toronto Region. TRCA, 1-96. Retrieved from https://trca.ca/app/uploads/2017/02/3058-LCRC-2016-Final-WEB.pdf

Toronto City Planning Division. (2013). City Planning's Strategic Plan 2013-2018. City of Toronto. Retrieved from https://www.toronto.ca/city-government/accountability-operations-customerservice/long-term-vision-plans-and-strategies/city-plannings-strategic-plan/ 
Toronto City Planning Division. (2017). The City of Toronto Zero Emissions Buildings Framework. City of Toronto. Retrieved from https://www.toronto.ca/wp-content/uploads/2017/11/9875-ZeroEmissions-Buildings-Framework-Report.pdf.

Toronto Environmental Task Force (ETF). (2000). Clean, green and healthy: a plan for an environmentally sustainable Toronto. City of Toronto. Retrieved from https://docplayer.net/9755850-Clean-green-and-healthy.html

Toronto Environment Office (TEO). (2007). Change is in the air - Climate Change, Clean Air and Sustainable Energy Actions Plan: Moving from Framework to Action (Phase 1). City of Toronto. Retrieved from https://books-scholarsportalinfo.ezproxy.lib.ryerson.ca/uri/ebooks/ebooks0/gibson_cppc/2011-08-22/1/10478660

Toronto Food Policy Council. (2012). GrowTO: An Urban Agriculture Action Plan for Toronto. Toronto Food Policy Council. Retrieved from http://tfpc.to/news/growto-action-plan

Toronto Public Health. (2010). Cultivating Food Connections: Toward a Healthy and Sustainable Food System for Toronto. Toronto Food Policy Council, 1-36. Retrieved from http://tfpc.to/wordpress/wp-content/uploads/2011/10/Cultivating-Food-ConnectionsTorontoFood-Strategy-FINAL.pdf.

Toronto Public Health. (2013). Next Stop Health: Transit Access and Health Inequities in Toronto. City of Toronto. Retrieved from https://www.toronto.ca/legdocs/mmis/2013/hl/bgrd/backgroundfile56681.pdf

Toronto Public Health. (2015). A Climate of Concern: Climate Change and Health Strategy for Toronto. City of Toronto. Retrieved from https://www.toronto.ca/legdocs/mmis/2015/hl/bgrd/backgroundfile-81509.pdf

Tozer, L. (2018). Urban climate change and sustainability planning: an analysis of sustainability and climate change discourses in local government plans in Canada. Journal of Environmental Planning and Management, 61(1), 176-194. doi: 10.1080/09640568.2017.1297699

Turcu, C. (2013). Re-thinking sustainability indicators: local perspectives of urban sustainability. Journal of Environmental Planning and Management, 56(5), 695-719. doi: 10.1080/09640568.2012.698984

United Nations. (n.d.). UN Documentation: Environment. United Nations. Retrieved from https://research.un.org/en/docs/environment/conferences 
United Nations. (2017). The Sustainable Development Goals Report. United Nations Statistics Division (UNSD), 1-60. Retrieved from https://unstats.un.org/sdgs/files/report/2017/thesustainabledevelopmentgoalsreport2017.pdf.

United Nations Conference on the Human Environment (UNCH). (1972). Report of the United Nations Conference on the Human Environment. Retrieved from http://www.un.org/ga/search/view_doc.asp?symbol=A/CONF.48/14/REV.1

United Nations Conference on Environment and Development (UNCED). (1992). Agenda 21. United Nations. Retrieved from https://sustainabledevelopment.un.org/outcomedocuments/agenda21

United Nations Environment Programme (UNEP). (2016). The Emissions Gap Report 2016: A UNEP Synthesis Report. United Nations Environment Programme (UNEP). Retrieved from http://uneplive.unep.org/theme/index/13\#egr

United Nations Statistics Division (UNSD). (2014). United Nations General Assembly's Open Working Group on Sustainable Development Goals, New York, 19 July 2014. Retrieved from https://unstats.un.org/unsd/environment/envpdf/Issue35.pdf

United Nations World Commission on Environment and Development (WCED). (1987). Report of the World Commission on Environment and Development: Our Common Future. New York, USA: Oxford University Press

Vogt, W. P. (2005). The Dictionary of Statistics \& Methodology ( $3^{\text {rd }}$ Ed.). SAGE Publications Inc. doi: $10.4135 / 9781412983907$

Wang, J., Shen, X., Sun, Y., \& Qu, A. (2016). Classification with Unstructured Predictors and an Application to Sentiment Analysis. Journal of the American Statistical Associations, 111(515), 1242-1253. doi: 10.1080/01621459.2015.1089771

White, M. A. (2013). Sustainability: I know it when I see it. Ecological Economics, 83, 213-217. doi: 10.1016/j.ecolecon.2012.12.020

Wiersum, F. K. (1995). 200 Years of Sustainability in Forestry: Lessons from History. Environmental Management, 19(3), 321-329. doi: 10.1007/BF02471975

Wu, J., \& Wu, T. (2012). Sustainability Indicators and indices: an overview. Handbook of Sustainable Management, 65-86. doi: 10.1142/9789814354820_0004 